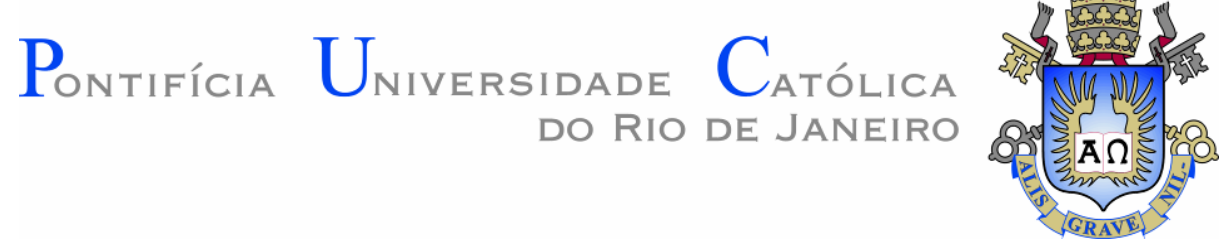

Bernardo Frankenfeld Villela Pedras

EnvironRC: Integrating collaboration and mobile communication to offshore engineering virtual reality applications

Dissertação de Mestrado

Dissertation presented to the Programa de Pós-Graduação em Informática, of the Departamento de Informática do Centro Técnico Científico da PUC-Rio, as partial fulfillment of the requirements for the degree of Mestre em Informática.

Advisor: Prof. Alberto Barbosa Raposo 


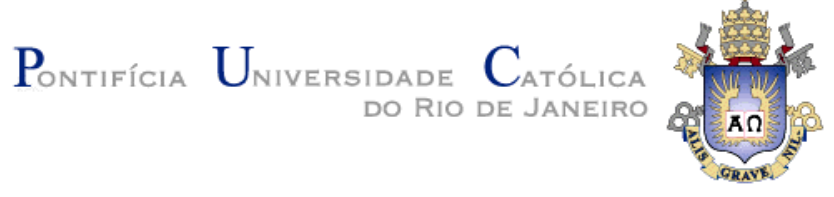

Bernardo Frankenfeld Villela Pedras

\title{
EnvironRC: Integrating collaboration and mobile communication to offshore engineering virtual reality applications
}

Dissertation presented to the Programa de Pós-Graduação em Informática, of the Departamento de Informática do Centro Técnico Científico da PUC-Rio, as partial fulfillment of the requirements for the degree of Mestre.

\author{
Prof. Alberto Barbosa Raposo \\ Advisor \\ Departamento de Informática - PUC-Rio \\ Prof. Markus Endler \\ Departamento de Informática - PUC-Rio \\ Prof. Hugo Fuks \\ Departamento de Informática - PUC-Rio
}

Prof. José Eugenio Leal Coordinator of the Centro Técnico Científico da PUC-Rio 
All rights reserved

\section{Bernardo Frankenfeld Villela Pedras}

Graduated in Computer Engineering from Pontifícia Universidade Católica do Rio de Janeiro - PUC-Rio in 2009.

Pedras, Bernardo Frankenfeld Villela

EnvironRC: Integrating collaboration and mobile communication to offshore engineering virtual reality applications / Bernardo Frankenfeld Villela Pedras ; advisor: Alberto Barbosa Raposo. - 2015.

90 f. : il. ; $29,7 \mathrm{~cm}$

Dissertação (Mestrado em Informática)-Pontifícia Universidade Católica do Rio de Janeiro, Rio de Janeiro, 2015.

Inclui bibliografia

1. Informática - Teses. 2. Sistemas colaborativos. 3. Comunicação mobile. 4. Integração mobile. 5. Interação 3D. I. Raposo, Alberto Barbosa. II. Pontifícia Universidade Católica do Rio de Janeiro. Departamento de Matemática. III. Título. 


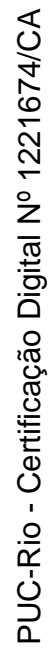

To my parents, Christine and Paulo. 


\section{Acknowledgments}

First, I would like to thank my family for all the support, love and help during the time needed to complete this work. I would like to specially thank my sister, Pauline Meierfrankenfeld, for all the help and dedication during some difficult moments.

A very special thank you to my beloved fiancée, Mayra Calil, for all the love and incentive. Thank you for understanding and providing me with all the support I needed.

I would also like to thank my advisor, Prof. Alberto Raposo, for doing everything possible to provide all the needed resources for this work to take place.

Big thanks to my friends of the MorningStar and TecGraf Galilleu team for providing a friendly environment that made this work possible. I would like to thank Ismael dos Santos for the many teachings and collaborations that made me the professional I am today.

Finally, thanks to PUC-Rio and Petrobras for all the assistance given. 


\section{Abstract}

Pedras, Bernardo Frankenfeld Villela; Raposo, Alberto Barbosa (Advisor). EnvironRC: Integrating collaboration and mobile communication to offshore engineering virtual reality applications. Rio de Janeiro, 2015. 90p. MSc. Dissertation - Departamento de Informática, Pontifícia Universidade Católica do Rio de Janeiro.

Offshore Engineering visualization applications are, on most cases, very complex and should display a lot of data coming from very computational intensive numerical simulations. To help analyze and better visualize the results, 3D visualization can be used in conjunction with a Virtual Reality (VR) environment. The main idea for this work began as we realized two different demands that engineering applications had when running on VR setups: firstly, a demand for visualization support in the form of better navigation and better data analysis capabilities. Secondly, a demand for collaboration, due to the difficulties of coordinating a team with one member using VR. To meet this demands, we developed a Service Oriented Architecture (SOA) capable of adding collaboration capabilities to any application. The idea behind our solution is to enable real-time data visualization and manipulation on tablets and smartphones. Such devices can be used to help navigate the virtual world or be used as a second screen, helping visualize and manipulate large sets of data in the form of tables or graphs. Furthermore, we want to allow collaboration-unaware application to collaborate with as little reworking of the original application as possible. Another big advantage that mobile devices bring to the engineering applications is the capability of accessing the data on remote locations, like on oil platforms or refineries, and so allowing the field engineer to check the data or even change it on the fly. As our test application, we used ENVIRON, which is a VR application for visualization of 3D models and simulations developed in collaboration with a team from the Institute Tecgraf of PUC-Rio. We added this solution to ENVIRON and it was tested with an experiment and during a review process of Offshore Engineering using VR Setups (Power wall and CAVE).

\section{Keywords}

Collaboration; Mobile-communication; Mobile-Integration; 3D-Interaction 


\section{Resumo}

Pedras, Bernardo Frankenfeld Villela; Raposo, Alberto Barbosa (Orientador). EnvironRC: Integrando colaboração e comunicação móvel a aplicações de Engenharia Offshore em ambientes de realidade virtual. Rio de Janeiro, 2015. 90p. Dissertação de Mestrado - Departamento de Informática, Pontifícia Universidade Católica do Rio de Janeiro.

Aplicações de visualização de Engenharia Offshore são, na maioria dos casos, muito complexas e devem ser capazes de representar muitos dados vindos de simulações numéricas computacionalmente intensivas. Para ajudar a melhor analisar os resultados, visualização 3D pode ser usada em conjunto com ambientes de Realidade Virtual (RV). A ideia principal desse trabalho começou quando reconhecemos duas demandas que aplicações de engenharia tinham ao rodar em ambientes RV. Primeiramente há uma demanda para suporte à visualização na forma de melhorias na navegação e na capacidade de analisar os dados. Em segundo lugar, há também uma demanda por colaboração devido às dificuldades de coordenar uma equipe com um dos membros utilizando RV. Para atender estas demandas, nós desenvolvemos uma arquitetura orientada a serviços (SOA) capaz de adicionar colaboração a qualquer aplicação. A ideia por trás da nossa solução é permitir a visualização de dados em tempo real através de tablets e smartphones. Estes dispositivos móveis podem ser usados para ajudar a navegar o mundo virtual ou serem usados como uma segunda tela, ajudando a visualizar e a manipular grandes conjuntos de dados na forma de tabelas ou gráficos. Além disso, queremos adicionar as funcionalidades de colaboração a uma aplicação com o mínimo possível de alterações na aplicação original. Outra vantagem importante que dispositivos móveis adicionam a aplicações de engenharia é a capacidade de acessar os dados em locais remotos, como plataformas de petróleo e refinarias, e assim permitindo ao engenheiro de campo manipular os dados no local de trabalho. Como aplicação teste, utilizamos o ENVIRON, que é uma aplicação de RV para visualização de modelos e simulações de engenharia, desenvolvida em conjunto com a equipe do Instituto Tecgraf da PUC-Rio. Adicionamos esta solução ao ENVIRON e testamos com um experimento e durante o processo de análise de Engenharia Offshore usando ambientes RV (PowerWall e CAVE). 


\section{Palavras-chave}

Sistemas colaborativos; Comunicação mobile; Integração mobile; Interação 3D 


\section{Summary}

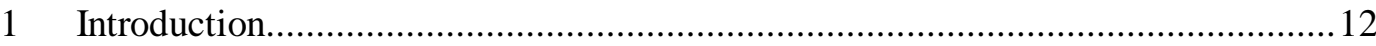

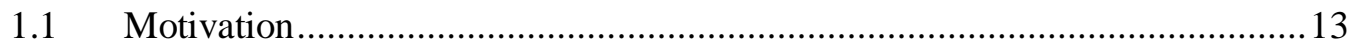

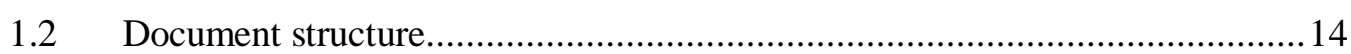

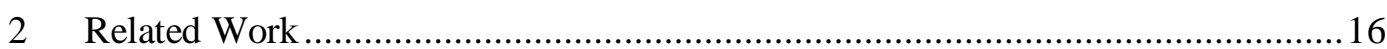

2.1 Immersive applications and environments .................................................. 16

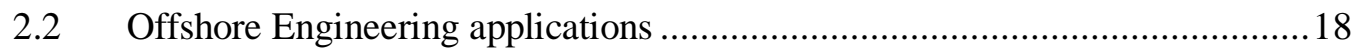

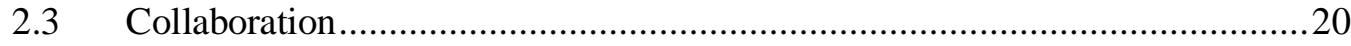

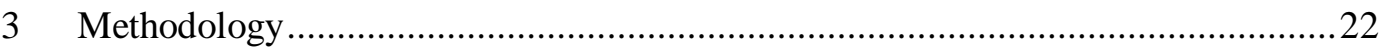

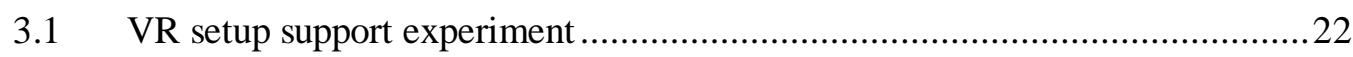

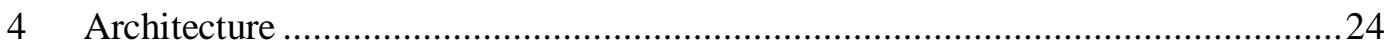

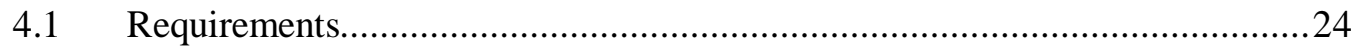

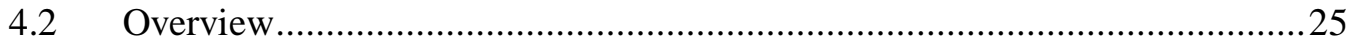

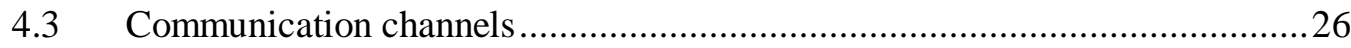

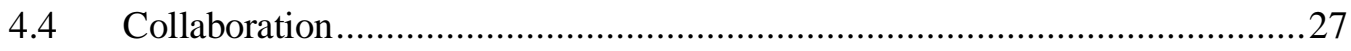

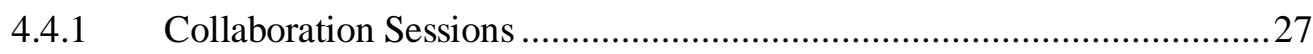

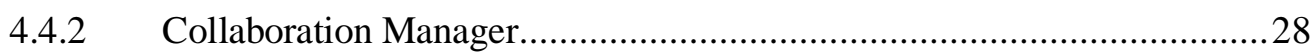

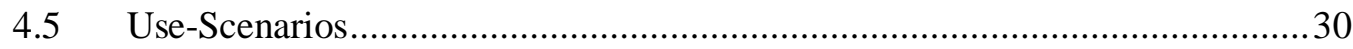

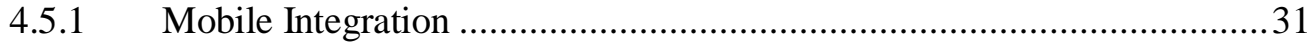

4.5.2 Single Mobile / Multiple instances ………….............................................33

4.5.3 Multiple Mobile / Remote users ................................................................34

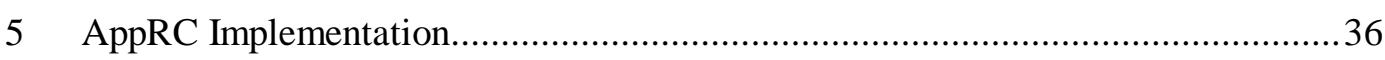

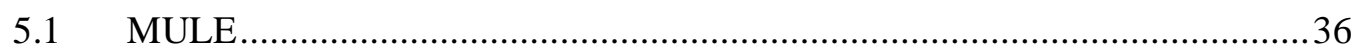

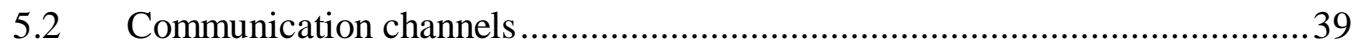

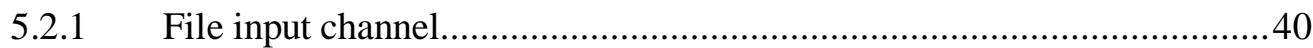

5.2.2 TCP/IP Socket input channel............................................................ 40

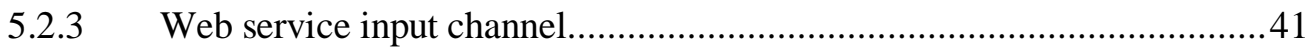

5.2.4 Mobile WebService input channel .......................................................42

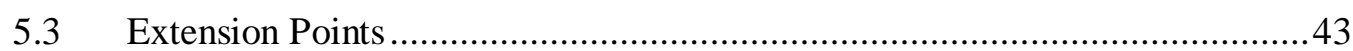

5.3.1 Mobile Application Service...............................................................4

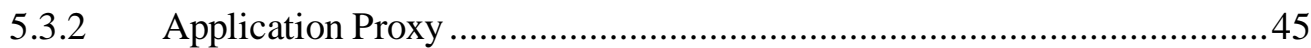

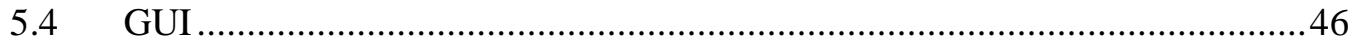

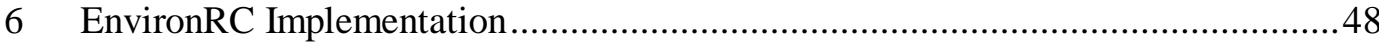

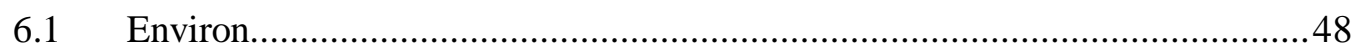

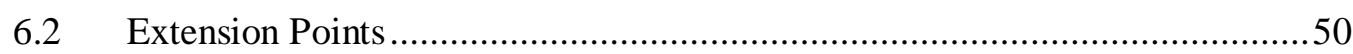

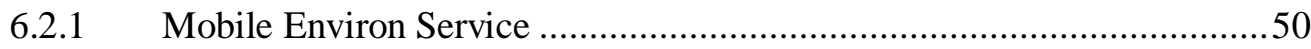

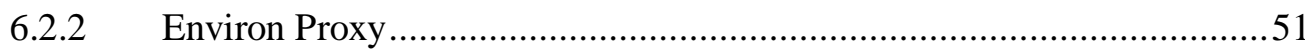




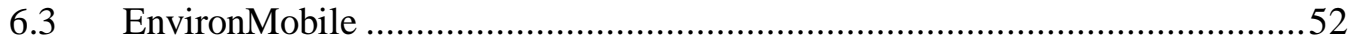

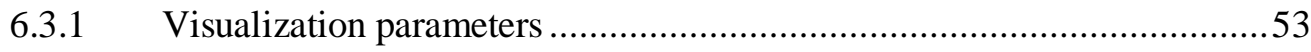

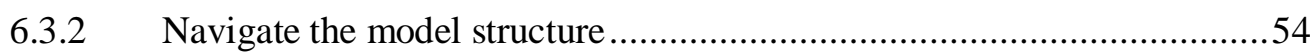

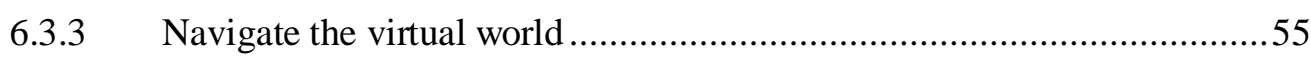

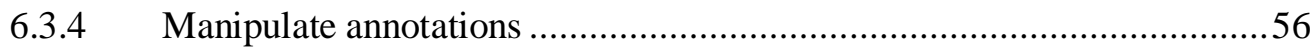

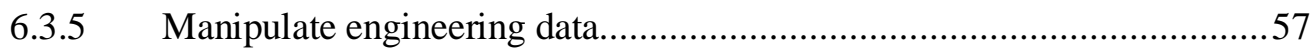

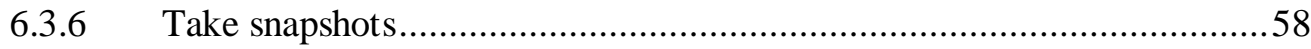

6.3.7 Manipulate the collaboration session .................................................59

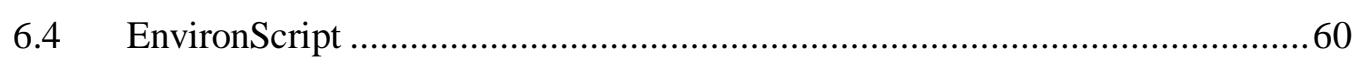

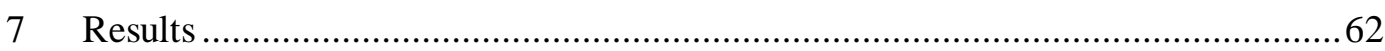

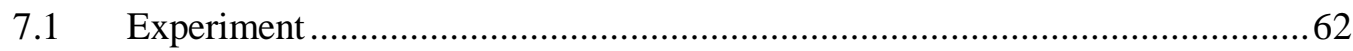

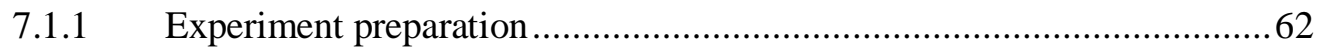

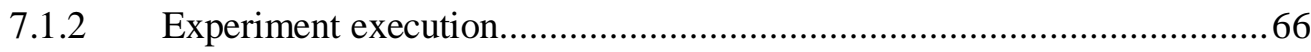

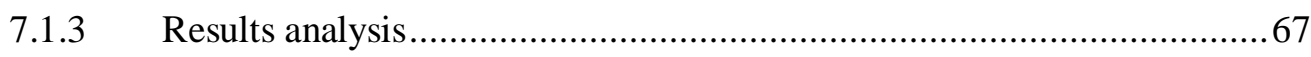

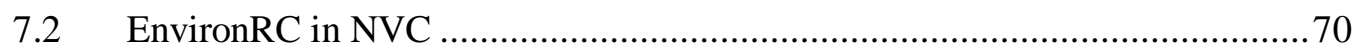

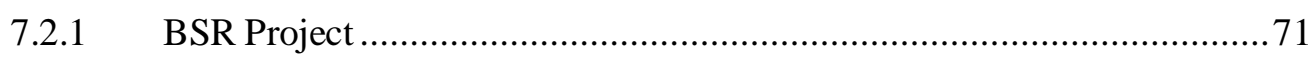

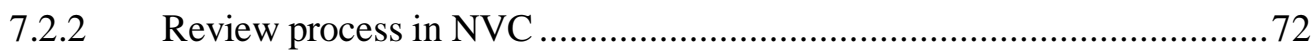

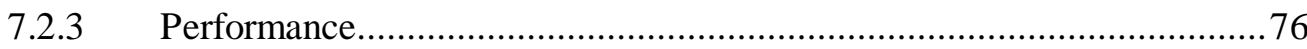

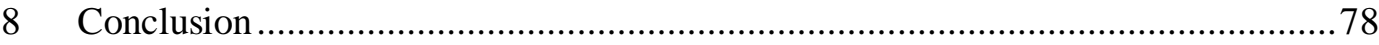

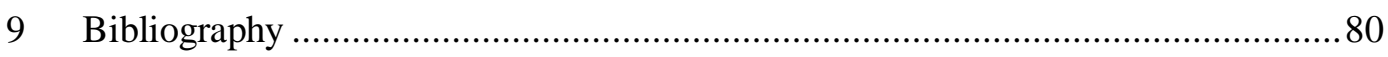

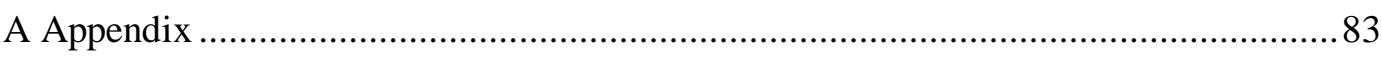

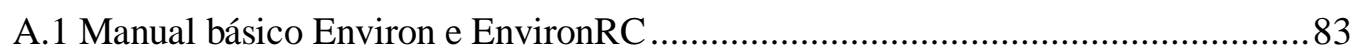

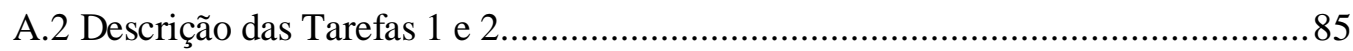

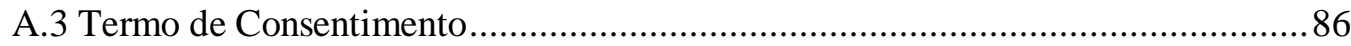

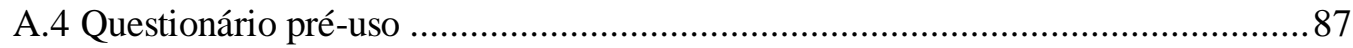

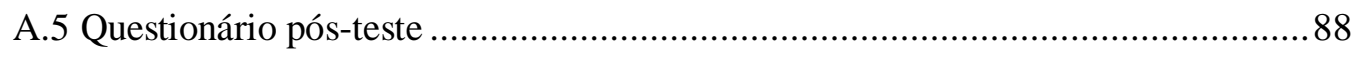

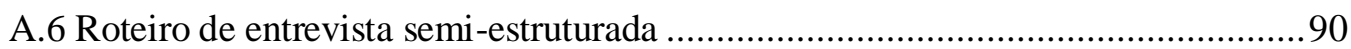




\section{List of Figures}

Figure 1 - Environ running on a cave setup at Cenpes - Petrobras ..................................16

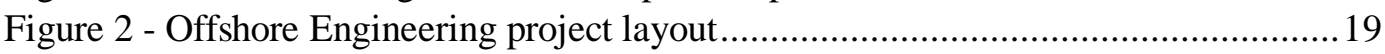

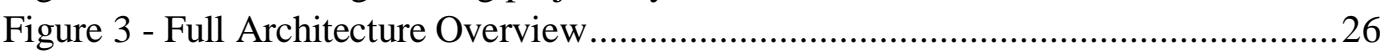

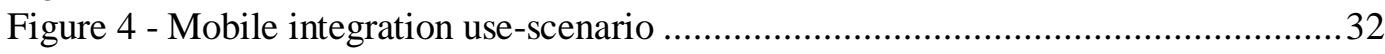

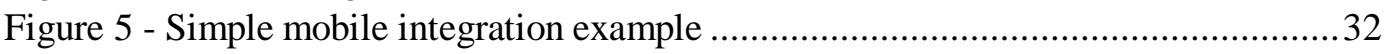

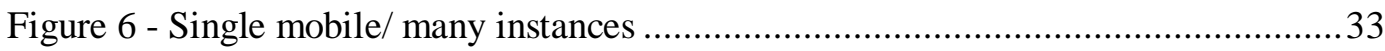

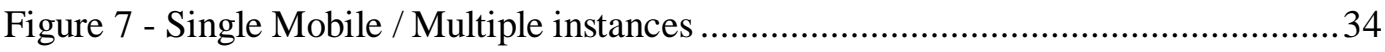

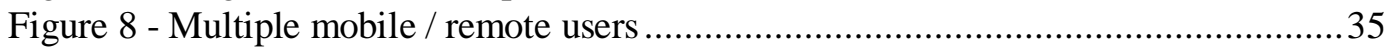

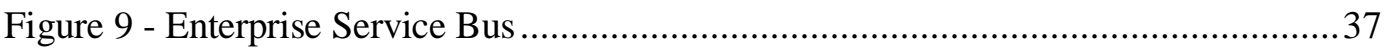

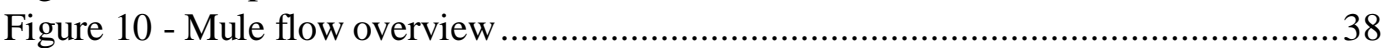

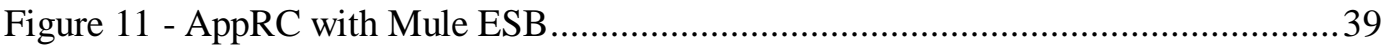

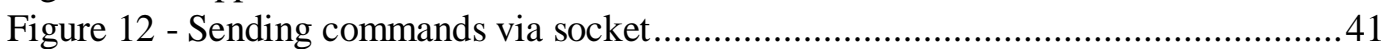

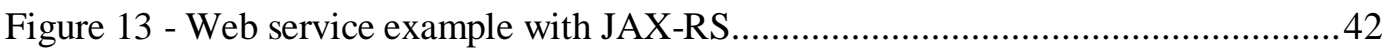

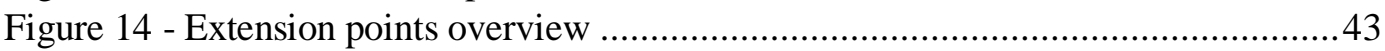

Figure 15 - Mobile application service extension point ...............................................4

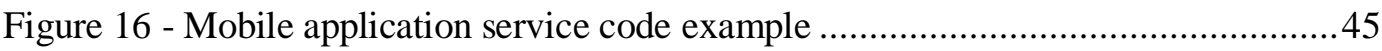

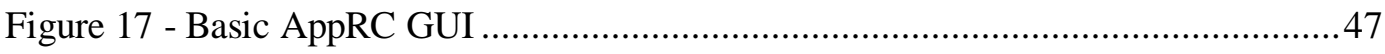

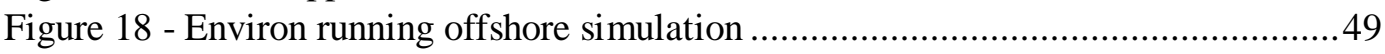

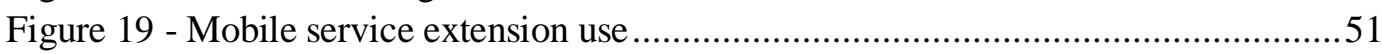

Figure 20 - Environ mobile visualization settings .....................................................53

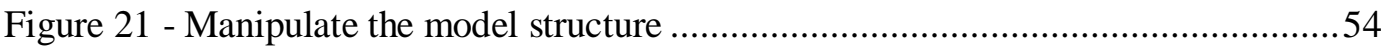

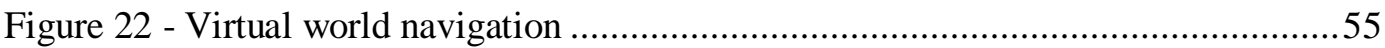

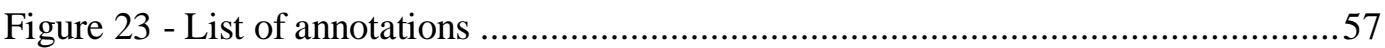

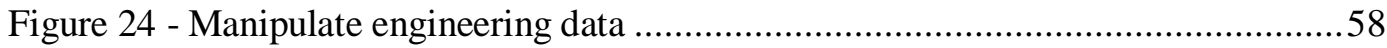

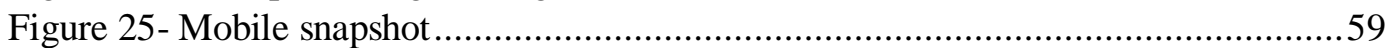

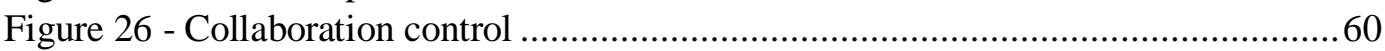

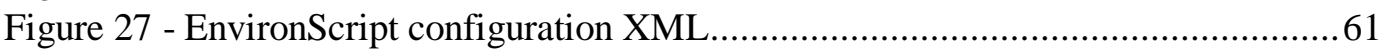

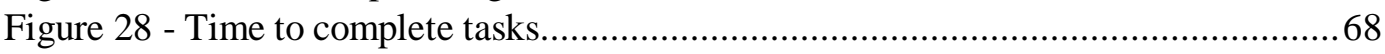

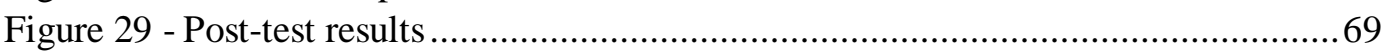

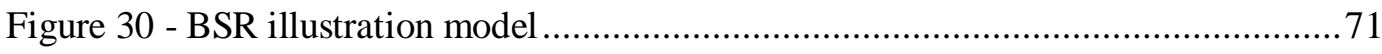

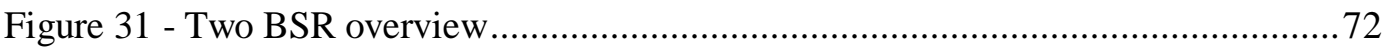

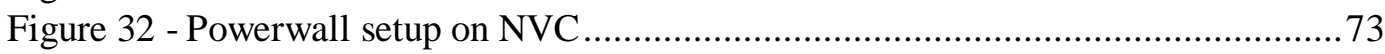

Figure 33 - EnvironRC on BSR Review process...................................................... 74

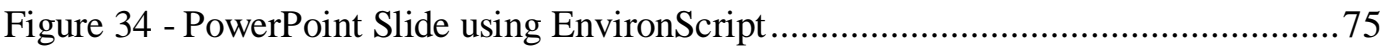

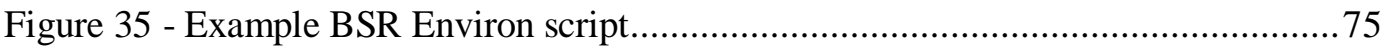

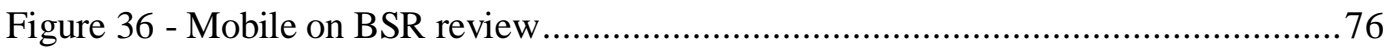




\section{Introduction}

Offshore engineering systems require many multi-disciplinary specialists. Offshore engineering visualization applications are, in most cases, very complex and should display a lot of data coming from very computational intensive numerical simulations. To help analyze and better visualize the results, 3D visualization can be used in conjunction with a Virtual Reality (VR) environment. ENVIRON [1] is one such application developed in collaboration with a team from the Institute Tecgraf of PUC-Rio and was the focus of our study.

The main idea for this work began as we realized two different demands that engineering applications had when running in VR setups: demand for visualization support in the form of better navigation and better data analysis capabilities and demand for collaboration.

First, since the models being visualized originated from large numerical simulations, we noticed the need for a better user-interface to allow the user to visualize large amounts of data, without disturbing the virtual world representation on the main VR screen. Engineering data are mostly represented by large tables of numbers and graphs, which are not suited for display in VR environments.

Second, we realized that having an immersive VR environment brought real benefits for the review process of large simulations [2]. However, a problem remained; it was hard for the user in the VR setup to communicate and make his observations useful. A better way to collaborate and produce useful data from the VR sessions was needed. A further motivation for collaboration comes from the inherited multi-disciplinary aspect of offshore engineering. To analyze the results, many different specialists (mostly geographically separated) need to work together on the same model.

Therefore, to solve these problems, we developed a Service Oriented Architecture (SOA) capable of adding external communication and collaboration capabilities to any application. The idea behind our solutions is to enable collaboration-unaware [3] [4] applications to collaborate with as little reworking of the original application as possible. Collaboration-unaware applications are 
originally developed to be single user applications, but may be used collaboratively by means of an external support system. This external support system may be an application sharing system or a GUI event multiplexing system. In both cases the applications do not explicitly support collaboration; they are implemented as single user applications. This is important since, in our case, the applications developed for OE projects fits in this type.

In addition, to solve the user-interface problem, we used the added communication mechanism of the application to enable real-time data visualization and manipulation with tablets and smartphones. Such devices can be used to help navigate the virtual world or be used as a second screen, helping visualize and manipulate large sets of data in the form of tables or graphs. Another big advantage that mobile devices bring to the engineering applications is the capability of accessing the data in remote locations, like on oil platforms or refineries, and so allowing the field engineer to check the data or even change it on the fly.

We have developed and tested the proposed architecture with an application called EnvironRC (Environ Remote Control). EnvironRC is an application that adds the benefits of integration with mobile devices, visualization support and collaboration to ENVIRON. We opted to demonstrate the benefits of using EnvironRC in VR session with an experiment. Furthermore, we present a real world use of the collaboration aspect of EnvironRC to help offshore engineers review simulation results.

Furthermore, we developed a generic and extensible version of EnvrionRC, called AppRC [5]. AppRC is a framework that can be extended to be used by any other application that wishes to add external communication and collaboration functionalities.

\subsection{Motivation}

This work started as a part of the ENVIRON development and the demands we recognized while running ENVIRON in many VR environments in NVC (Collaborative Visualization Center) at CENPES/Petrobras. Environ is an 
application capable of displaying in VR the results of offshore engineering applications as 3D rendered scenarios.

Our solution started as a simple solution to integrate mobile navigation to ENVIRON. After a while being developed only as part of ENVIRON, it grew to become a generic framework to integrate external communications to any existing application, called AppRC [5].

Taking inspiration on the extensive work done in the field of Collaboration [2], we decided to incorporate to our solution a downsized version of the CEEcollaboration structure.

The motivation for this work comes from the benefits associated with enabling Environ (or any application) running in a virtual environment to efficiently collaborate in Real-time with other users in different environments (including normal Desktop, Tablets, cell phones etc.).

\subsection{Document structure}

The sequence of chapters of the present work is organized as follows.

Chapter 2 presents the related works that inspired the creation of our collaboration solution, AppRC. It also serves as a theoretical basis of this work, outlining and explaining the three main areas of interest: Collaboration, Offshore Engineering and Immersive applications in VR environments.

In Chapter 3 we define our experiment methodology, describing why we chose to run the experiment and the specific details and documents of the experiment.

In Chapter 4 we explain the overall architecture of our solution. Beginning by defining the requirements our solution should meet. After that, we give an overview of the architecture and describe how the components are connected through the communication channels. We then explain the collaboration aspect of the architecture and finally we define 3 main use-scenarios that serve as examples of how our architecture works. 
Chapter 5 and 6 are dedicated to showing how our solution was implemented. We divided the implementation in two steps. Chapter 5 is about the implementation of AppRC, the generic solution that can be used by any application. We explain how it is structured and how the integration of new applications is achieved by using what we called "Extension Points". Chapter 6 is about the implementation of EnvironRC, a specific use of the AppRC solution to be used with Environ and the main focus of our study. We explain three implementation challenges in further detail; first, we discuss how we used each "Extension Point" of AppRC, then we explain the implementation of EnvironMobile, a IOS mobile application and finally, the implementation of the small helper application called EnvironScript.

In Chapter 7 we present our results using the entire presented solution both with an experiment and with the use in a real-world scenario. We used EnvironRC to help in the review process of a big offshore project called BSR. We describe in further details the challenges and the benefits that EnvironRC brought to the offshore engineers.

Finally, we present the conclusions and discuss possible future works in Chapter 8. 


\section{Related Work}

This chapter is divided in three subsections; immersive environments, offshore engineering and collaboration. These sections represent the main areas of interest of our work and we will use each section to explain in more detail what they are and how they apply to this dissertation.

\subsection{Immersive applications and environments}

The goal of immersive applications is to provide the user with a life-like experience and immerse the user in the virtual environment (Figure 1). Real-Time 3D applications are the main type of application to achieve this goal. Real-time 3D applications use different techniques to achieve the immersion, including: best possible visual output, stereoscopic 3D for depth perception, precise and immediate response to the user inputs, among others.

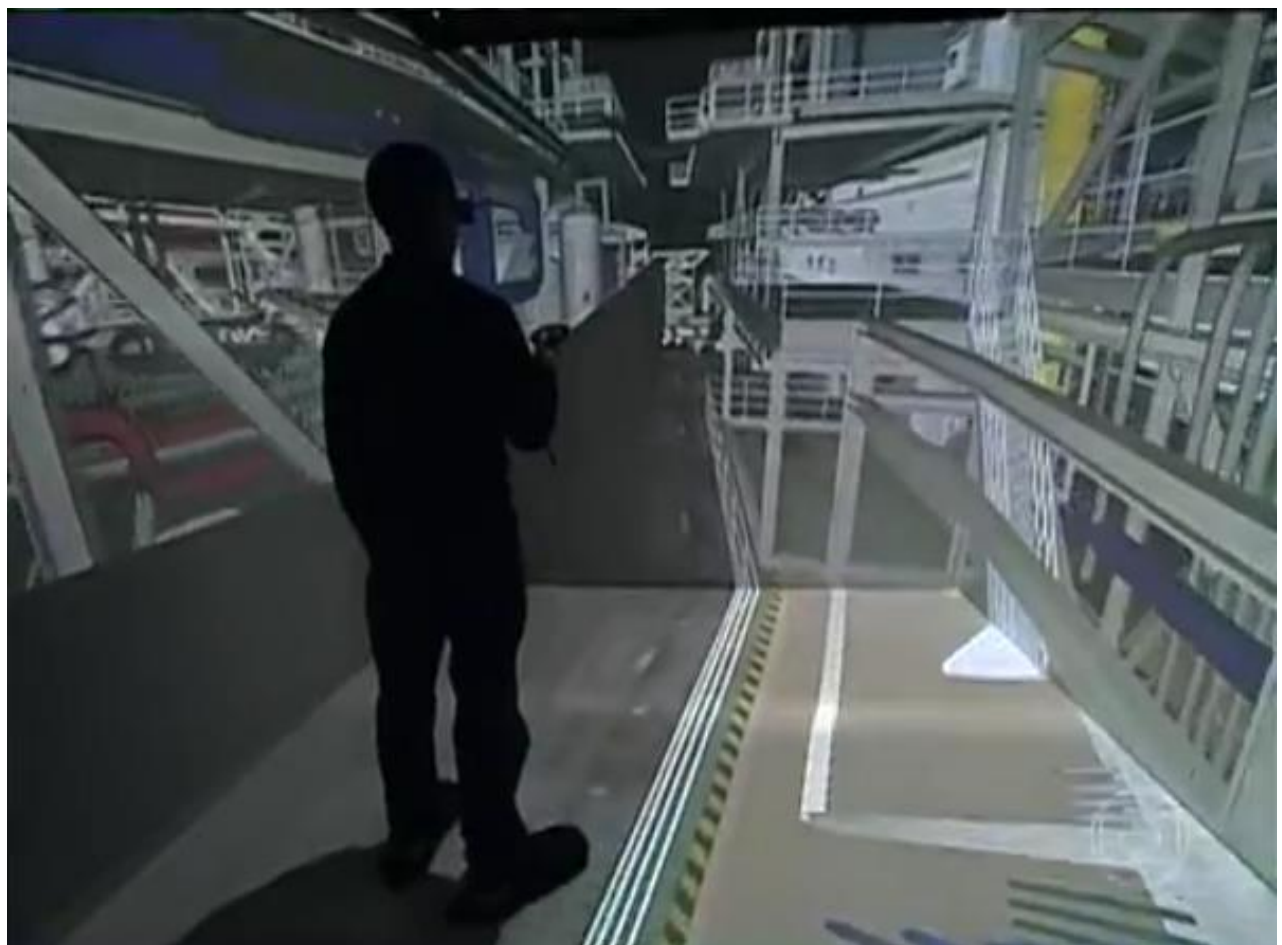

Figure 1 - Environ running in a cave setup at Cenpes - Petrobras

Many different immersive environments were build. Some of the most wellknown are "Powerwalls", CAVE [6] and L-Shape displays. Many engineering applications can benefit from the use of virtual environments. These environments can be used for many tasks, for example: Immersive visualization for training 
purposes, evaluation of Virtual Environments on human scale, visualization of large amount of Data, visualization of large fields as 3D environment.

VR visualization technologies enhance the content knowledge within any engineering design activity. Used in conjunction with collaboration, VR visualization provides valuable insights for better Decision Support with risk mitigation.

While there are huge benefits of using virtual environments, many problems arise when running complex applications in an engineering virtual environment, especially applications that were not built from the ground up with such environments in mind (as is often the case).

There are many applications that utilize mobile devices to enhance the VR experience. Most of them focus on implementing efficient ways to navigate or to interact with the 3D world. Medeiros [7] presents an efficient way to navigate in an immersive environment with the use of a tablet. Further discussions and concepts for navigation with mobile devices can be found in [8], [9] and [10].

Most implementations of navigation functionalities in VR systems rely on the VRPN (Virtual-Reality Peripheral Network) [11], which is a device-independent and network-transparent system for accessing virtual reality peripherals in VR applications. VRPN provides a communication standard for developers who want to utilize different sensors as inputs to their application. Although the VRPN framework is widely adopted as the communication channel for navigation input information, it does not provide a good way to handle other kinds of information, like symbolic input, large amount of data or more complex data structures like photos or videos.

LVRL (Lightweight Virtual Reality Libraries) [12] is a way to port an application to a VR system. It also defines an input communication channel that is based on the VRPN implementation, leaving some room for the developer to implement custom channels. Since the main goal of LVRL is to port the entire application, requiring reworking of the application to use the LVRL, there is no concern in keeping the communication channel generic. 
There are some proprietary mobile application development systems that integrate a sort of framework to manage the messages from the mobile application to a server application. Flick [13], for example, provides a framework restricted for testing and debugging the server-client communication. The Maximo Integration Framework (MIF) [14] is defined as a framework that provides web services and Service Oriented Architecture (SOA) technologies to support application services and coordination between enterprise systems such as synchronization and integration of data between applications. It is a specific framework that handles data transfers to IBM's Maximo system. Although restricted to the Maximo system, some solutions were developed to integrate the SOA architecture of MIF with mobile devices [15], [16].

\subsection{Offshore Engineering applications}

Offshore engineering (OE) systems require many multi-disciplinary specialists, involving the areas of structural calculus, meteo-oceanography (currents, waves and wind forces), hydrodynamics, risers (rigid or flexible steel pipes for carrying oil from the well in subsurface up to the production unit), mooring systems, submarine equipment, seabed foundations and Geologic/Geotechnical risk assessment. Deepwater production systems, including floating production units (platforms or ships) and all the equipment playing a part in the production process, are some of the objects of interest for offshore systems. (Figure 2) 


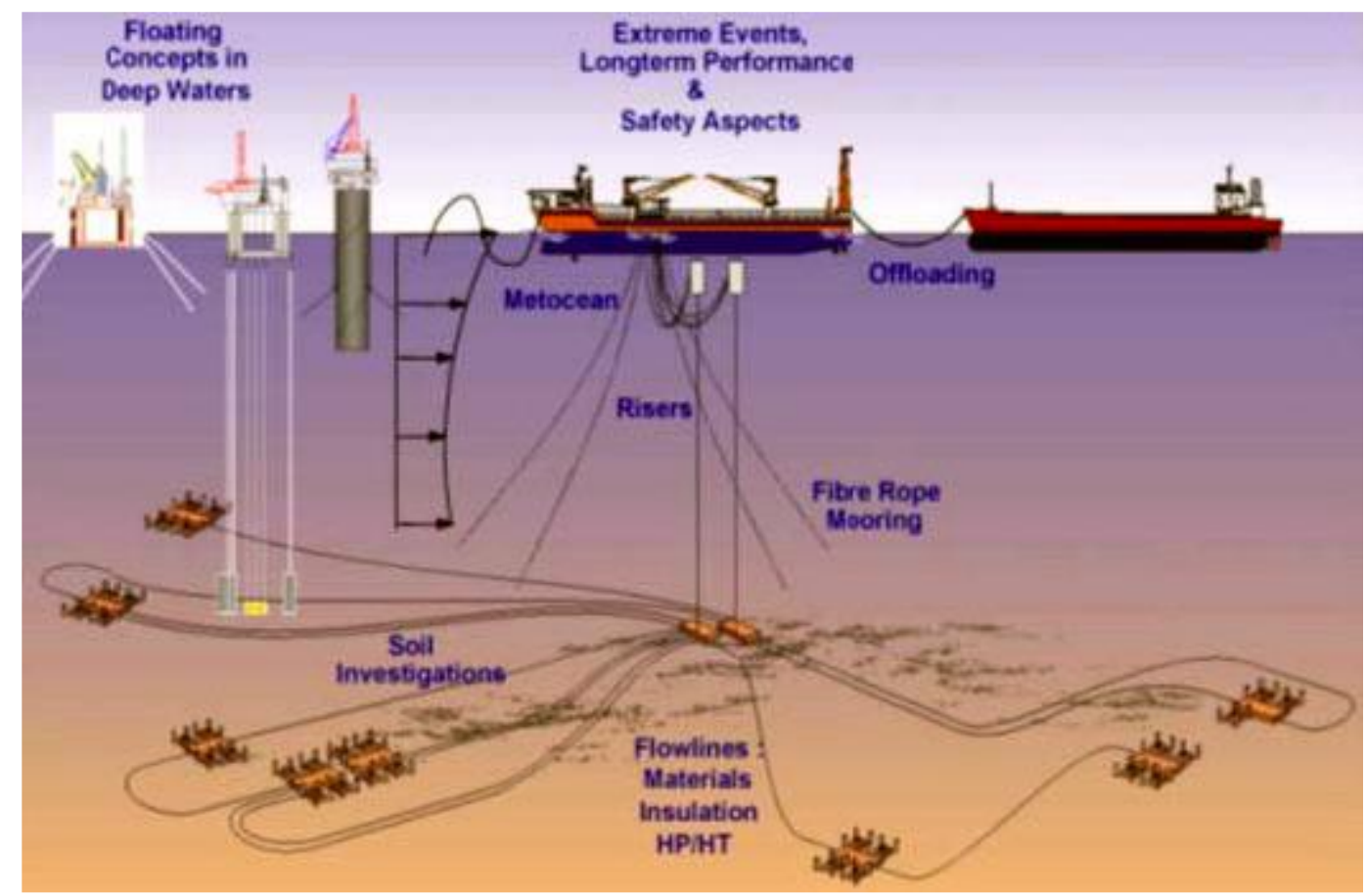

Figure 2 - Offshore Engineering project layout

Due to their huge complexity, OE projects are divided into smaller interrelated subprojects where each one deals with an abstract representation of the others. Because decisions are interdependent, collaboration is a key point in this area. Each team activity or new decision can affect other activities

The changes to a parameter of one of the subprojects could affect all the other subprojects. For example, changes to the environmental conditions (wave, wind or currents) will affect the simulation of the platforms position and this new movement would propagate to all risers and, therefore, should be carefully analyzed to guarantee compatibility with the structural balance of the production unit.

To help integrate all simulators and make sure all simulation results from the intermediate steps in the workflow are consistent with each other, a data format is used called GXML [17] that is able to store all the data coming from different sources.

To account for all variables and parameters, OE applications are typically very computational intensive and run large amounts of numerical simulation. Some of these simulations may require huge computational efforts to be processed, even for powerful computational grid clusters. Another challenge for OE applications is related to the visualization of such results. Visualization should be as precise as 
possible in order to provide the user a full understanding of the results of the simulation.

As already discussed in section 1.1, Offshore applications were part of the focus of our work because the stand to benefit a lot from the integration of our solution.

\subsection{Collaboration}

Collaborative systems should not only allow multiple users to interact with shared objects but also to communicate and to coordinate their actions. Collaboration may be seen as the combination of communication, coordination and cooperation [18]. Communication is related to the exchange of messages and information among people. Coordination is related to the management of people, their activities interdependencies and the used resources. Cooperation is the production of common artifacts taking place in a shared space through the operations available to the group.

Briggs [19] defines many key concepts of collaboration engineering, involving team goals and how to define the objective of a collaboration work. For our work, we are especially interested in the concepts he defined as Pattern of Collaboration, Capability, Constraints and Rules. We use the pattern of collaboration as our collaboration session types (section 4.4), Capability, constraints and rules are used to dictate the permissions within the collaboration session.

As mentioned before, the messages exchanged should always try to achieve the goal of a Collaborative system (Communication, coordination and cooperation). In the broader approach of CEE [2], a special attention was given to the communication between users (with the implementation of a video conference channel). We do realize the importance of informal communication between the users as a way to enhance team awareness [20], but we decided to leave the informal communication outside the scope of the project, since there are already many ways to achieve this communication.

As discussed earlier, The AppRC solution started as a specialization of the much bigger and generic collaboration environment called CEE. The focus of CEE was 
to create a collaboration framework where many different users can work at the same time across different platforms. However, CEE requires a network and server infrastructure, which is not suited for the integration of mobile devices. 


\section{Methodology}

As mentioned in Chapter 1, we have two main goals with this dissertation: enable engineering visualization applications to be used in VR setups and add collaboration. Therefore, we decided to test both aspects of this work with two different methodologies.

To test the VR setup support, we decided to run an experiment with users to help determine the impact on the immersion experience while using a tablet connected to the main visualization system.

For the collaboration aspect of our solution, we present a real-world use of EnvironRC to help offshore engineers analyze the results of many simulations in a presentation setup. Further studies and a complete case-study of the collaboration aspect are left as future works.

\subsection{VR setup support experiment}

We chose to perform an experiment because of the nature of the problem we were trying to analyze. The user experience when using a CAVE is subject to many different aspects, such as, time needed to complete tasks, usability, user experience, immersion perception, among others. By running a controlled experiment, we will try to analyze qualitative and quantitative aspects of this experience.

The objective of our experiment was both descriptive and explanatory. We wanted to describe how the users interacted with the system and what their thoughts were. At the same time, we wanted to examine if the use of a tablet device in VR setups had positive impact in the VR session, both in terms of time needed to complete a task and user experience.

We recruited participants for the experiment that had familiarity with computers, had experience with complex three dimensional applications such as games and 3D modeling software and had experience using VR setups. The decision to recruit only users with experience in VR setups was made to avoid large distinctions in execution time. VR setups can be very confusing and take a large amount of time for a new user to get used to. So, by having only experienced users, we can avoid problems with training bias. 
The experiment consisted of the users performing two tasks in a CAVE VR setup. Both tasks were performed first with Environ (without EnvironRC) and afterwards with EnvironRC. To ensure that all users had the same experience with both EnvironRC and Environ, we conducted a training session before the experiment. In the training session, the users had unlimited time to try both applications and ask questions.

To collect the data, we used different techniques:

- Pre-test question form.

- Post-test question form.

- Time to perform each task.

- Semi-structured interview.

The pre-test form was used mainly to select the participants' profile. Post-test question form and the time to perform each task were used as a quantitative measurement of each user performance and experience. The semi-structured interview was designed to collect qualitative information about the use of the system and to help describe the experience in further detail.

Further details on how the experiment was conducted and the results are described in section 7.1. 


\section{Architecture}

\subsection{Requirements}

As mentioned before, there are two main goals for this project. First, we want to provide a better user interface for users in VR environments. Second, we want them to be able to collaborate with remote users and exchange engineering data in real time.

To achieve these goals, we set the following requirements on our solution:

- The solution should be generic and extensible

- Although the focus of this work is to study our solution used with Environ, we want the solution to be as generic and extensible as possible to enable its use with other applications with little extra work.

- The solution should require minimum reworking of the original application.

○ The original application (in our case, Environ) should not be rewritten. All the collaboration and communication layers should be external to the application itself.

- The solution should add very low overhead.

- While running the original application with the added benefits of our solution, there should be very little performance impact.

- The solution should be responsive and interactive.

$\circ$ The communication between all the users collaborating with different devices should be fast and always responsive.

- The solution should have a minimalistic interface.

○ The interface should be very small and non-intrusive, but should give the user feedback of the current status of the collaboration. 
- The solution should be portable.

- There should not be any hardware or software requirement to run the collaboration solution. It should run on any simple machine without any extra support (like application servers).

The only requirement we set on the user-application (in our case, Environ), is that the application should have some way to receive commands from an outside source. We left open what exactly this command-passing mechanism is, since it depends heavily on many technical aspects of the application, such as, programing language, platform and internal architecture.

\subsection{Overview}

In this section, we present the architecture overview of the generic AppRC solution. EnvironRC, the specific implementation of AppRC for the Environ application follows the same architecture and the specific details of its implementation will be discussed in chapter 6 .

The goal of our architecture is to integrate external communications and enable collaboration in a collaboration-unaware application. Therefore, our architecture is resolved around supporting many instances of the application running on multiple machines and devices.

Our solution is divided in three main components.

1. AppRC Server

2. AppRC Client

3. Mobile Application

AppRC Server works as the central HUB of all communications. All users are required to communicate through the Server. It also manages all collaboration aspects including users and permissions. The server receives (via the Collaboration BUS) all messages and routes it to the corresponding receivers. (Figure 3) 


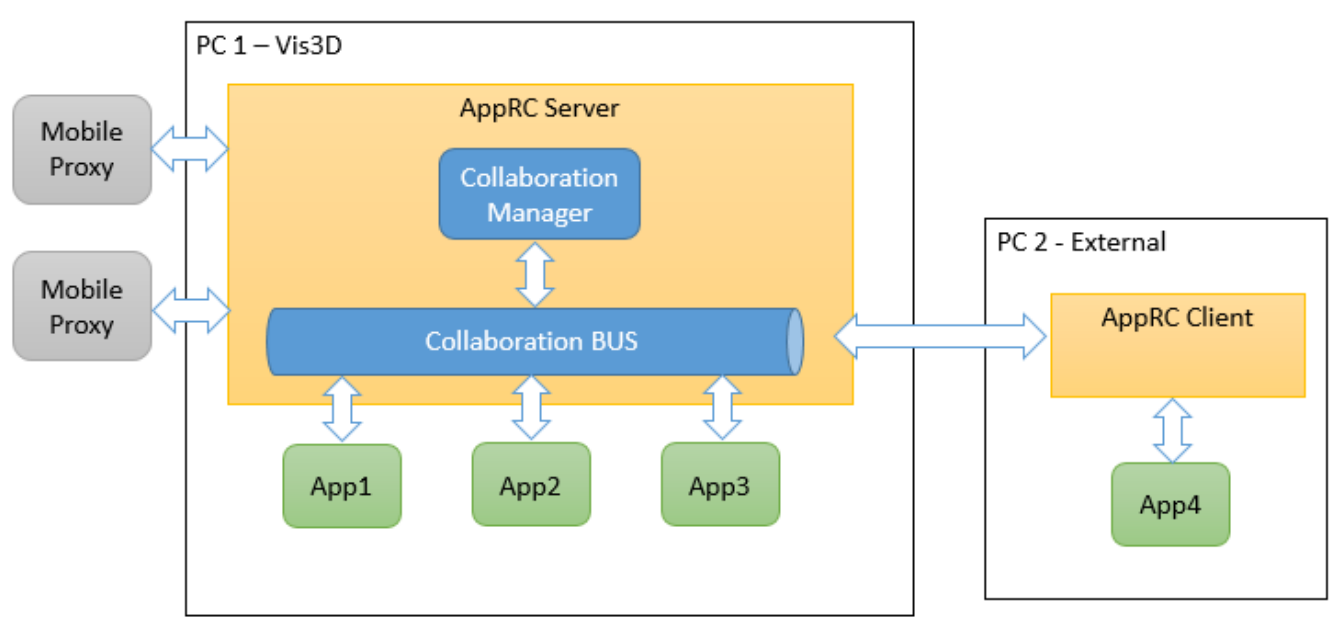

Figure 3 - Full Architecture Overview

AppRC Client works as a proxy of the main server running on a different machine. It only passes the messages along to the main server. For the collaboration BUS, there is no distinction between an instance of the application running on a same machine or on a remote device.

Each application instance is both an Inbound and Outbound Endpoint (defined in more detail in section 5.1), capable of receiving and sending messages. The Mobile Proxy works almost the same as an instance of the application, with the important distinction of being exclusively an Inbound Endpoint. The reason for this decision is so that the mobile application can only request information it needs, and does not have to always listen to incoming messages.

\subsection{Communication channels}

AppRC Server has four different kinds of possible external communication channels for input messages:

- Basic text file

- Socket

- WebService

- Mobile communication 
AppRC Server is responsible for passing the commands received by each input channel to the corresponding application instance. The connection between AppRC Server/Client and the application instance is done, in the case of EnvironRC, through a local socket connection. For the generic AppRC, this connection implementation is left open because it depends on specific connection capabilities of the application. This communication channel will be presented in more detail in Section 5.3, where we discuss the implementation of the Extension Points.

\subsection{Collaboration}

In this section we discuss the collaboration aspect or our architecture. First, in the following section, we define the concept of "Collaboration Session" and the rules governing each type of session. Then, in section 4.4.2, we describe the implementation of the Collaboration BUS and Collaboration Manager in further detail. Furthermore, we discuss how the collaboration session is managed using control messages.

\subsubsection{Collaboration Sessions}

In order to manage the message exchange between all the participants of a work session, some rules must be defined to stablish a collaboration session. A collaboration session represents the type of collaboration the users should do. As was the case with CEE collaboration framework, we anticipate three kinds of collaboration sessions.

- Informal

- Classroom

- Lecture

In an Informal Session each participant can send and receive messages from any other participant without any restrictions. The Collaboration Manager only passes the messages to all other participants of the session. In a Classroom session 
one specific participant, the instructor, acts as a coordinator of the session which means that he/she is the only one able to send messages to other participants. The instructor is also allowed to pass control of the collaboration session among participants. Users can also request the coordination role to the current coordinator who can accept or reject the request. The Lecture session has a speaker that acts as the coordinator of the session, with the same characteristics of a Classroom session. However, in this type of session there is no switch of control between the coordinator and participants. At any time, a user can leave the session, for doing some private work, and join the session in later time.

\subsubsection{Collaboration Manager}

The Collaboration manager is responsible for keeping track of all activity on the connected endpoints, and synchronize the information accordingly.

The main component of the collaboration manager is the Collaboration BUS. The Collaboration BUS provides both synchronous and asynchronous communication to the instances of the application. The Collaboration manager is the module with which each instance of the application can interact.

The Collaboration manager is responsible for passing messages along the collaboration BUS. There are two main kind of messages: First, the messages that need to be passed and processed by the application instances. These messages represent commands and instructions that an application instance can read and execute. The second kind of messages is what we call "control messages". These are messages that each user can send to interact with the collaboration session. These messages represent control commands such as asking the collaboration manager for permission to join a working session, message to add a new application instance to the session or to disconnect a user from the session.

We defined eight control commands to manipulate the collaboration environment. 
- USE_APP(ID) $\rightarrow$ Used to select the default application instance

- CREATE_APP(ID) $\rightarrow$ Used to create a new application instance

- $\quad$ START_APP(ID) $\rightarrow$ Used to run a new application instance

- CLOSE_APP(ID) $\rightarrow$ Used to shut down and remove an application instance

- BROADCAST_BEGIN $\rightarrow$ signals that all messages should start being broadcast

- BROADCAST_END $\rightarrow$ signal the end of a message broadcast

- CHANGE_SESSION_TYPE(Type) $\rightarrow$ Used to change the current session type (Informal, classroom or lecture).

- REQUEST_CONTROL $\rightarrow$ used in classroom sessions to control and start sending update commands to other users.

As already discussed in section 4.4.1, we defined three types of collaboration sessions. In order to maintain the restrictions and rules of each collaboration session type, we defined two types of users: Manager and Participant. Every time the collaboration manager receives a new control message, it first checks if the sender of the message has the required permission to perform the control operation under the current collaboration session type.

To illustrate the use of the control commands and the permission restrictions, we will use an example scenario: three application instances running under the classroom session type. Application number one is the manager of the session and applications 2 and 3 are setup as participants. A possible sequence of messages received by the collaboration manager:

1. Application $1 \rightarrow$ USE_APP(App2)

2. Application $1 \rightarrow$ commands to application 2 only

3. Application $1 \rightarrow$ BROADCAST_BEGIN 
4. Application $1 \rightarrow$ Commands to all Apps

5. Application $1 \rightarrow$ BROADCAST_END

6. Application $1 \rightarrow$ commands to application 2 only

7. Application $2 \rightarrow$ CHANGE_SESSION_TYPE(Informal)

8. Application $3 \rightarrow$ try to send command to app 2

9. Application $1 \rightarrow$ CHANGE_SESSION_TYPE(Informal)

10. Application $3 \rightarrow$ try to send command app 2

Since Application 1 is the manager of the classroom session, it starts by sending a control command to tell AppRC that Application 2 is the default receiver of any message. It then sends some commands to Application 2 (as the default). On item 3, Application 1 starts broadcasting its messages to all apps, ending on message 5. After the broadcast is over, the messages are again sent to the default application as seen on item 6. After that, Application 2 tries to request a change in the session type to informal. This request results in an error since Application 2 is not the manager of the session and the message is ignored. Next, in item 8, Application 3 tries to send commands to the default application. This also results in an error since the session type is defined as classroom and only the manager can send messages. Finally, on item 9, Application 1 successfully changes the collaboration session type to informal allowing Application 3 to send the command to Application 2 on item 10.

\subsection{Use-Scenarios}

We studied three main use-scenarios to demonstrate the benefits of our solution. We chose these scenarios as they represent real world situations and reflect the benefits of adding our solution to engineering applications running in VR setups. In each scenario, we identify the main problem the application has when running in VR and how our solution should solve it. 
- Scenario 1 - Mobile Integration

- Scenario 2 - Single Mobile / Multiple instances

- Scenario 3 - Multiple Mobile / Remote users

In the next sections, we will discuss each of these scenarios in more detail, the motivation behind them and how our architecture is implemented.

\subsubsection{Mobile Integration}

The integration of mobile functionality is a new demand for many different kinds of applications and services. Nowadays it is almost expected of an application or a service to have some kind of mobile integration. The first kinds of services to utilize mobile platforms were, for the most part, related to mobile phones, social networks or media playback. But with the computational power of current smart devices, a lot of other kinds of applications can utilize the smart devices to enhance its functionalities. There are a lot of benefits that a mobile device can bring when integrated to an application. The first one is the obvious gain in mobility. No longer does the user need to be on a desktop inside an office to access or manipulate the data. A second benefit are the included sensors present in most smart-devices. Sensors like GPS Location can, for instance, add important usability information to the application so that it can respond according to the user's location. Most smart devices also have sensors like accelerometers and multi-touch screens that can help interact with the application, helping to navigate in a 3D-world, or to see large amounts of data, for example.

We are especially interested in the use of mobile devices to aid the visualization of engineering data and simulations. Many applications and simulators have been developed over the years for traditional desktops and/or clusters. It is still impossible to run such simulations or applications on a mobile device as a standalone application because of performance issues, and even if it were possible to run entire simulations on smart devices, it wouldn't be the best way to do it because all the generated data must be stored and centralized in databases or servers, 
and it wouldn't be practical to transfer such large amounts of data for each simulation. So, mobile devices should be used to add its benefits to an existing application or simulator, creating a collaborative environment between the main application (running all the heavy work) and different connected mobile devices.

This situation illustrates the main problem we try to address in this first scenario. How to build a collaborative environment between an existing application and mobile devices with minimum reworking of the existing application?

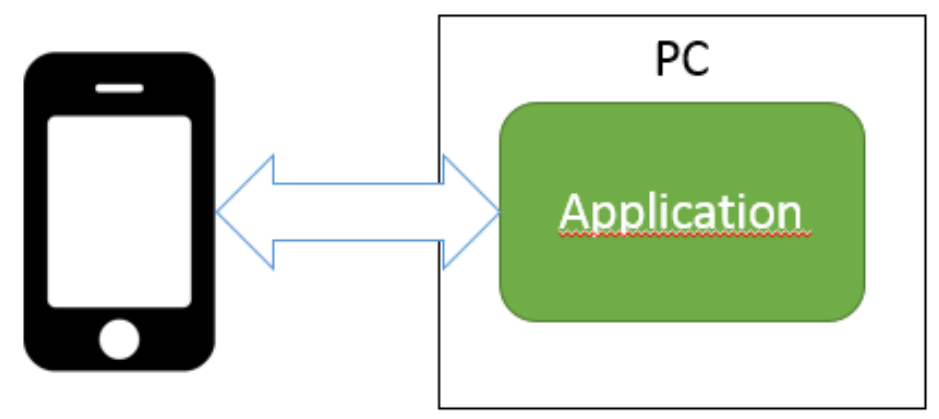

Figure 4 - Mobile integration use-scenario

For this scenario, we need only a main computer running the engineering application and a Mobile device that can communicate and interact with the main application. (Figure 4)

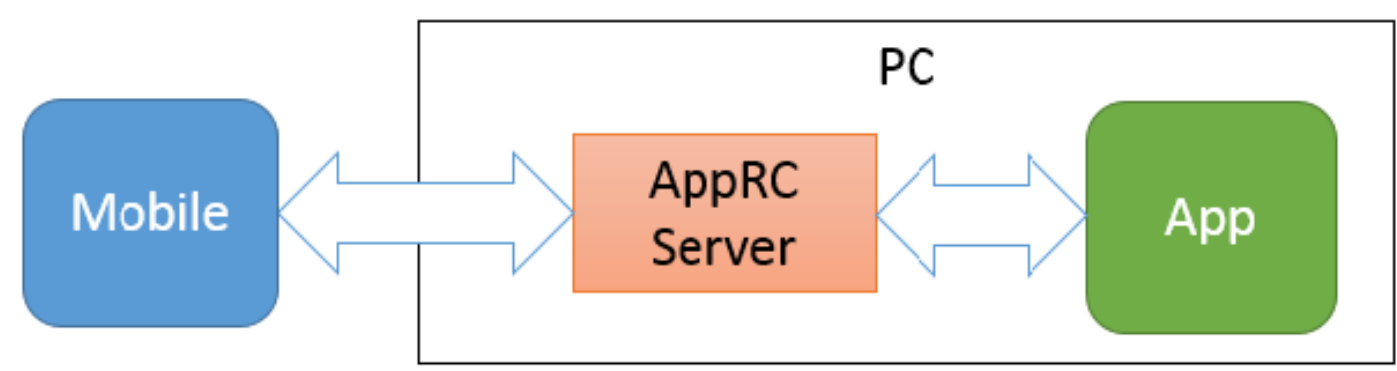

Figure 5 - Simple mobile integration example

As shown in Figure 5, the architecture is very simple. We do not need any kind of proxy client and the communication can occur directly between the application and the mobile device. According to Scenario 1, the developer of the application can integrate mobile communication to an existing application without worrying about the communication and connection code directly. 


\subsubsection{Single Mobile / Multiple instances}

We built this scenario around the idea of having a Powerwall setup. Powerwalls are typically very large displays with massive resolution, and so, capable of displaying many contents at the same time. As most applications were not built with such large resolutions in mind, the most effective way to use the benefits of a Powerwall visualization setup is to open many instances of the application at the same time. Each instance using a part of the full Powerwall screen enabling the user to view all instances simultaneous side by side and compare and analyze the results.

Another instance of this is use-scenario in a VR environment is when the user has multiple VR applications running in background, each of them with a different visualization model. This typically happens in CAVE setups, as each model has to be loaded and properly setup for visualization, a multi-model visualization, where the user is able to change between models by running multiple instances of the application in background.

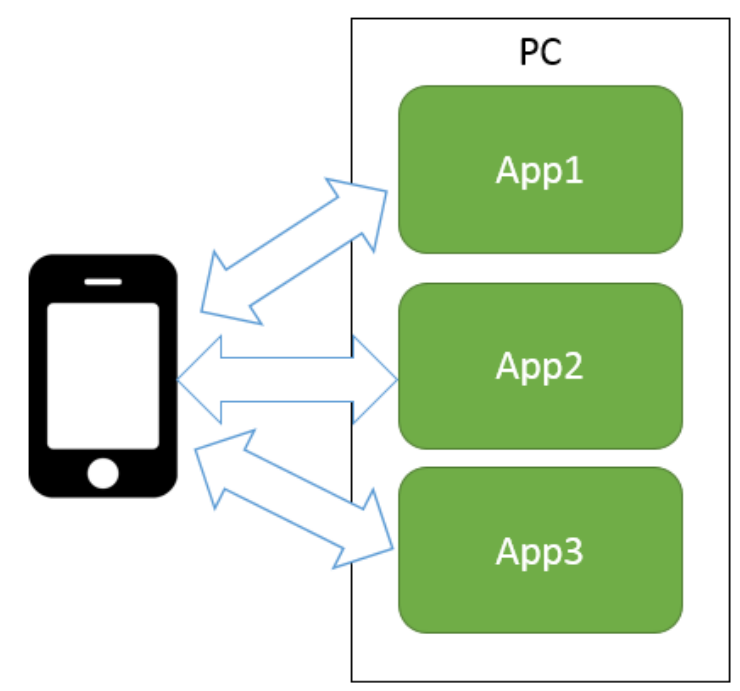

Figure 6 - Single mobile/ many instances

Many instances of the application running simultaneous on the same computer brings new challenges. There is now a need to coordinate the different instances of the application on top of managing the collaboration and messages between them. It is also important for the user to be able to broadcast messages to all instances of the application. A representation of this scenario can be seen in Figure 6. 
In Figure 7, we can see how this scenario is represented using our architecture. Here we need the AppRC Server to be running with the collaboration BUS to manage the communication and route the messages to the corresponding application instances.

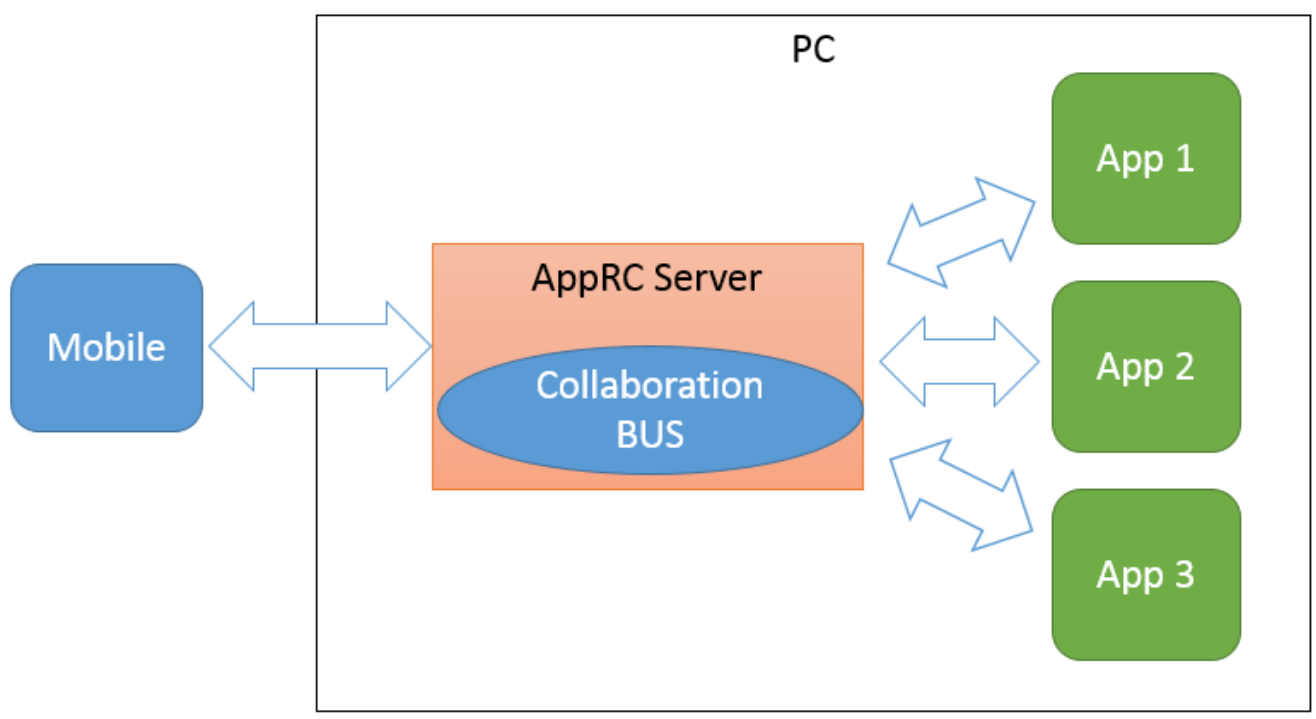

Figure 7 - Single Mobile / Multiple instances

\subsubsection{Multiple Mobile / Remote users}

This scenario represents the most complete use of our solution. It encapsulates many different uses of the collaboration infrastructure. (Figure 8)

It represents for instance the use of the application for a presentation setting, where there are many models being presented in the main screen and each viewer of the presentation has a mobile device and can request on-demand specific details of the main model. 


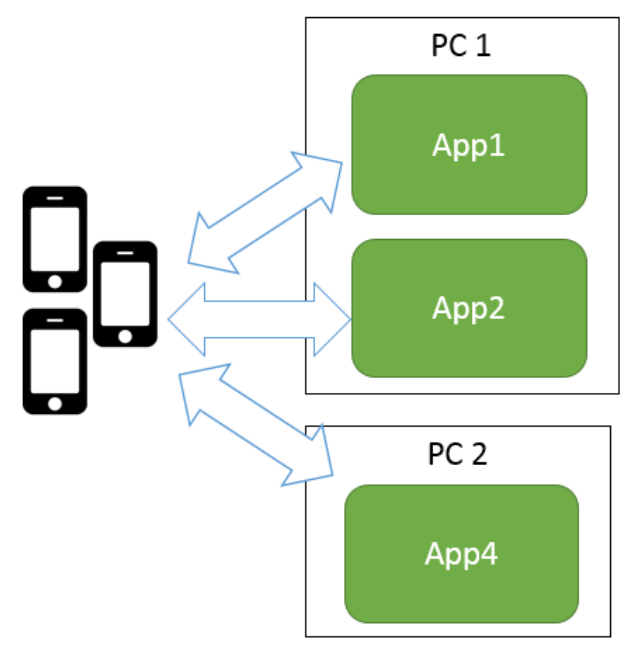

Figure 8 - Multiple mobile / remote users

Another use-scenario is during a review process of a model. Sometimes not all the participants are co-located for the presentation. This is especially interesting for offshore engineering applications due to its inherited multi-disciplinary aspect. To analyze the results, many different engineers (mostly geographically separated) need to work together on the same model. The main review process occurs in the main visualization environments while remote users can join in and collaborate with the working session.

Here we need the remote machine to run the AppRC Client and connect it to the running session of the AppRC Server. The connection of AppRC Client (running on a remote machine) and AppRC Server (running on the main visualization machine) is done through a direct socket connection. The fact that there is a remote user running AppRC Client does not affect the collaboration session. For all collaboration participants, all other participants are accessible through the same means (collaboration BUS). 


\section{AppRC Implementation}

In this chapter, we will explain how we implemented AppRC and the concept of Extension Points. The implementation of EnvironRC and how, using the Extension Points concept, we were able to create a solution for Environ application will be discussed in chapter 6 .

AppRC was developed in Java as a Netbeans Platform application using Mule ESB [23]. It is designed to have a simple user interface for basic monitoring and controlling different communication channels.

Another important aspect of AppRC is its support for managing multiple instances of the application running at the same time. This functionality is very important when running an application on very large displays for example, as it allows the user to manipulate from a single source, multiple instances of the application, providing an efficient way to compare simulation results or data. To achieve this goal, we adopted the concept of application instances session. Each session can run a single instance of the application and the user can create and manage multiple sessions.

In the next sections, we will discuss the implementation of the main features of AppRC, starting with a discussion of how we used MULE to handle the incoming communications. After that, in section 5.2, we describe in further detail how each communication channel works. In section 5.3 we discuss the concept of extension points and finally in section 5.4 we show the AppRC user interface and some usability examples.

\subsection{MULE}

The internal architecture of our solution uses the concept of Service Oriented Architectures (SOA) in the form of Mule ESB implementation. We use the benefits of SOA to build a communication bus inside our framework so that the input services can exchange message with the base application service. This section describes the concept of an EAI (Enterprise Application Integration) and the Mule ESB implementation. 
EAI is the use of software and computer systems architectural principles to integrate a set of enterprise computer applications. The idea behind EAI is to provide an integration framework where multiple applications and systems can cooperate across the enterprise. The problem is that each sub-system or application inside the enterprise could be running on different operating systems, using a different database or be built on different computer languages. The main benefits of using an EAI are:

1. Data integration - Manages communications between the systems of the enterprise.

2. Vendor Independence - Extracts business rules from the application, implementing them in the EAI itself, so that if an application is changed to another vendor, there is no need to change the business rules.

3. Common Facade - An EAI system can work as a front-end for a cluster of applications.

There are many projects and implementations of EAI, like Mule ESB [23], Apache Camel [24] or Spring Integration [25]. For our framework we used Mule ESB because it is an open-source lightweight enterprise service bus (ESB) implementation.

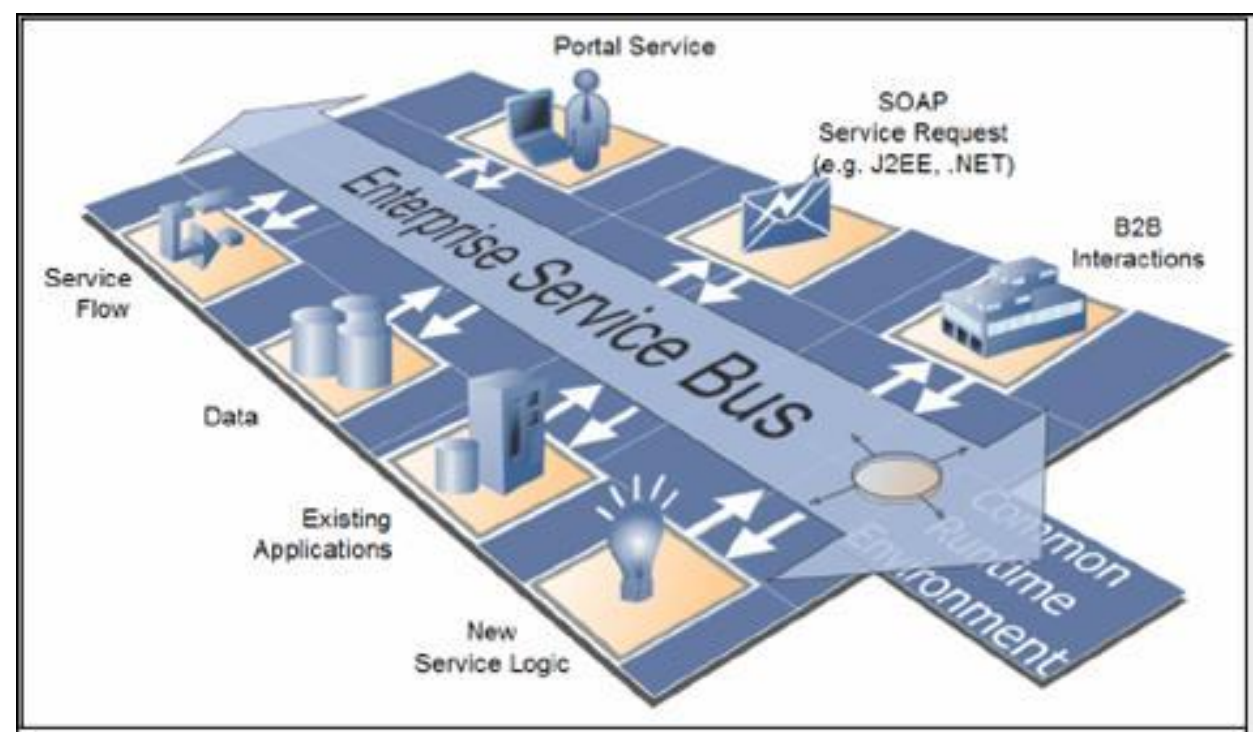

Figure 9 - Enterprise Service Bus 
ESB is considered the basis of SOA (Service Oriented Architecture) because it provides the required technology to realize the benefits the Service Orientation has to offer. The structure of an ESB is, as its name suggests, an integrated BUS that manages communication between services and applications inside the enterprise. The BUS has a shared message format and needs adapters to translate the message from the BUS to each application or service (Figure 9). Furthermore, ESB provides a common platform to manage security, transformations, message forwarding, transactions and monitoring. ESB acts as a middleware between application integration and service orientation.

Mule ESB enables the integration of not only applications, but also of resources like databases, file systems, web services, etc. It provides the infrastructure that allows developers to build, configure, debug and deploy applications that receive, process and deliver data as units called Messages. There are two kinds of basic building blocks of Mule for processing messages.

1. Message Processors: filter, manipulate, forward or validate messages inside a Mule application.

2. Message Sources: also known as Inbound Endpoints, receive the message.

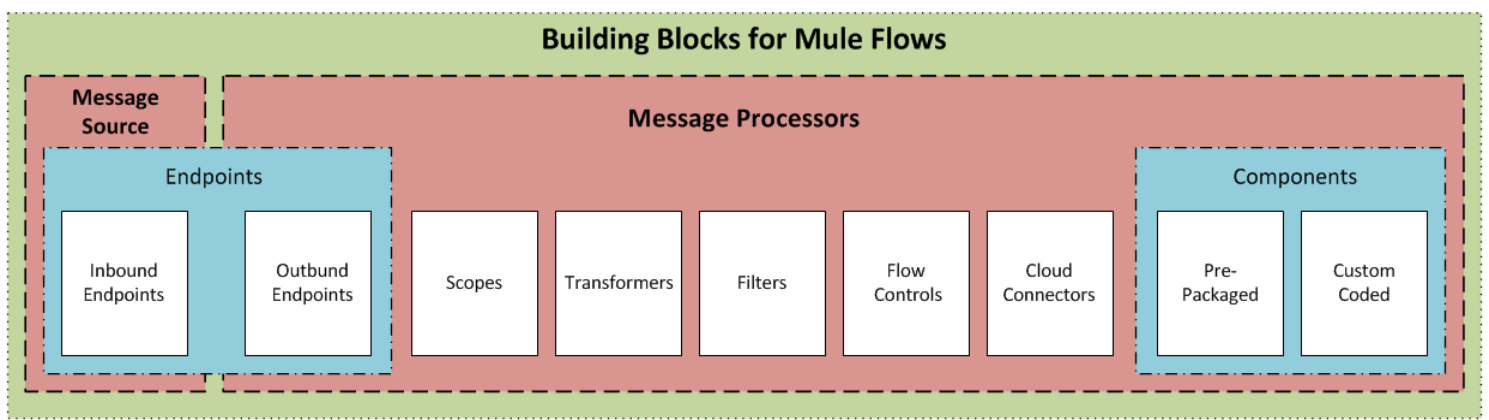

Figure 10 - Mule flow overview

Endpoints work as a specific channel where a service can send messages (inbound endpoints) or a channel where another service can consume the message (outbound endpoints). The process of receiving a message and processing it inside the Mule ESB is defined as a Mule flow. A Flow is the core of any Mule application, organizing and structuring the message forwarding process. Simple Mule 
applications are composed of a single Mule Flow (Figure 10) but more complex applications can have many flows running in parallel.

\subsection{Communication channels}

As already discussed in section 4.3, AppRC supports four different communication channels (file, socket, WebService and mobile service). Using Mule ESB implementation, we defined two Mule flows. The first one, called App Flow, handles mobile devices incoming messages. The second one, called Mobile flow, handles all other incoming messages (file, socket and WebService) (Figure 11)

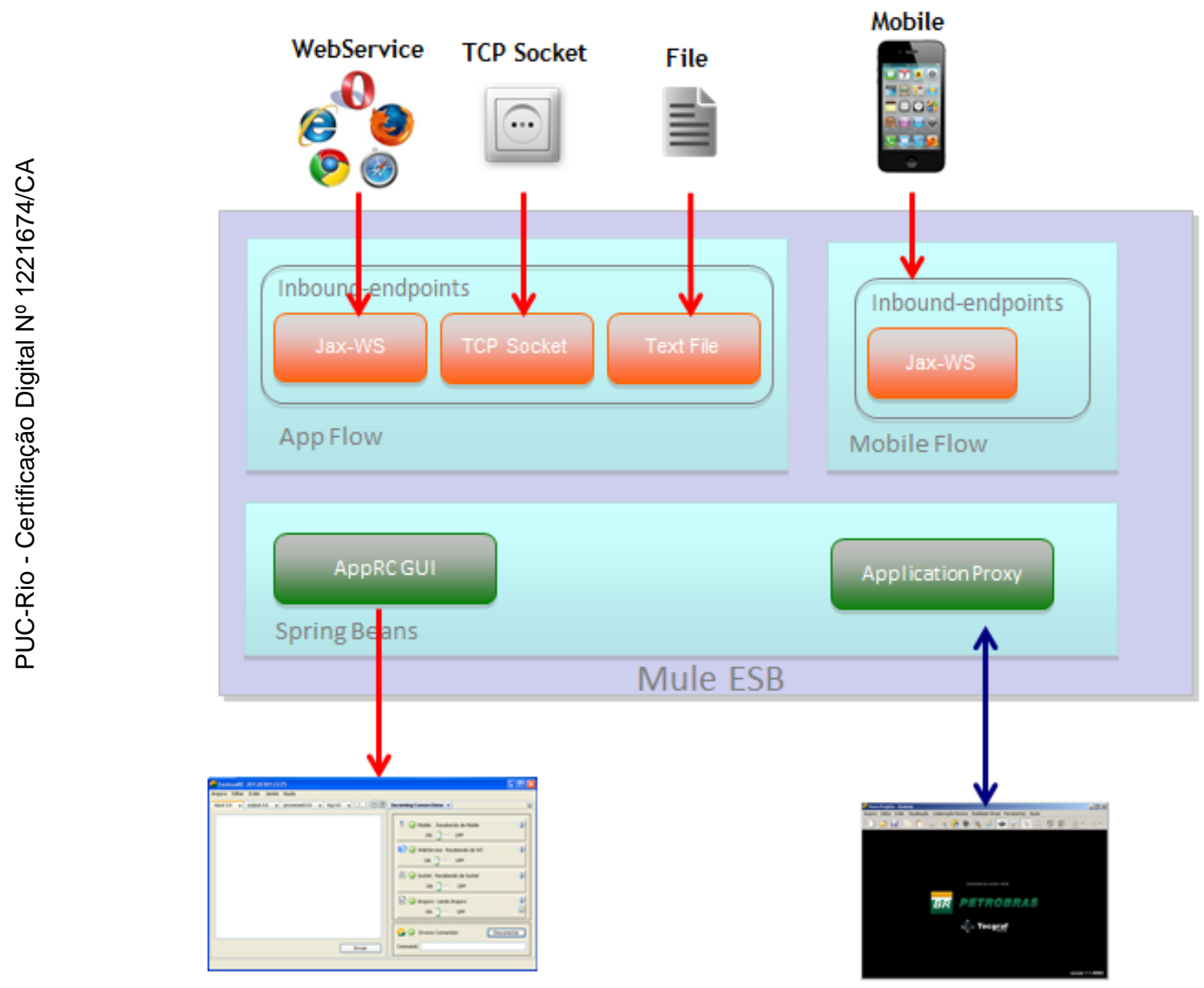

Figure 11 - AppRC with Mule ESB

Therefore, with Mule ESB, we were able to implement the four command input channels. The following subsections briefly describe how each channel was implemented. 


\subsubsection{File input channel}

The simplest way to exchange messages between two applications is via text files. Therefore, we implemented this kind of interface in our solution, even if it is not the most efficient way to exchange message, since both applications have to be running on the same machine or have access to a shared file system. We defined four basic text files, three of them read-only and one of them write-only, dedicated to sending commands to the applications. The files are:

- $\quad$ input.txt - Write-only, everything written in this file will be consumed by the AppRC and processed as commands to the application.

- output.txt - Read-Only, writes outputs from the application.

- $\quad$ processed.txt - Read-Only, keeps track of all processed commands.

- $\underline{\text { log.txt }}$ - Read Only, log of the execution, mostly used for debugging.

The user, through the basic GUI, can set the location of the files.

\subsubsection{TCP/IP Socket input channel}

Sockets are the communication API between processes in a network More specifically, a socket is a connection point trough which a process can send and receive information; it is the interface between the application process and the transport layer protocol. At the sender position, the application sends its message through a socket. At the other side, the transport layer protocol is responsible to deliver the message to the right socket destination.

We implemented the socket input as a basic TCP socket where the server (AppRC) waits the commands as serialized text bytes on a specific port and passes the message over to the application. Figure 12 shows a simple java code for sending commands to our framework using socket channel. We opted for adding the socket communication channel because of the wild spread use of sockets and because of its simplicity. 


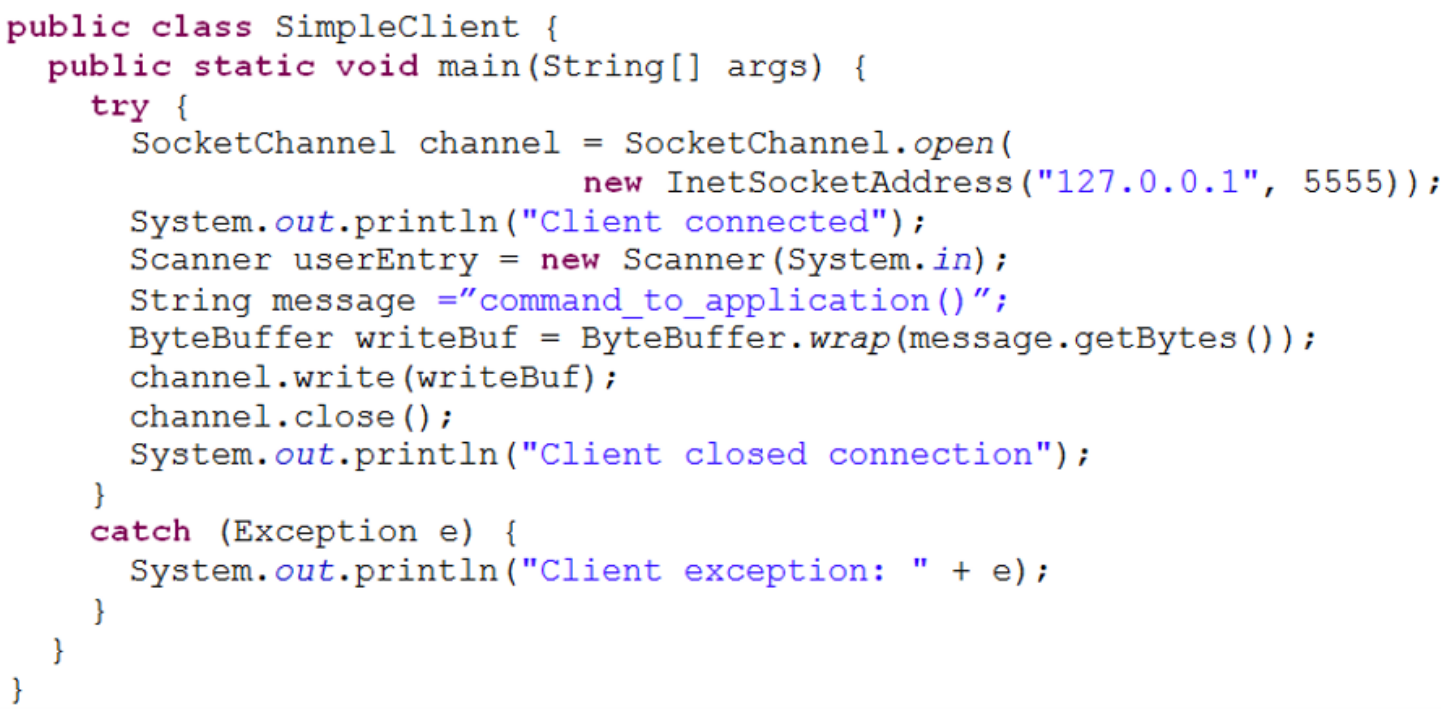

Figure 12 - Sending commands via socket

\subsubsection{Web service input channel}

We use the reference Jersey RESTful (JAX-RS) implementation coupled with the Mule ESB framework. As described in section 5.1, the Mule ESB handles the incoming messages through the web service in the form of flows. For an external application to use the web service, we defined two simple commands that can be accessed via the following URI:

- http://localhost:65082/webService/sendCommand/"command" where "command" is a simple command to be sent to the application

- http://localhost:65082/webService/sendCommandPost/ where the command can be sent using the POST resource of the RESTful web service. Best used for passing long commands or scripts to the application. 


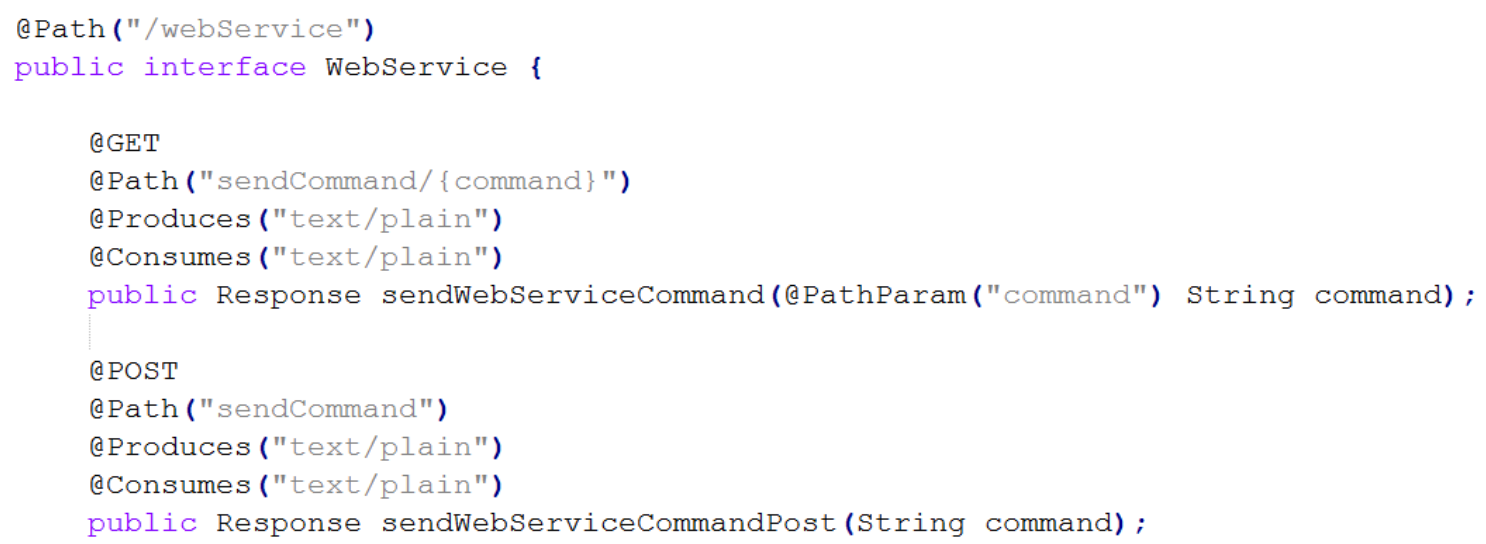

Figure 13 - Web service example with JAX-RS

As we can see in the figure (Figure 13), we used the JAX-RS annotation to define the web service URI and attributes. The result of a processed command is written to the output.txt file (as described in Section 5.2.1) and returned to the client as a JSON object.

\subsubsection{Mobile WebService input channel}

The mobile channel was implemented the same way as the normal web service with some adjustments to account for some general mobile connectivity functionalities and the use of Mobile Application Service extension point (described in section 5.3). We defined three general commands that are responsible to manage the connected devices and applications. The commands are:

- connect - connects a new mobile device.

- disconnect - disconnects a mobile device.

- callCommand - calls a command that passes data to the application.

The CallCommand method is used to call one of the defined methods of the application. In section 5.3.1 we describe in more details how the commands are organized and sent to the application. 
AppRC is capable of managing multiple connected devices at the same time, displaying information in the GUI about each device (type, connection status, name, etc.). It also resolves the problem of concurrency of commands by arranging the incoming messages in a queue and delivering them to the applications only when the application is ready to consume that message.

\subsection{Extension Points}

In order to keep AppRC generic and extensible, we decided to simplify the work needed to integrate AppRC to a new application and defined only two extension points (Figure 14) that need to be addressed by the application developer.

On top of the four input channels, an adapter had to be implemented to handle the communication between the $\operatorname{ESB}(\mathrm{AppRC})$ and the application (Application Proxy). The problem is that each application may export its functionality in a different way. Environ, for example, supports LUA commands via a local socket connection. However, other applications may use direct command line calls, text file input or any kind of custom method of receiving commands. Moreover, since these methods may already be implemented in the application, we decided not to arbitrary force the use of any method as to avoid having to change any code in the application itself. Instead, we leave the implementation of an Application Proxy class as an extension point of AppRC, responsible for sending the message received and processed by AppRC to the application.

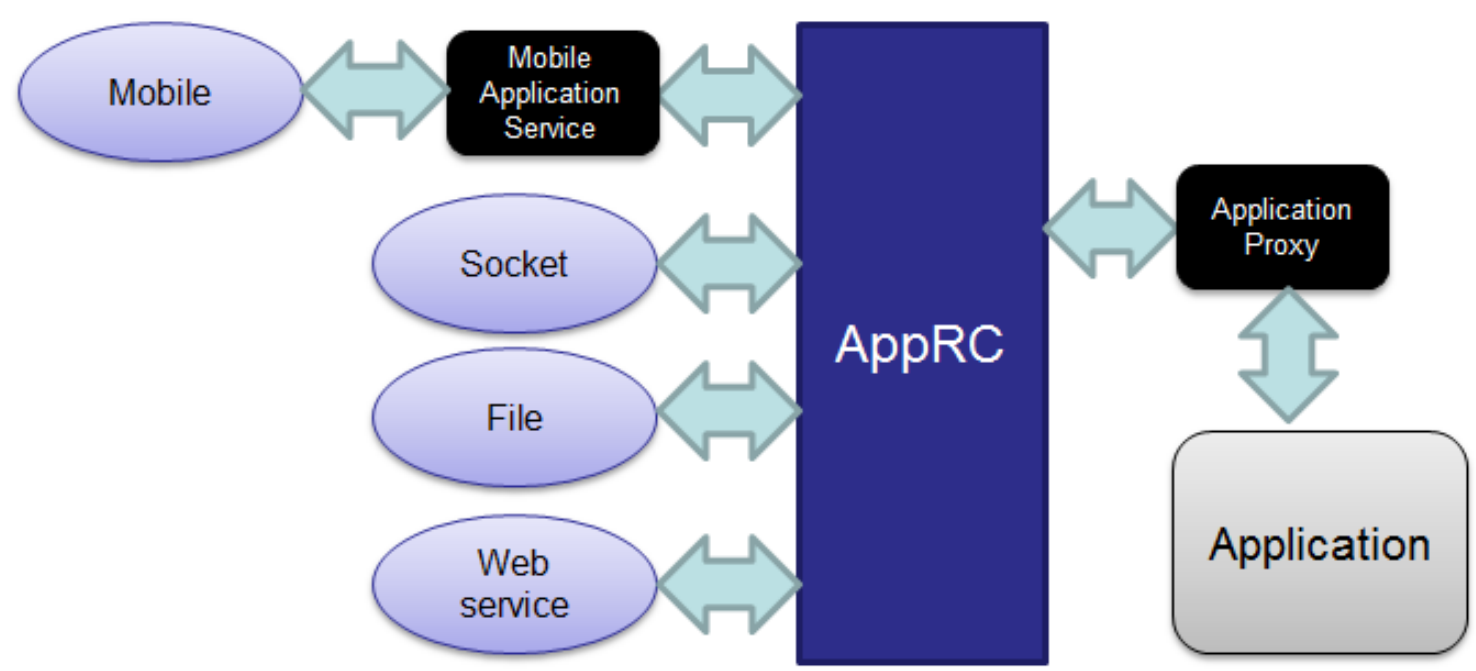

Figure 14 - Extension points overview 
Another extension point we decided to include is the Mobile Application Service. While developing a mobile application, it is useful to have a middle layer of abstraction between the responses from the application and the mobile application. In this layer, from a single mobile command, the developer could, for instance, request many commands from the application organize the data and then send it back to the mobile app in a way that is easy to process and display. By adding this extension point, we are creating a business logic layer without modifying the original application and keeping the mobile app development simple. If, in the other hand, the application already has a complete business logic or the mobile app already implements a complete set of commands, this extension point can be left out and no additional work is needed to integrate the mobile functionality.

The next sections explain how the extension points were developed. A detailed explanation of how exactly both extension points were implemented in EnvironRC can be found in Section 6.2.

\subsubsection{Mobile Application Service}

The idea behind the creation of this extension point is to provide a custom interface for the mobile app developer to use, allowing the development of more complex behaviors and business logic in a single command.

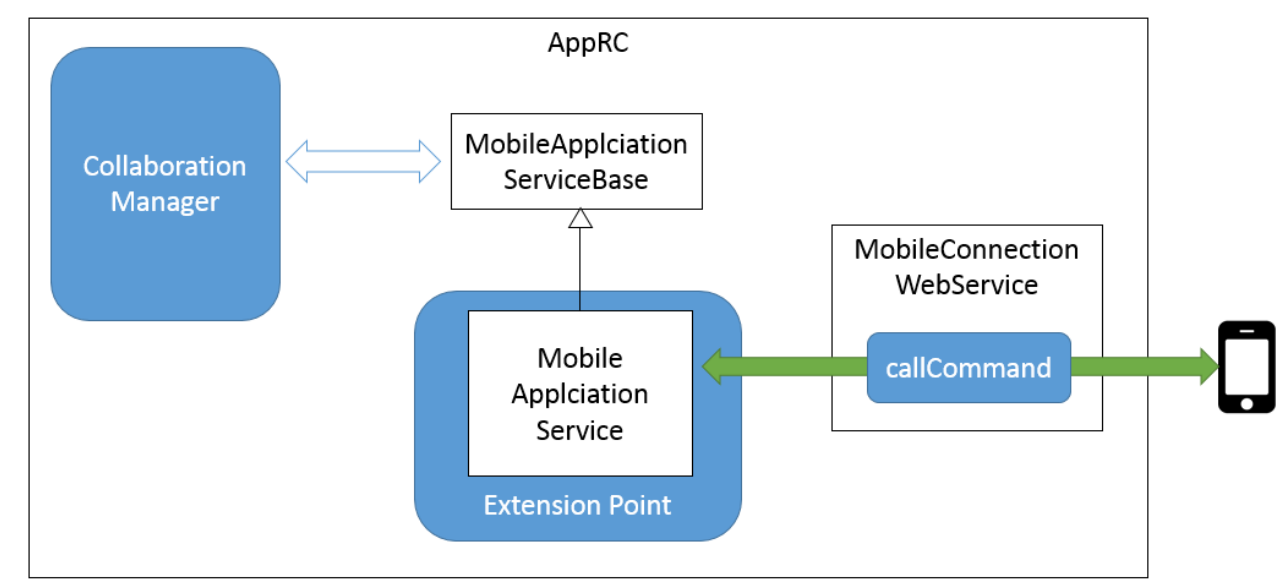

Figure 15 - Mobile application service extension point

As described in the previous section and seen in figure (Figure 15), the mobile connection input channel has a web service command called "callCommand". This web service has, as one of its parameters, the name of the command that should be 
called. These names are internally mapped to the name of public non-static methods of a user defined class (MobileApplicationService in Figure 15) that extends the framework base class called "MobileApplicationServiceBase". The base class "MobileApplicationServiceBase" provides the necessary methods to communicate with the collaboration manager so that the user defined subclass can access and send messages through the AppRC to the application.

The developer that wishes to use AppRC with a new application needs to define a simple Java class that extends "MobileApplicationServiceBase". Every non-static public method of this new class will represent a command that could be called from the mobile device. In Figure 16 we can see a basic example of a user defined extension point class as an example.

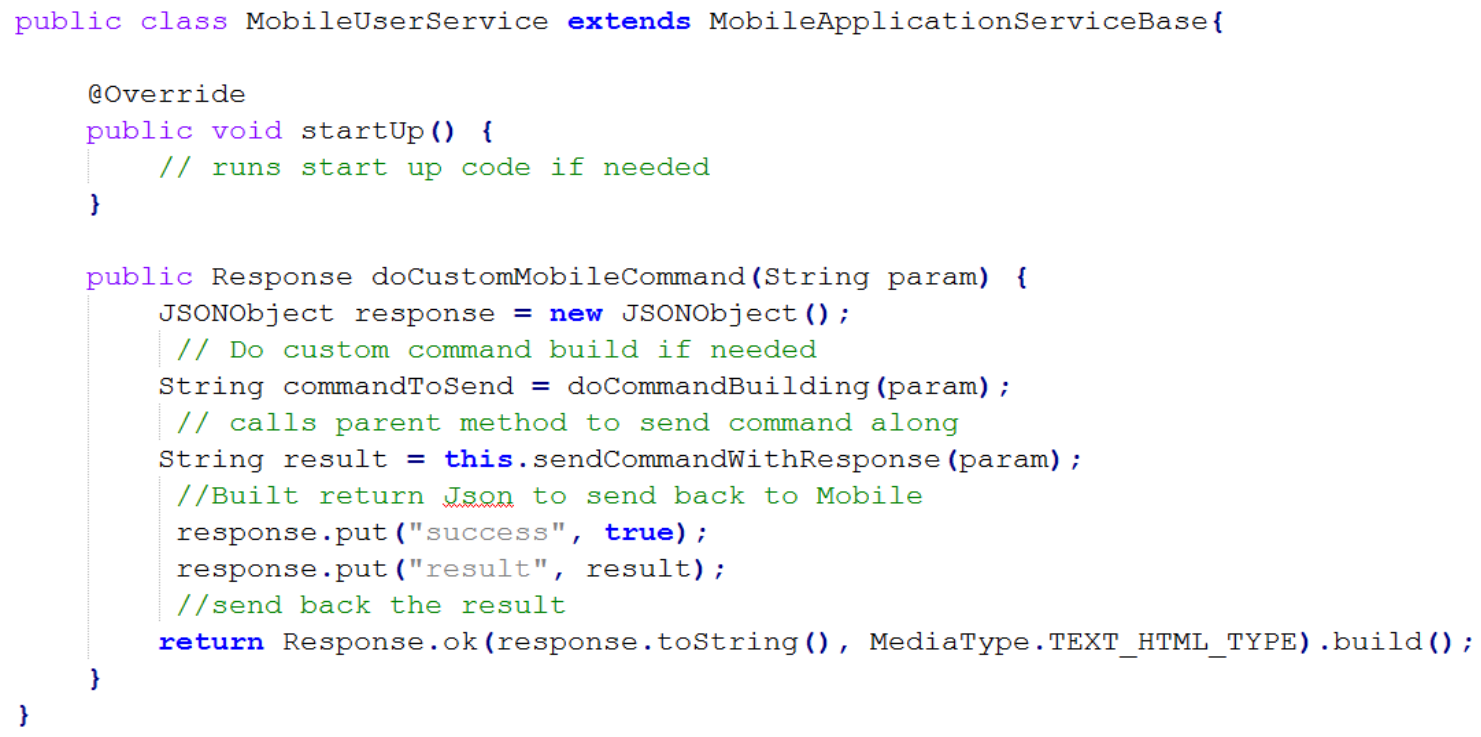

Figure 16 - Mobile application service code example

In the example, to call the command "doCustomMobileCommand" the mobile app should call "MobileConnectionWebService/callCommand" passing the name of the method as a parameter.

\subsubsection{Application Proxy}

The application proxy extension point is a required implementation of a base class that extends AppRC class Proxy. The user defined extension class must fulfill two goals. First, it needs to be able to send a message to the application and second it needs to notify the AppRC framework every time there is a message from the 
application. To achieve both goals some methods have to be implemented by the class.

- sendMessage - Method called by AppRC when there is a message to send to the application

- $\quad$ startApplication - method called by AppRC when a new Instance of the application is requested in a Session.

- close - method called by AppRC when an instance of the application should be terminated.

In addition, the base class Proxy provides some methods that the subclass should call when some event happens.

- notifyMessageToListners - this method should be called to notify AppRC of a new message coming from the application

- notifyMessageResponseToListeners - this method should be called to notify AppRC of a message coming from the application as a result from a previous request

- notifyShutdownToListeners - should be called to notify AppRC when the application instance has been shut down or disconnected.

The exact implementation of the message interface between the Proxy class and the application is left open to the developer in order to keep the framework generic and usable by any kind of application. Using Environ, we implement the interface using a local socket connection, but its usability will heavily depend on the application.

\subsection{GUI}

On Figure 17 we present the basic interface. The left side shows the connected mobile devices, in the middle section we can see the contents of the four basic files that AppRC writes and reads. It is possible for the user to write commands directly to input.txt file and send it to the application. The right side shows the status of each 
input channel and, in a second tab, the status of the connected application instances. It is also able to run in the background as not to disturb the main visualization.

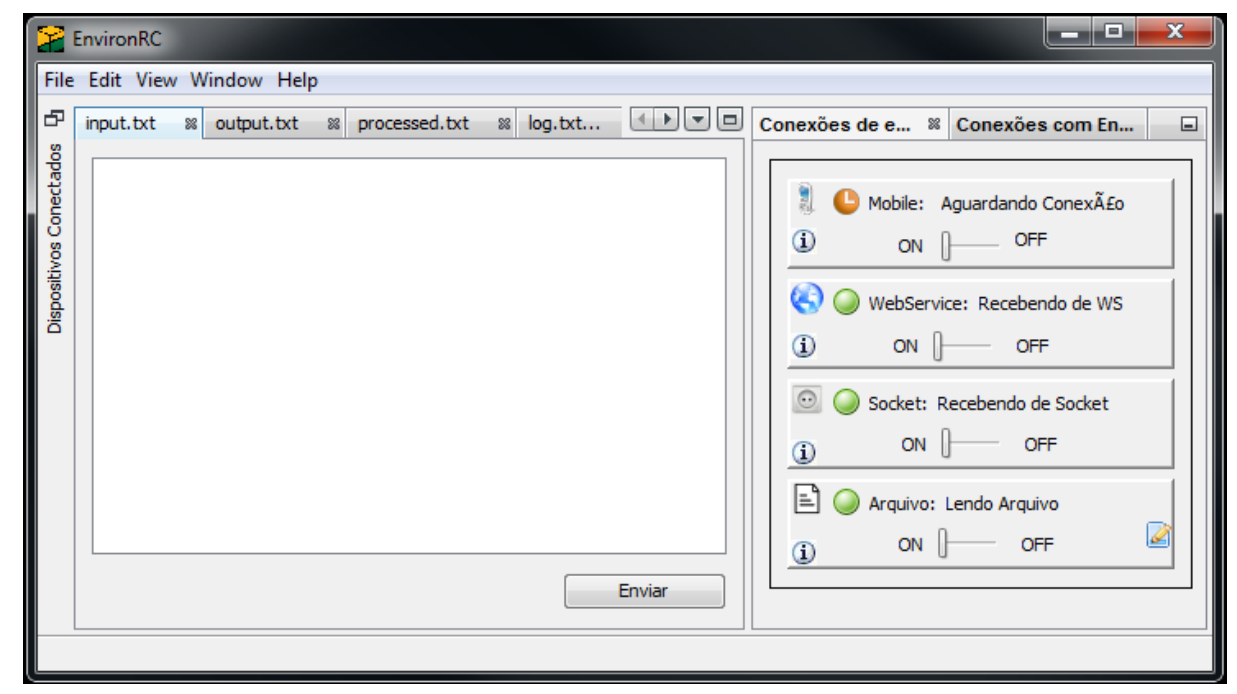

Figure 17 - Basic AppRC GUI

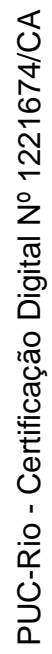




\section{EnvironRC Implementation}

EnvironRC is our specific use of the AppRC generic solution for the Environ offshore engineering visualization application. In the following section, we will describe the aspects of Environ that are relevant for our work. After that, we discuss the implementation of the Extension Points (Section 6.2). Afterward, in Section 6.3, we explain the implementation of the mobile application. Finally, we describe a lightweight application to simplify the sending of commands trough EnvironRC called EnvironScript (Section 6.4)

\subsection{Environ}

Environ [1] is a tool designed to allow visualization of massive CAD models and engineering simulations both in desktop and VR immersive environments. It is a system composed of a 3D environment for real-time visualization and plug-ins to import models from other applications, allowing users to view and interact with different types of 3D data, such as refineries, oil platforms, risers, pipelines and terrain data (Figure 18). It enables the user to view the simulation in real-time as a 3D environment and enables, at the same time, the user to view all the simulation data and engineering information. 


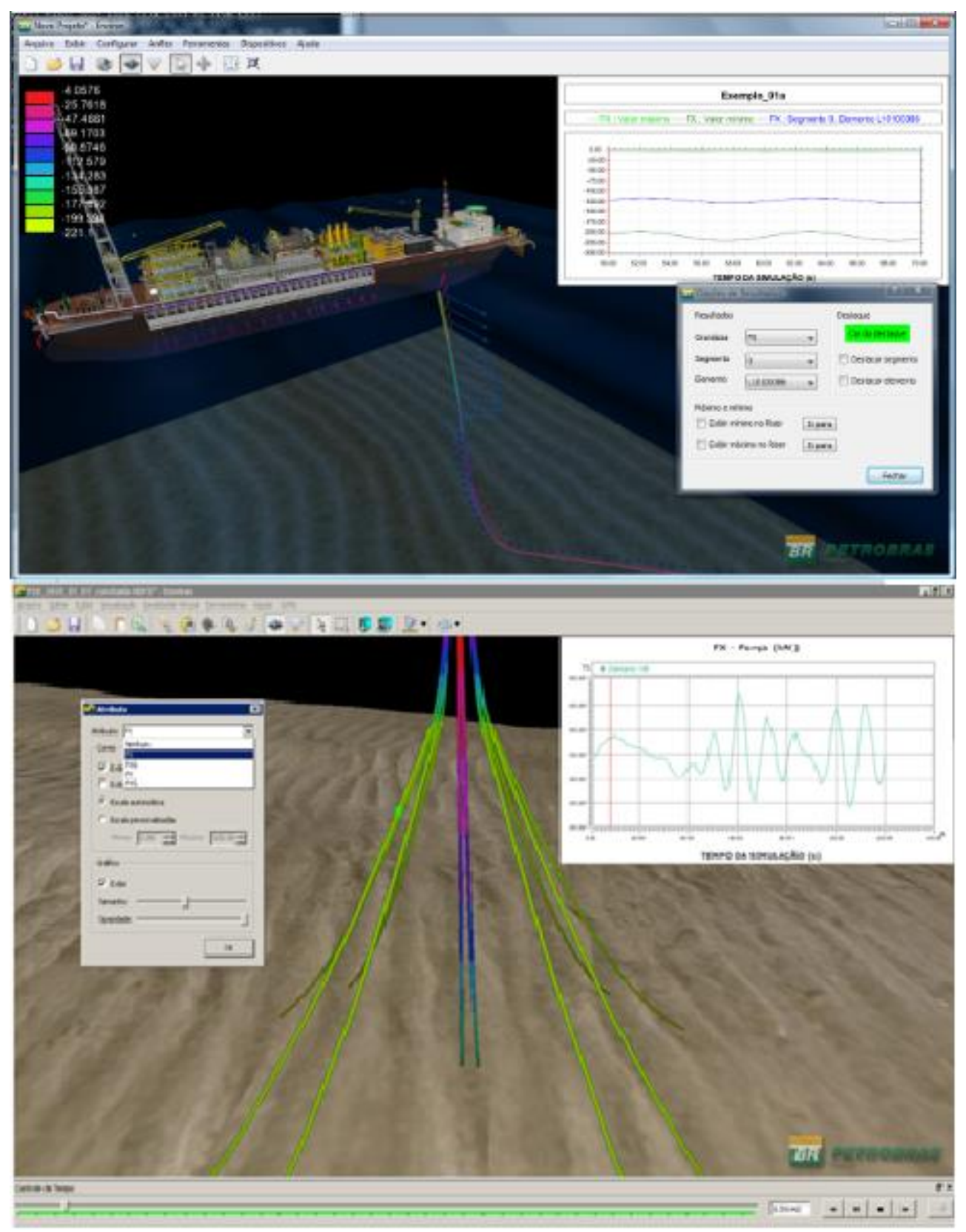

Figure 18 - Environ running offshore simulation

Environ was chosen as our test application because it is both a virtual environment application and a complete offshore engineering application, able to manipulate large amounts of simulation data.

Environ provides a full script interface using the LUA language [21]. With this script language, it is possible to execute many complex operations inside Environ programmatically. At the same time, it provides a perfect way to send commands 
from an external application to Environ. A sample LUA script for Environ looks like this:

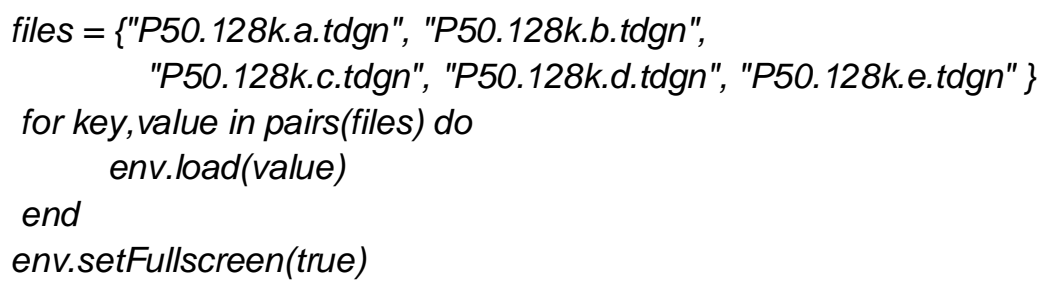

The above script loads many models and sets Environ to run in full screen. To achieve the integration needed by our framework very few changes were needed on the application side, since Environ already had a way of receiving messages and commands through LUA scripts.

\subsection{Extension Points}

EnvironRC implements both extension points discussed in the previous sections. In this section, we will discuss the implementation details of both extension points.

\subsubsection{Mobile Environ Service}

To help in the development process of the mobile App for Environ, we created a custom Mobile Application Service to handle high-level commands coming from the mobile device. The mobile service is also able to do some logic depending on the command. A good example of the benefits of using this extension point is the handling of active selection of model objects in Environ. We display in the mobile device interface a list of selected objects. With many users using the system at once, (many mobile devices at the same time for instance) it can be a problem to maintain the current selected objects list updated in all devices. So, we implemented as part of the Extension Point, a layer of business logic that is in charge of keeping the selection consistent across all connections. When there is a request from a Mobile Device to get the selected elements, the custom mobile service will not pass the 
command direct to the application, instead it process the command internally and responds accordingly.

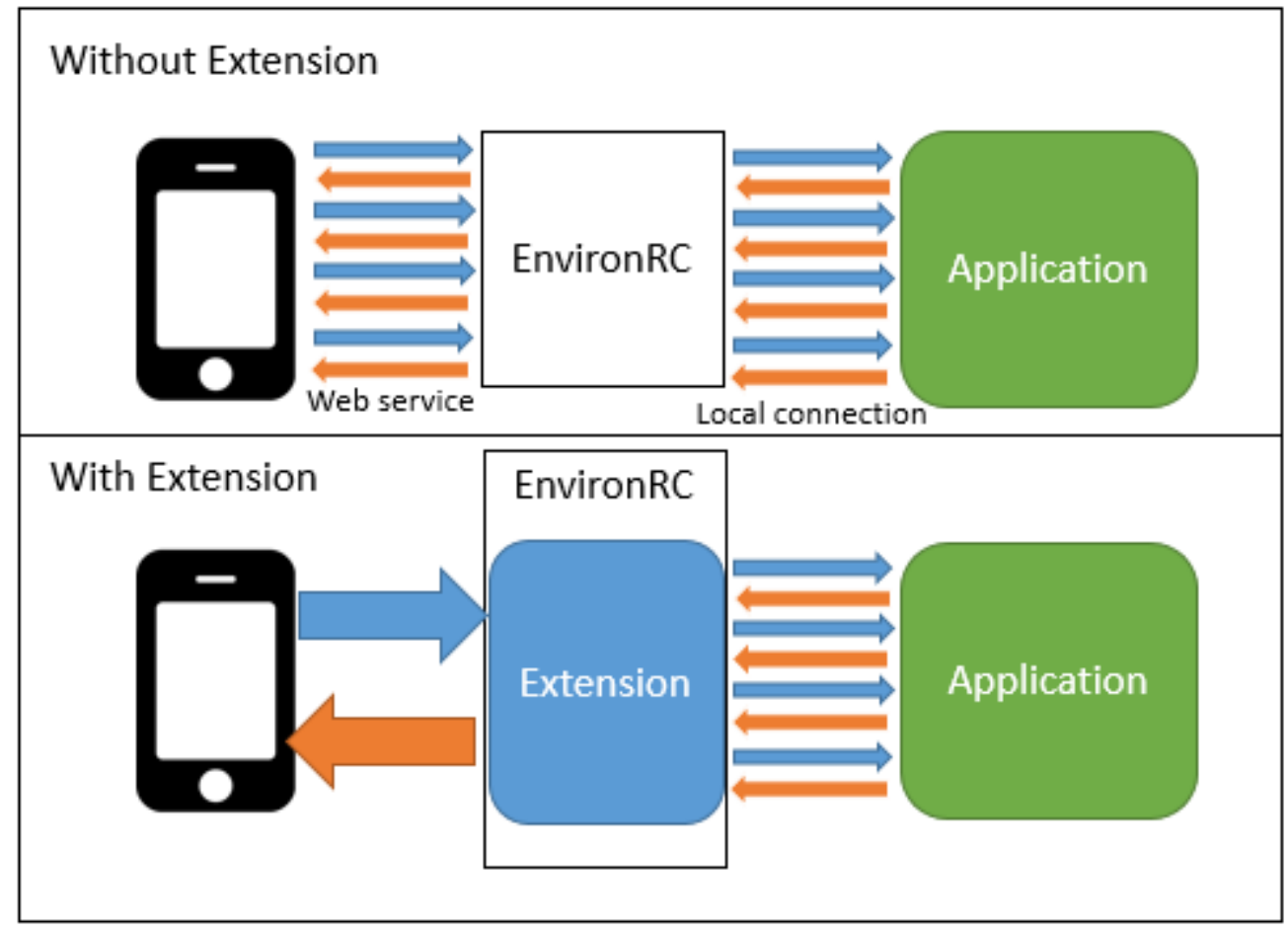

Figure 19 - Mobile service extension use

Another way we took advantage of this Extension point was to integrate many requests into a single web service call. When we open the "settings" page of the mobile application (further detail in section 6.3), each setting parameter must be requested to the Environ application as a different LUA command. This would generate many web services calls and would make the application less responsive (Figure 19). Therefore, what we did was create a custom command using the Mobile Service extension point to request all needed settings parameters in one web service call, heavily reducing the communication delay.

\subsubsection{Environ Proxy}

The implementation of communication between EnvironRC and Environ was done using a local socket connection. We had to implement the framework Extension Point to send the LUA commands to Environ using the socket structure. 
The implementation of the socket connection was done in a separate thread that keeps consuming the messages from environ and passing it along to the AppRC collaboration structure. The thread also consumes a message queue end sends the new messages to environ.

\subsection{EnvironMobile}

EnvironMobile is an IOS application developed mainly to help in the visualization process of complex offshore engineering models in VR environments. It was developed with the Objective $\mathrm{C}$ language as a hybrid application (IPad and IPhone). It works as an extension of the main application, enabling the user to setup parameters and view details of the main model being visualized. EnvionMobile connects to environ using the Mobile connection input channel of EnvironRC.

We defined and implemented seven base functionalities for EnvironMobile:

- Configure visualization parameters

- Navigate the model structure

- Help navigate the virtual world

- Create and delete annotations

- View and manipulate engineering data

- Take snapshots of the scene

- Manipulate the collaboration sessions

In the next sections, we will discuss the implementation of each of these functionalities in further detail. 


\subsubsection{Visualization parameters}

Being a complex application as it is, Environ can have many parameters to setup depending on the kind of visualization the user wants to use. These parameters range from simple visualization tools like showing the ocean or terrain information, to complex values tied in to the simulation, like forces applied to risers or sea current values. As the user will probably need to change the values and inspect different information during the visualization, it was very important that these parameters be made available to the mobile device in his or her hands. Therefore, our first priority was to implement a complete set of commands for visualization parameters and the interface to manage them. (Figure 20 shows a sample of the Mobile interface). We followed the standard settings interface of the IOS platform.

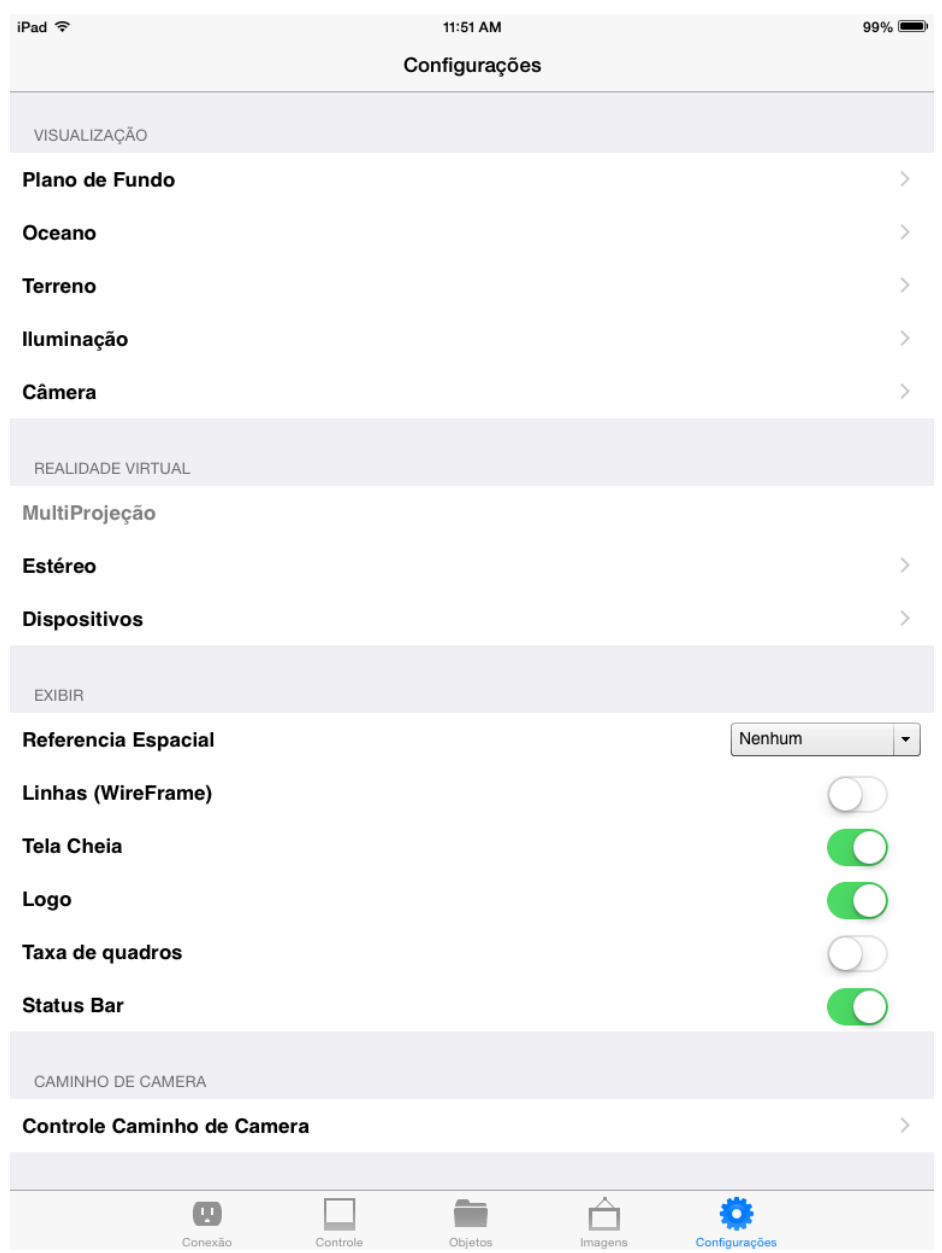

Figure 20 - Environ mobile visualization settings

The visualization parameters of Environ include settings of the 3D scene, like skybox, ocean and terrain settings. We can also set the camera and light settings of 
the visualization. Another important set of visualization parameters are the VR settings. These include stereoscopic 3D, multi-projection and devices (like fly sticks) settings.

\subsubsection{Navigate the model structure}

The visualization scene of Environ is structured in a hierarchical way, because for very complex scenes and simulations it becomes harder to select a specific object in the 3D world. So, having a tree like object hierarchical structure can help to select and check more detailed information of a given object. However, bringing up the objects tree in a context menu during a session in an immersive environment like a CAVE can be distracting and disturb the immersion. Thinking about that, we implemented a way for the user to view the complete objects tree with the tablet and access the details, navigate to or even manipulate the data of any object.

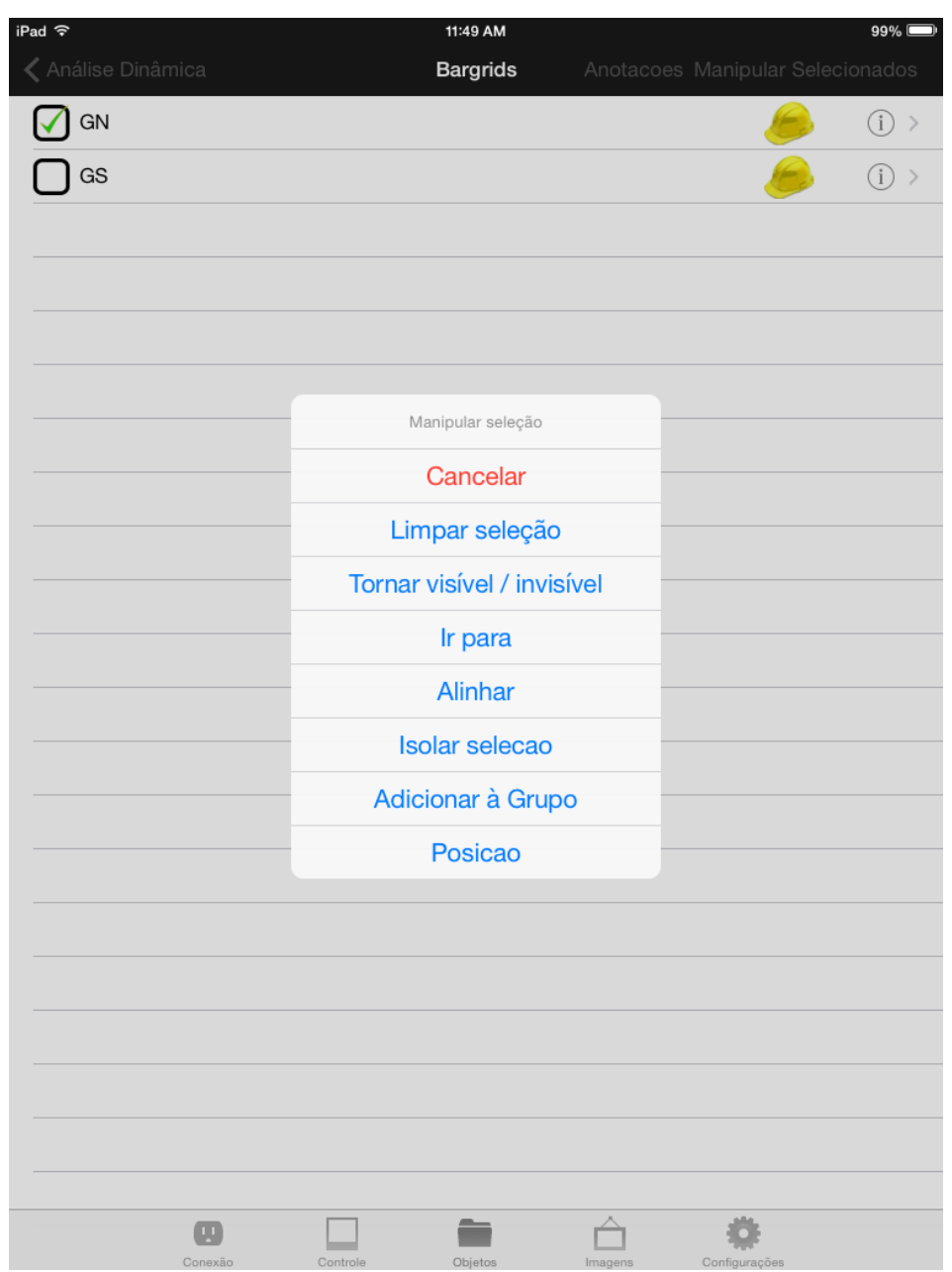

Figure 21 - Manipulate the model structure 
On Figure 21, we can see how the interface works. We present the user with a list of all elements of the current hierarchical level. The user can then tap the arrow on the far right side of the element to navigate to its children or he can tap the element to access some commands to be performed on that element, like: navigate to the element, turn the element visualization to invisible, clear the elements selection among other commands.

\subsubsection{Navigate the virtual world}

As seen in the related works section, many methods to navigate the virtual world were already discussed, including using mobile devices. For the Environ application, only simple navigation methods were implemented. The method mimics the use of navigation with the keyboard [Figure 22].

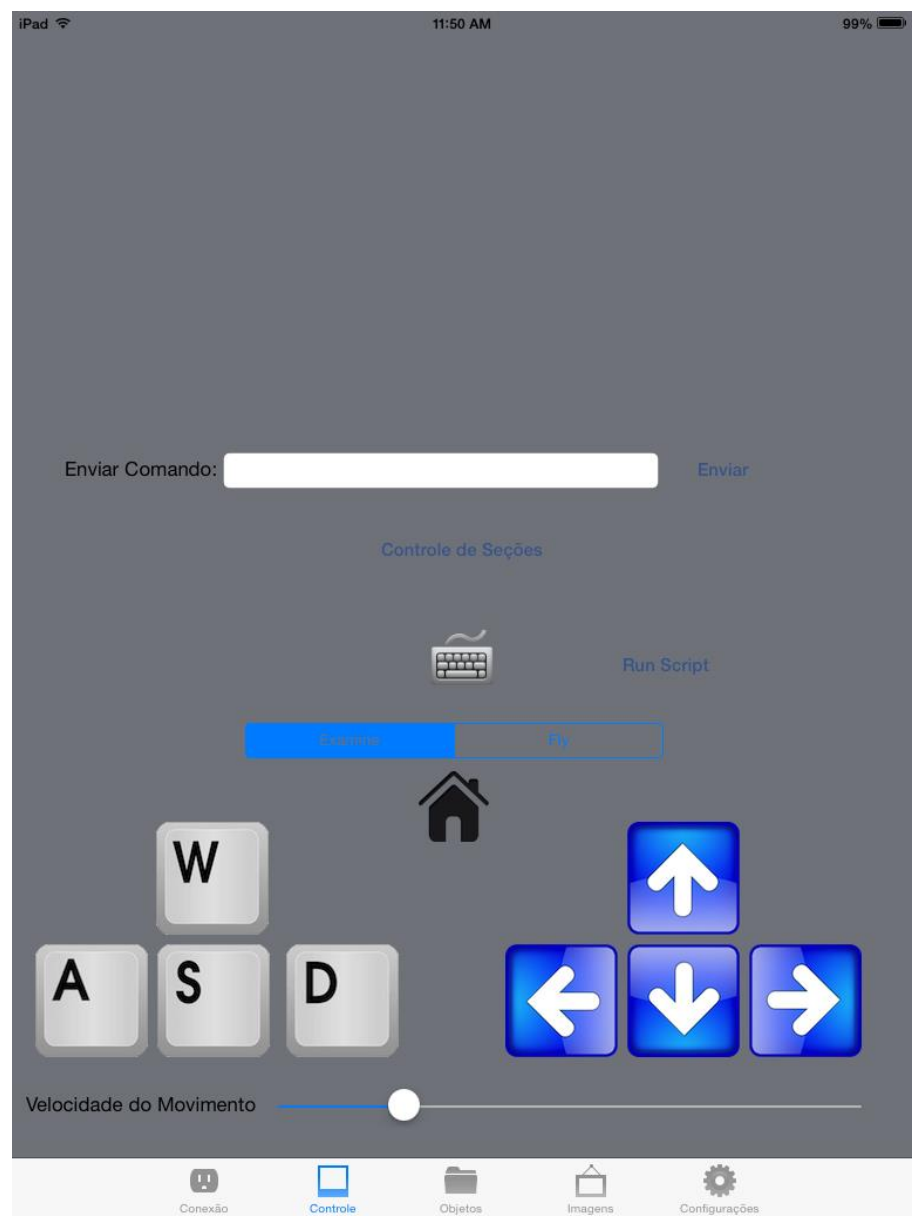

Figure 22 - Virtual world navigation

Although it might be a very simplistic implementation of 3D world navigation, it can be of much help to be able to come closer or move away from an 
object using the mobile device. Environ has two types of 3D world navigation paradigms; "Examine" and "Fly". Using the Examine mode, the user camera has a set point of view center point, and he moves around this center point. It is very useful when analyzing a specific point in the model. The other mode is Fly, in which the controls work as if the user was flying through the scene.

Our communication and collaboration solution supports any kind of navigation, including more complex implementations using the internal sensors of the mobile device like accelerometers and gyroscopes. However, it fell out of the scope of our work and in our experience with EnvironRC in VR Setups, the use of the simple provided controls in conjunction with the ability to select any structure from the model and directly navigate to it, although not optimal, proved very effective in helping the visualization.

\subsubsection{Manipulate annotations}

Virtual 3D annotations are a very useful feature of Environ. They help the user understand details of the virtual model since each annotation is always coupled to a specific part of the model being visualized. All annotations can be seen in the mobile device as list (Figure 23). This is especially useful when the user needs to setup a list of tasks to be done in a remote location. For example, a user using the desktop application can create a sequence of annotations, each representing a task that needs to be done on s specific part of the model. A second user in a remote location (an oil platform for example) connected to the same session, can see the annotations and its locations and perform the tasks. He can even create new annotations or edit the ones already present. 


\begin{tabular}{|c|c|}
\hline iPad $\curvearrowright$ & $99 \%$ \\
\hline Anotações & + \\
\hline Boia Sul de Sapinhoá & $>$ \\
\hline Boia Norte de Sapinhoá & $>$ \\
\hline FPSO Cidade de São Paulo & $>$ \\
\hline Malha de Elementos Finitos & $>$ \\
\hline Strakes for VIV reduction effects & $>$ \\
\hline
\end{tabular}

\subsubsection{Manipulate engineering data}

As mentioned before, when inside the VR environment, any kind of menu or big text block viewed in the application disturbs the immersion. A mobile device offers a second screen where we could display many kinds of data like: large tables of numbers, graphs, detailed information, etc.

We implemented a way for the user to request engineering data detail of any object of the scene (Figure 24). This feature proved the most useful when using the mobile device in VR setups, as it helps the review process of an offshore simulation when the user can see multiple data tables of the specific simulation timestamp being presented in the main visualization screen. 


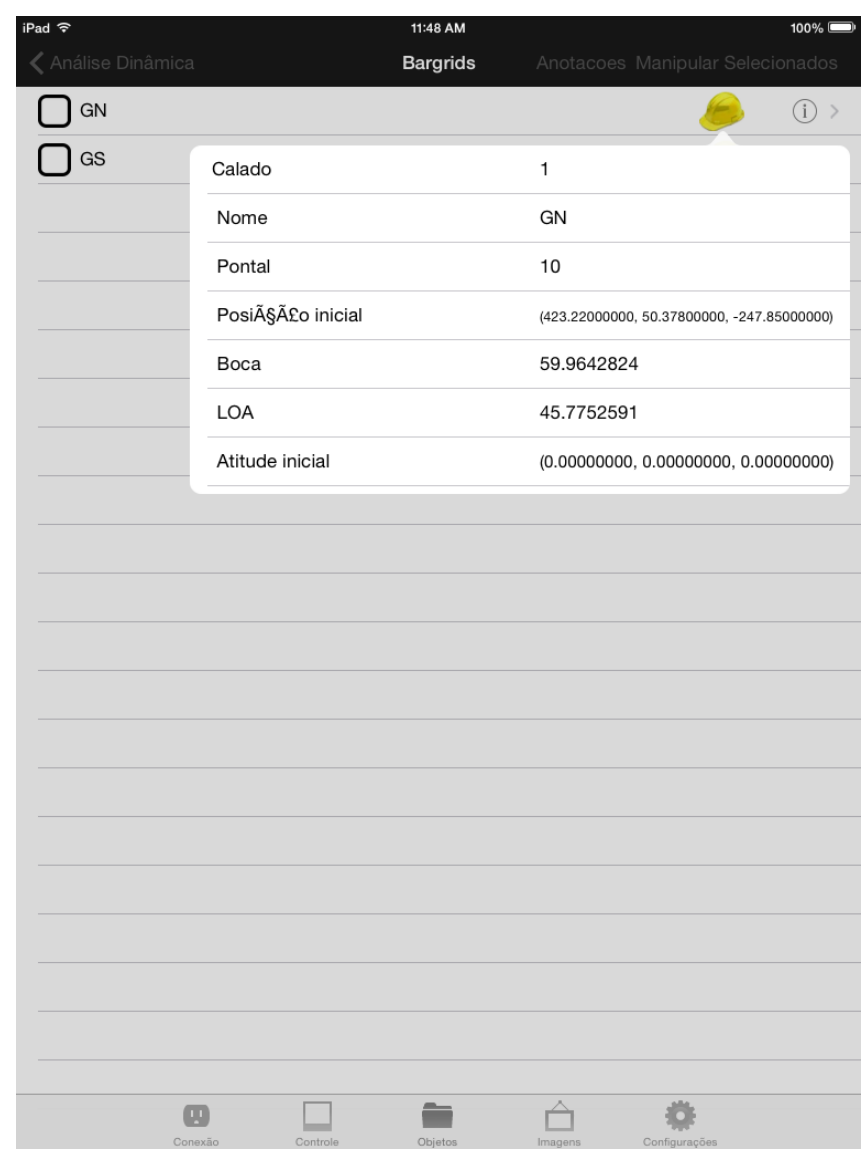

Figure 24 - Manipulate engineering data

\subsubsection{Take snapshots}

A useful feature of EnvironMobile is the ability to take snapshots of the current simulation. It is a useful way to collaborate with remote users, since they can receive images of the simulation model while on the field. This can help the field engineer using the mobile device identify and compare the simulation with the real world engineering hardware. 

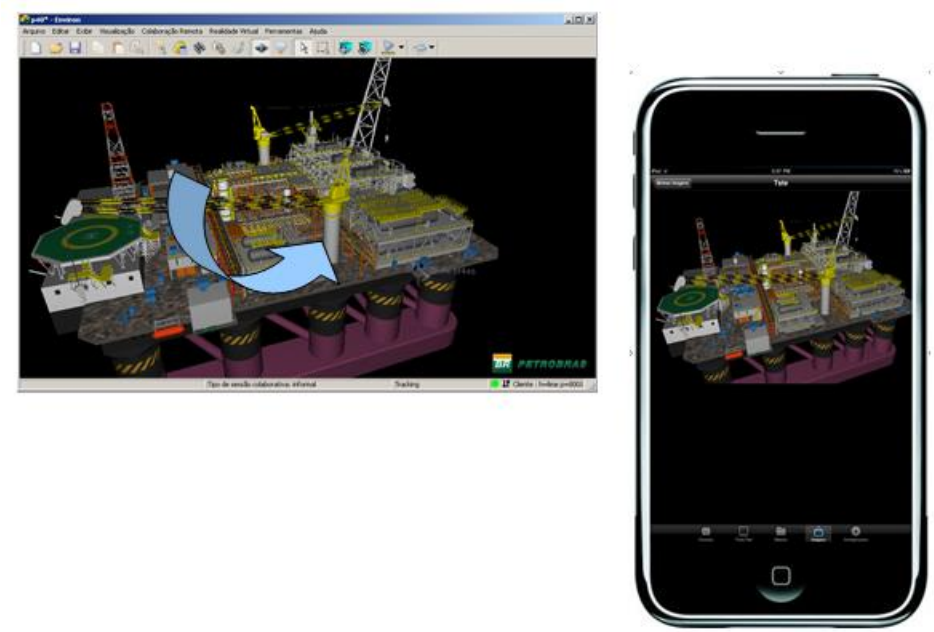

Figure 25- Mobile snapshot

A more complete implementation of this feature would include the ability to stream as video the content of the visualization directly to the mobile device in realtime. However, to implement this complete feature would require a lot of extra work and was left outside the scope of the current work.

\subsubsection{Manipulate the collaboration session}

In order to manage the collaboration aspect of EnvironRC, we implemented a special screen to manipulate the collaboration session. Here the user can see the available applications to send commands to, the number of other users in the session, create new instances of the application, start broadcasting a message or remove an application session from the session. 


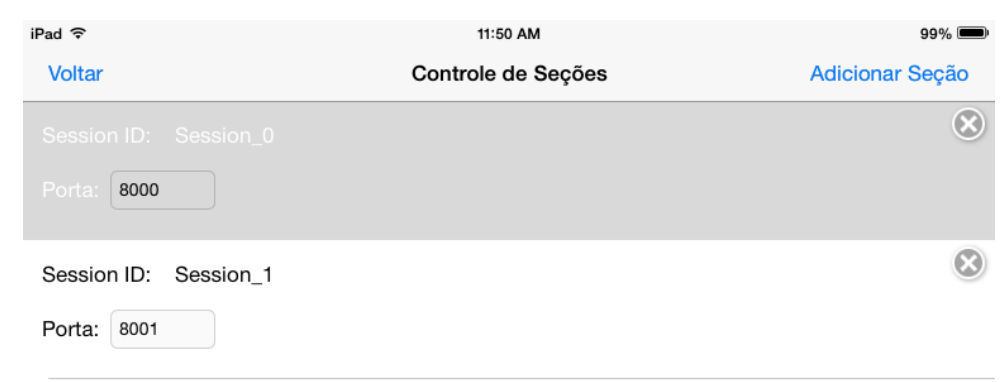

Figure 26 - Collaboration control

This is the only functionality that does not concerns environ directly. It invokes only methods of EnvironRC that do not connect directly to Environ. It manipulates the collaboration session using only control messages (as described in section 4.4).

\subsection{EnvironScript}

EnvironScript is a Java application that was developed to help an external application send commands to Environ. The motivation to create this simple application was to enable a PowerPoint presentation to control an Environ application running on another computer.

In order to communicate with EnvironRC, the application has to use one of our four input channels (file, socket, web service and mobile web service). PowerPoint is an application over which we do not have any control or any easy 
way to access sockets, write files or send web service requests. Therefore, we created the EnvironScript application. It is a command line application that receives the LUA scripts it needs to send to environ along with a configuration file in XML format.

EnvironScript is essentially an easier way to send simple scripts to Environ. It has, however, some important limitations. It only sends the scripts to be executed by the target applications in the sessions, it cannot process responses. It can also only use the web service and socket input channels.

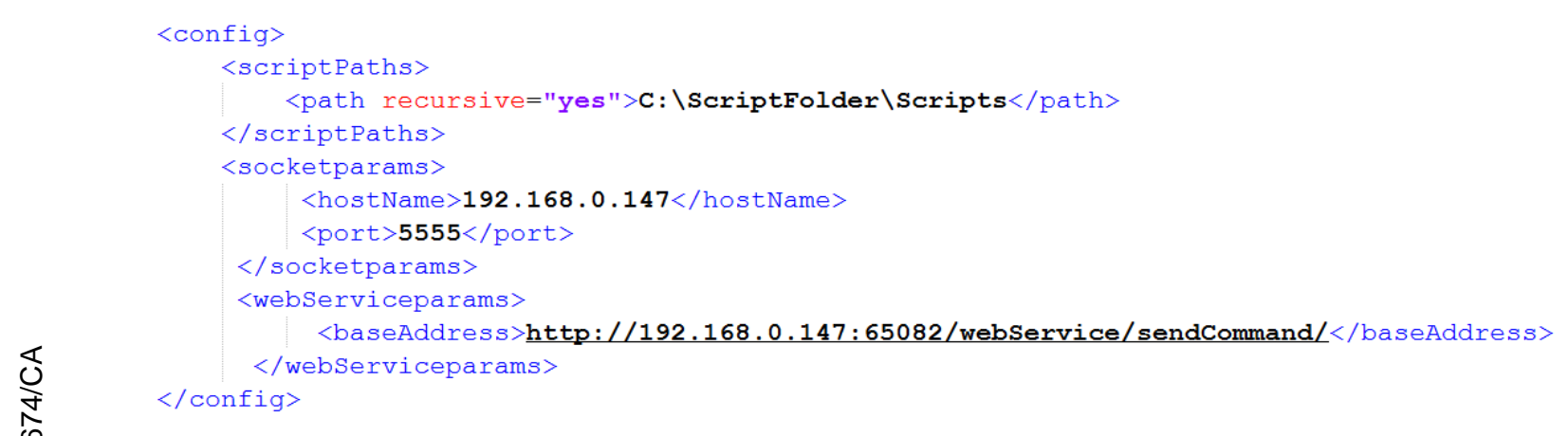

Figure 27 - EnvironScript configuration XML

An example of a XML configuration file can be seen in Figure 27.There are two main parameters that need to be setup in the configuration XML. First is the folder in which EnvironScript will look for the scripts to send. Second is the address where the AppRC Server is running on, that is, its IP address and port. 


\section{Results}

In this chapter, we will discuss two main results of EnvironRC. First, in section 7.1, we describe the experiment that was conducted with users to determine the benefits of having a mobile device while using a VR setup. Second, in section 7.2, we present a real-world case of EnvironRC being used in NVC (Collaborative Visualization Center) in CENPES/Petrobras.

\subsection{Experiment}

The goal of our experiment was to analyze and determine the benefits (if any) for the user experience of running Environ in a VR session with and without our solution. For the experiment, the users had to perform a series of tasks during a VR session in two different conditions: first without our solution and then using the mobile device connect to the Environ application through EnvironRC. To complete the tasks without EnvironRC, the participants were asked to use standard mouse and keyboard inputs. This decision was made because although there are many different devices to help navigate the 3D world (as discussed in Chapter 2), none of them can help the user manipulate engineering data or use 2D menus to configure the application. On top of that, most CAVEs setup today use keyboard and mouse to perform these tasks.

The experiment is described in the following sections in three stages: first we describe the steps needed to setup the experiment, then we discuss the experiment execution and finally we analyze the results.

\subsubsection{Experiment preparation}

The preparations steps needed to setup the experiment were:

- Definition of test environment.

- Definition of experiment tasks.

- Definition of participant profile.

- Preparation of materials and documents for the experiment. 
- Pilot test of the experiment.

The above steps are described in the following sections.

\subsubsection{Experiment environment}

To test our solution, we used a visualization system of type CAVE. A CAVE has the problems we wanted to address with this dissertation. Some of these problems include:

- Users have to be standing

- User has to use 3D glasses

- Multiple projection screens, making menu navigation hard

- Large projection screens, making texts harder to read

We used the CAVE VR system of Tecgraf/PUC-RIO. This specific CAVE has four projectors with optical head-tracking, giving the user a high degree of immersion.

The specific hardware configuration of the CAVE used was:

- Main PC running the CAVE: CPU Intel Core 17965 @ 3,20 Ghz; RAM 12GB; Windows 7 x64 OS

- 1x NVIDIA Quado Plex 2200 workstation

- Four big projection screens

- Four head-tracking sensors

- Tablet Ipad 2 running EnvironMobile

\subsubsection{Experiment tasks}

As mentioned before, one of the main problems engineering applications face when running in VR setups is the difficulty to represent any kind of $2 \mathrm{D}$ menu navigation. This happens specially when trying to read large amounts of data (as 
numbers or tables) or when trying to navigate 2D menus to change any visualization parameters.

To study the impact of our solution when trying to solve these problems, we defined two different tasks for the participants to perform. One of them to study the impact when reading large amounts of data and the second one was designed to study the impact of changing visualization parameters. Another important distinction between the two tasks is the fact that the first task requires the participant only to read the values he/she sees in the virtual world, while the second task requires the user to input numerical values as parameters. Both tasks are described in the following sections.

\section{$\underline{\text { Task } 1 \text { - Reading engineering data }}$}

The goal of task 1 is to test the impact of having a mobile device when trying to read engineering data values from a specific object. The participant starts with a full visualization of the offshore engineering model. The participant is asked to use the object navigation interface of Environ to select a specific object in the scene. Once selected, he/she should invoke the "go to" command to go to the selected object and visualize it. After that, the participant is instructed to read out loud the values of three engineering parameters of the selected object.

\section{$\underline{\text { Task } 2 \text { - Changing visualization parameters }}$}

Changing visualization parameters is a very common task when using VR setups. Visualization parameters include: graphic quality parameters, immersive system parameters, stereoscopic 3D parameters and others. The goal of this task is to change three visualization parameters:

1. Change the skybox from "color: black" to "sky: twilight".

2. Change the stereoscopic eye distance from 0,0175 to 0,02 .

3. Change the distance to parallax zero from 1,0 to 0,9 . 


\subsubsection{Participants' profile}

We recruited fourteen participants, with ages between 26 and 45. All of them had experience with VR setups. Only 2 of the participants had not used any kind of engineering applications in VR, but had experience with 3D software like modelling tools and games. All participants had at least a graduation degree in the field of computer science and $78 \%$ had a postgraduate degree in the field. There were thirteen males and one female participant.

\subsubsection{Experiment material and documents}

The documents used for the experiment (shown in Appendix A) were:

- Short Environ manual. (Appendix A.1)

- $\quad$ Task 1 and 2 Description. (Appendix A.2)

- Consent form (Appendix A.3)

- Pre-use question form (Appendix A.4)

- Post-use question form (Appendix A.5)

- Post-use interview script (Appendix A.6)

All documents for the experiment were written in Portuguese because the experiment was conducted in Rio de Janeiro, Brazil.

\subsubsection{Pilot test}

A pilot test of the experiment was conducted to validate the experiment material, documents and process. The goal of the pilot test was to identify any problems that were not accounted for. The results of the test run were not considered as part of our analyses.

Based on the results of the pilot test, we decided to make a single adjustment to the experiment; We decided to add a flat surface near the CAVE setup with a mouse and keyboard. Before the pilot test, we had decided that the participants would try to use the mouse and keyboard while standing, but in most VR setups there is often 
a support table nearby where the user can go to use mouse and keyboard if needed. Therefore, we decided to leave the table near the CAVE and the participant was free to use it to support the mouse and keyboard if he/she so wanted.

\subsubsection{Experiment execution}

The experiment was divided in seven steps:

1. Introduction to the study and pre-test question form

2. Reading of the short Environ and Environ Mobile manuals

3. Training session with Environ and Environ Mobile on Desktop

4. Reading of the Task description documents

5. Test execution

6. Post-test question form

7. Semi-structured interview

Before the experiment, the participant signed a consent form which explains the purpose of the tests and guarantees the reliability of the collected data. Furthermore, the consent form guaranteed the anonymity of the participants. After that, the participants were asked to fill in the pre-test question form. The main reason behind the pre-test question form was to determine the participants profile and their experience with both VR setups and engineering applications.

After the pre-test form, users were given the short manual of Environ and EnvironMobile. This document was designed to teach the user how to use the applications to complete the tasks. After reading the manual, the user was given free access to a Desktop computer running Environ and a tablet running EnvironMobile. At this stage, the user was free to experiment with both applications and to ask questions about how they worked. There was no time limit for the training stage.

After the training stage, the user was asked to complete each task twice, once using Environ and once using EnvironMobile inside the CAVE setup. There, the 
user had to wear stereoscopic 3D glasses and stand up inside the cave. He/she was first asked to complete both tasks without EnvironMobile. To do so, the participant could use mouse and keyboard. After that, he/she was asked to complete the same tasks using EnvironMobile. A measurement of time spent in each task with each device was taken.

Finally, after the execution of the tests, the participant was asked to fill in the post-test question form. This form was used as a tool to determine the user experience in the CAVE. Some aspects we wanted to study with the post-test form were: usability, how (or if) both solutions disturbed the immersion, impact of 3D glasses while using a tablet and others. The question form consists of eleven statements. We used a Likert scale for each statement where 1 represents full disagreement and 5 represented complete agreement. The full post-test question form can be found in Appendix A.5 and in Figure 29.

At the end, a semi-structured interview was conducted in order to determine how the participant felt about both ways of completing the tasks. Furthermore, we used the semi-structured interview to clarify the answers given by the participant in the post-test form and ask for improvement suggestions.

\subsubsection{Results analysis}

In this section, we will present the main observations done while running the experiment, as well as difficulties and suggestions the participant had.

First we will analyze the time needed by each participant to complete each task. The results can be seen in Figure 28. 


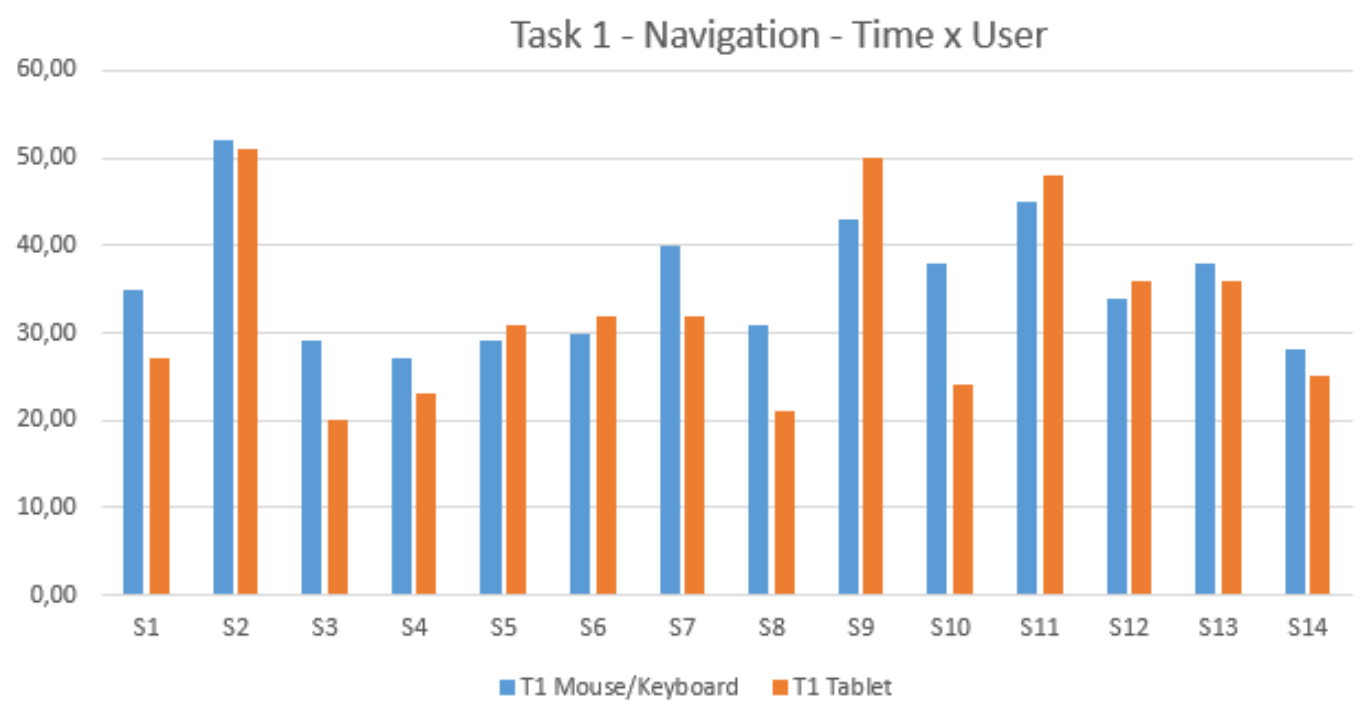

120,00

Task 2 - Configuration - Time x User

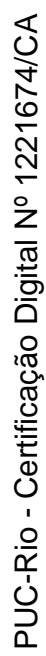

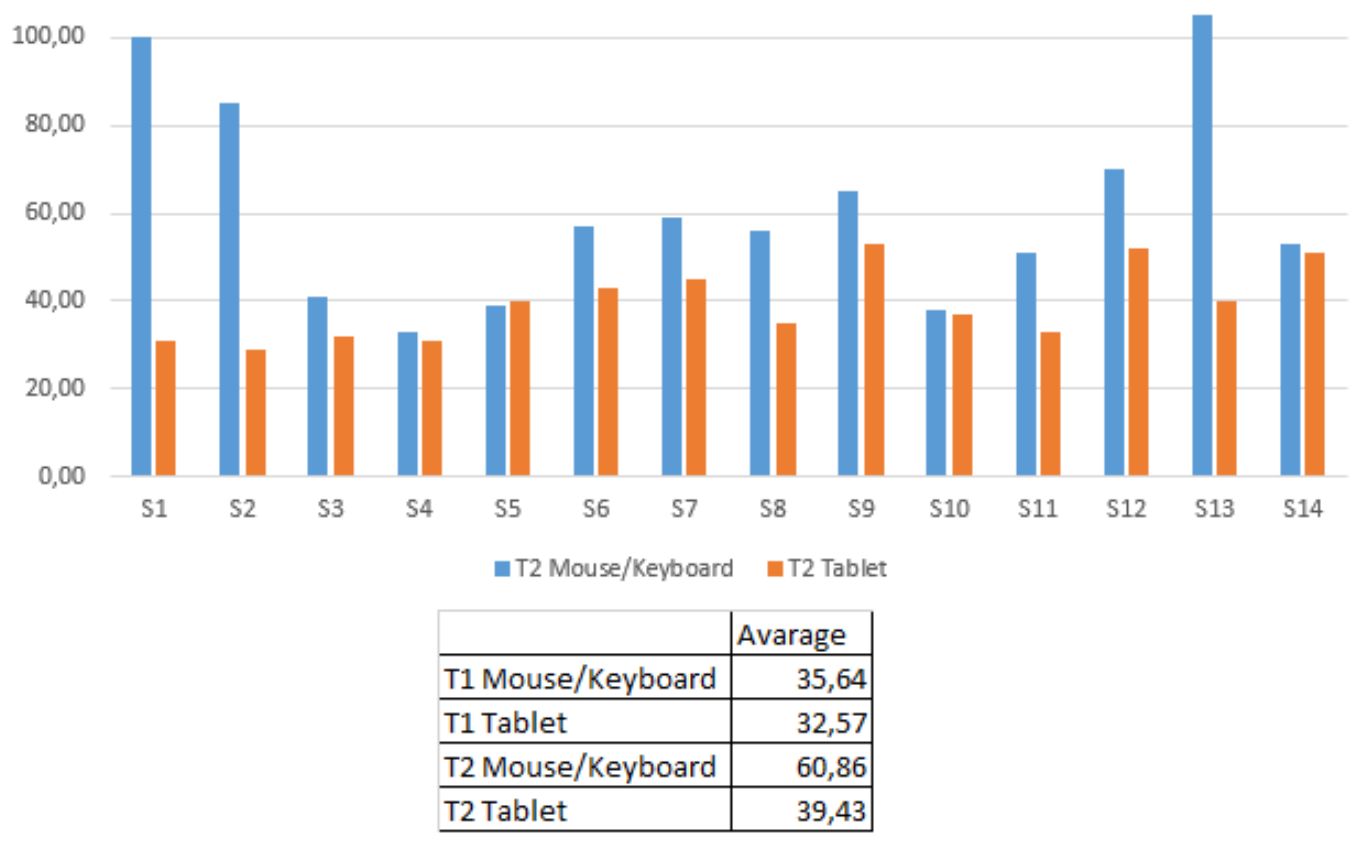

Figure 28 - Time to complete tasks

As most users had experience with VR setups and engineering applications, we could not observe any significant improvement in the time needed to perform task 1. On the other hand, we can observe that most users performed task 2 in significant more time when using mouse and keyboard. The different in results from task 1 and 
task 2 is most likely explained duo to the fact that task 2 required the user to input numerical values using the keyboard.

To further analyze and understand the results of the experiment, we show the result of the post-test question form in Figure 29.

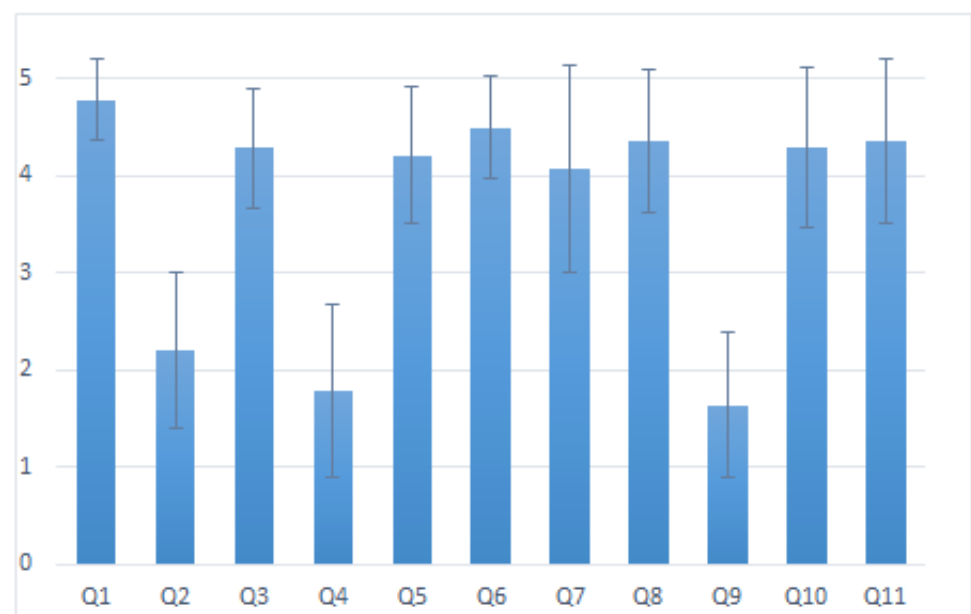

\begin{tabular}{|l||l||}
\hline Q1 & It was easy to navigate (T1) to the target object using mouse and keyboard on Desktop \\
\hline Q2 & It was easy to navigate (T1) to the target object using mouse and keyboard on the CAVE setup \\
\hline Q3 & It was easy to navigate (T1) to the target object using tablet device on the CAVE setup \\
\hline Q4 & It was east to alter the configuration values (T2) using mouse and keyboard on the CAVE setup \\
\hline Q5 & It was easy to alter the configuration values (T2) using tablet device on the CAVE setup \\
\hline Q6 & Having a tablet device had a positive effect on my experience in imerssive VR setups \\
\hline Q7 & I learned to use the tablet quickly \\
\hline Q8 & I felt confortable using the tablet \\
\hline Q9 & The 3D glasses made it more dificult to use the tablet device \\
\hline Q10 & I am satisfied with the time it took me to complete task 1 in the CAVE \\
\hline Q11 & I am satisfied with the time it took me to complete task 2 in the CAVE \\
\hline
\end{tabular}

Figure 29 - Post-test results

From Figure 29, we can see that the users thought the task was easier to complete using EnvironMobile in comparison with standard input devices. (Q1 Q4). During the semi-structured interview, most users reported that using mouse and keyboard in a CAVE was very unpractical and because of that, using a CAVE setup alone was very hard, often requiring a second person to help navigate the menus. These users thought that having a tablet made it practical to complete the tasks in the CAVE alone.

A very common complaint during the interviews was that the size of the text on the projection screen was very hard to read. There are two main reasons for that. First, the projection screen is very large and has a high resolution making the text 
very small. Second, most stereoscopic 3D glasses work using some kind of color filtering mechanism that makes the image darker, and therefore harder to read. To further analyze the impact of 3D glasses, we can see that most users thought the 3D glasses had a small impact when u sing the tablet screen (Q9). One user did complain that the colors on the tablet screen were not very clear using the 3D glasses, but he mentioned it was of low impact for his experience.

Some users mentioned that the EnvironMobile interface could be improved. One user suggested that the EnvironMobile interface should try to mirror the main Environ application perfectly. Furthermore, when asked about the impact the tablet had on the immersion, almost all users said that having to look away from the main projection screens to the 2D interface of the tablet did lower the immersion, but was of a much lesser impact than having to use mouse and keyboard. The results of Q6 further accentuate this difference, with most users agreeing that the tablet did have a positive impact on the immersion experience.

From the interviews, it became clear that although some users could complete the task in similar times with or without our solution, the use of keyboard and mouse did never offer a good immersion experience.

\subsection{EnvironRC in NVC}

The presented architecture and solutions are current in use in NVC (Collaborative Visualization Center) in CENPES/Petrobras. In this section, we will discuss a special use of EnvironRC during the review process of a very large offshore engineering project involving a BSR system (Riser sustaining buoy) (Figure 30). 


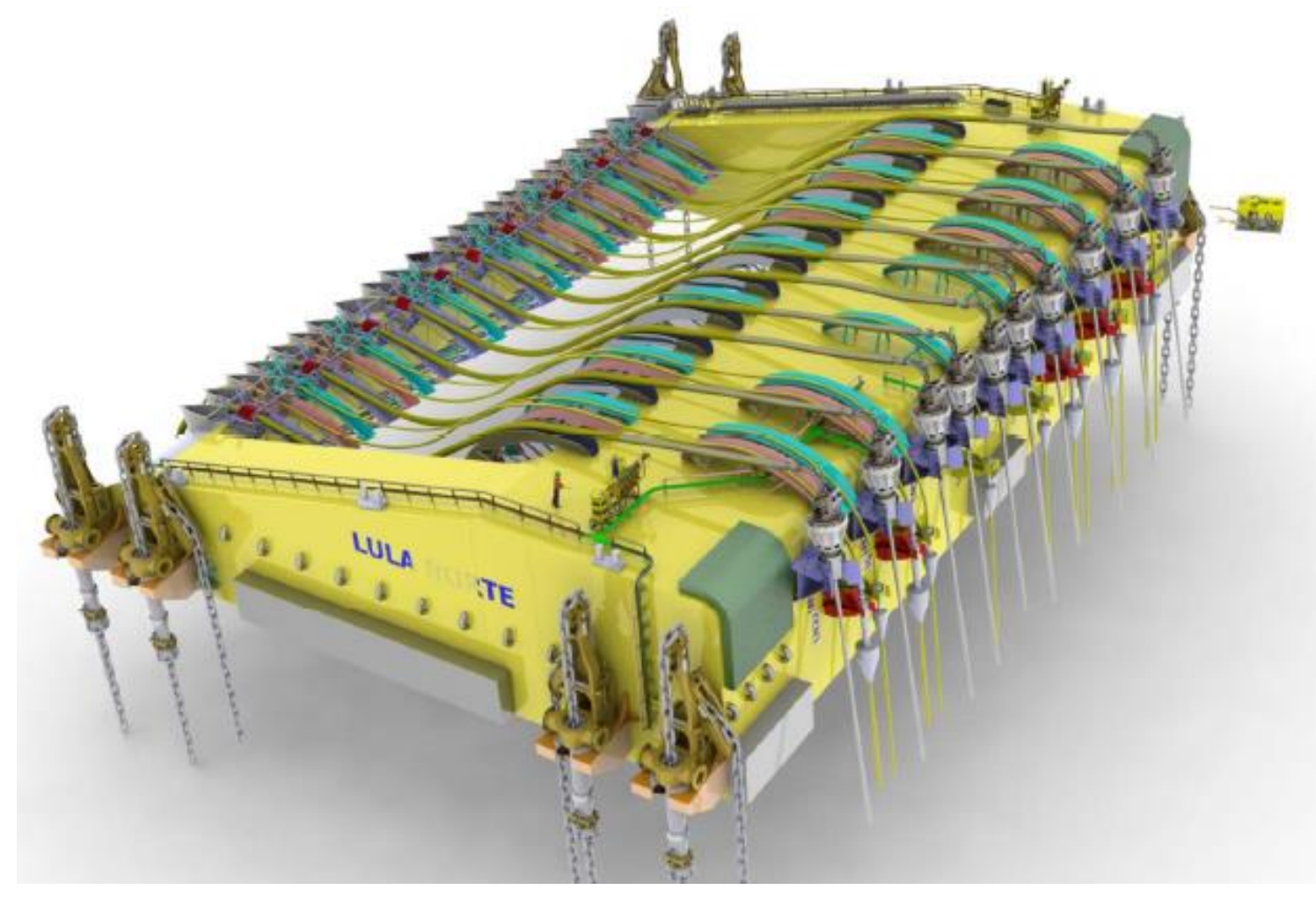

Figure 30 - BSR illustration model

\subsubsection{BSR Project}

The project we analyzed involves deep see oil exploration. The total sea depth at the oil field where the project was implemented is of $2140 \mathrm{~m}$. The project consists of a BSR that stays stationary around $250 \mathrm{~m}$ below sea level. The buoy structure is anchored to the sea floor by eight rigid anchor lines. The main goal of the buoy is to alleviate the stress on the risers induced by the movement of the platform. Without the BSR all the risers would go from see floor all the way to the platform, and they should be resistant enough to support all the forces coming from the movement of the platform. The platform suffers movement duo to the external forces applied to it (current, wave, winds etc...).

The BSR works as a way to separate the movement of the platform from the long risers' lines. There are two set of risers, first the flexible (and more expensive) risers going from the platform to the BSR (at 250m below sea level) (Figure 31). The second set of risers goes from the BSR to the sea floor (at $2140 \mathrm{~m}$ below sea level) and since the movement from the platform does not affect the second set of 
risers, they can be of a rigid and more cost effective type. The BSR works as a sort of damper, absorbing the movement of the platform and not transmitting it to the rigid risers. The way it achieves this is by having the ability to pivot on the side of the risers that goes to the platforms.

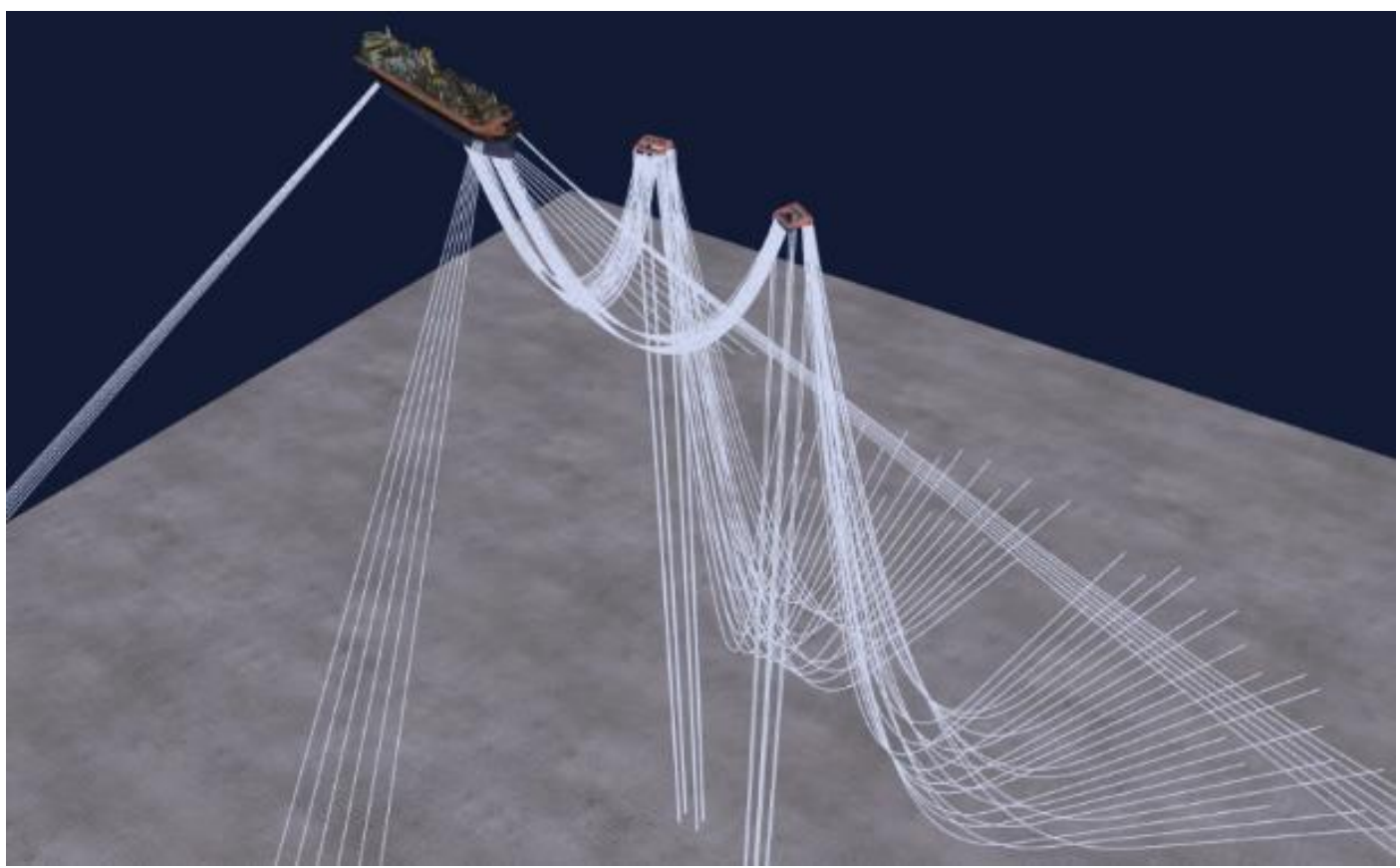

Figure 31 - Two BSR overview

The complete BSR Project took many years of study and involved many areas of the offshore engineer field, making it a very good example for our solution. There was a huge amount of simulations done for every step of the project. These simulations where divided in two main phases: installation phase and operational phase. There were more than a thousand simulation cases for each of the phases, involving every kind of failure or condition.

\subsubsection{Review process in NVC}

The simulations are a very complex numerical computational problem and have to run offline. Each simulation is then stored in a GXML file and these files can be opened and visualized by Environ in the Virtual reality setups in NVC.

The visualization capabilities of the VR setups in NVC help offshore engineers during the review process and these visualizations of big offshore engineering 
projects were the main motivation of this work. Our solution is used in NVC regularly to help the review and visualization of the results. One special case we would like to study in more details, is the review process of the BSR project that took place in the main visualization room of NVC and involved a large amount of simulations and a large amount of engineers.

Because of the number of people present on the day of the review, all the models were to be presented using the PowerWall setup. The PowerWall presentation room in NVC has the main visualization screen and a supporting screen for presentation (Figure 32). All offshore engineers were to present their results and show the simulated models that had interesting details and facts that could indicate some problems for the overall project.

The presenter (mostly offshore engineers) had a PowerPoint presentation that would run on the second screen and the simulation results would be presented on the main PowerWall screen. The presenter could send commands and control the simulation via the PowerPoint presentation as well as with an IPad running EnvironMobile. A complete schematic of how our solution was used to achieve this kind of integration and collaboration can be seen in Figure 33.

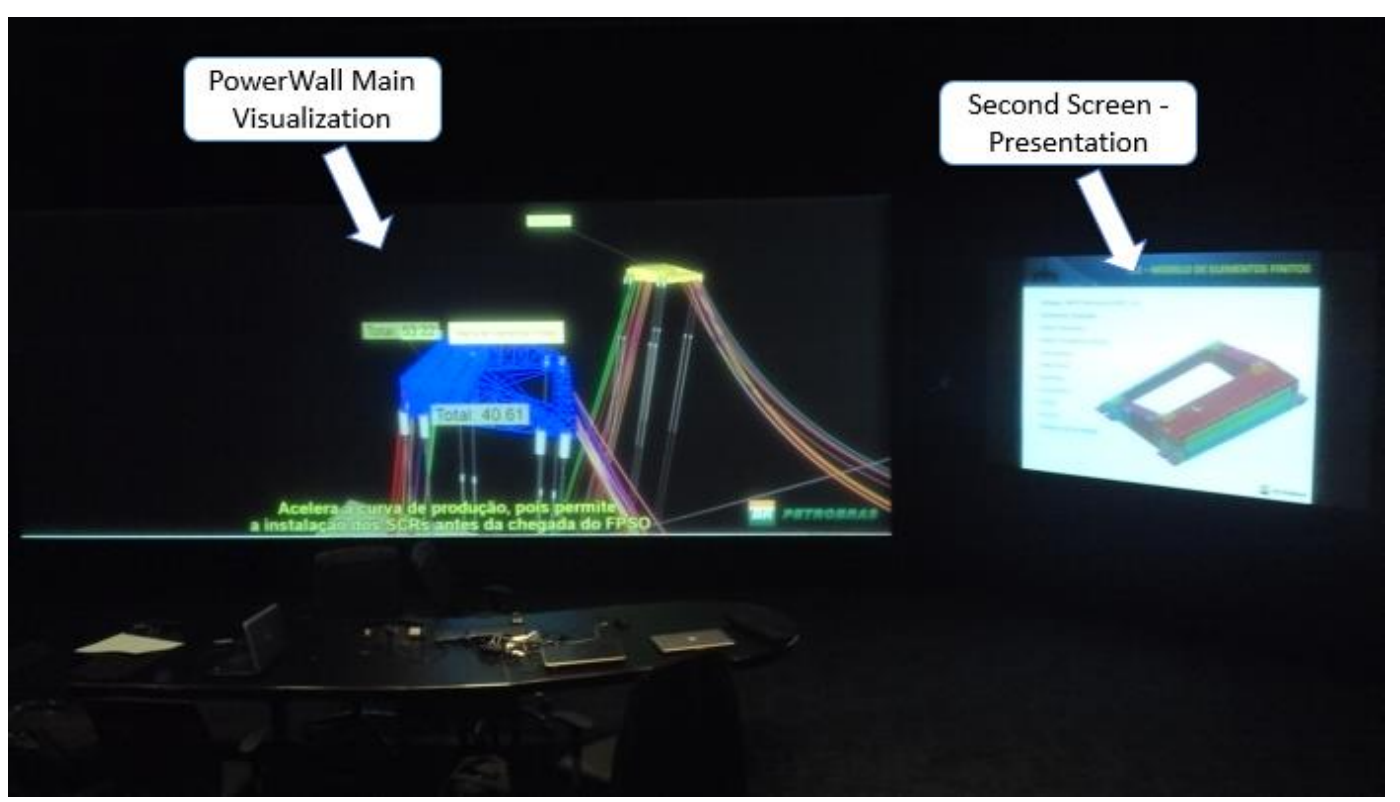

Figure 32 - Powerwall setup in NVC 


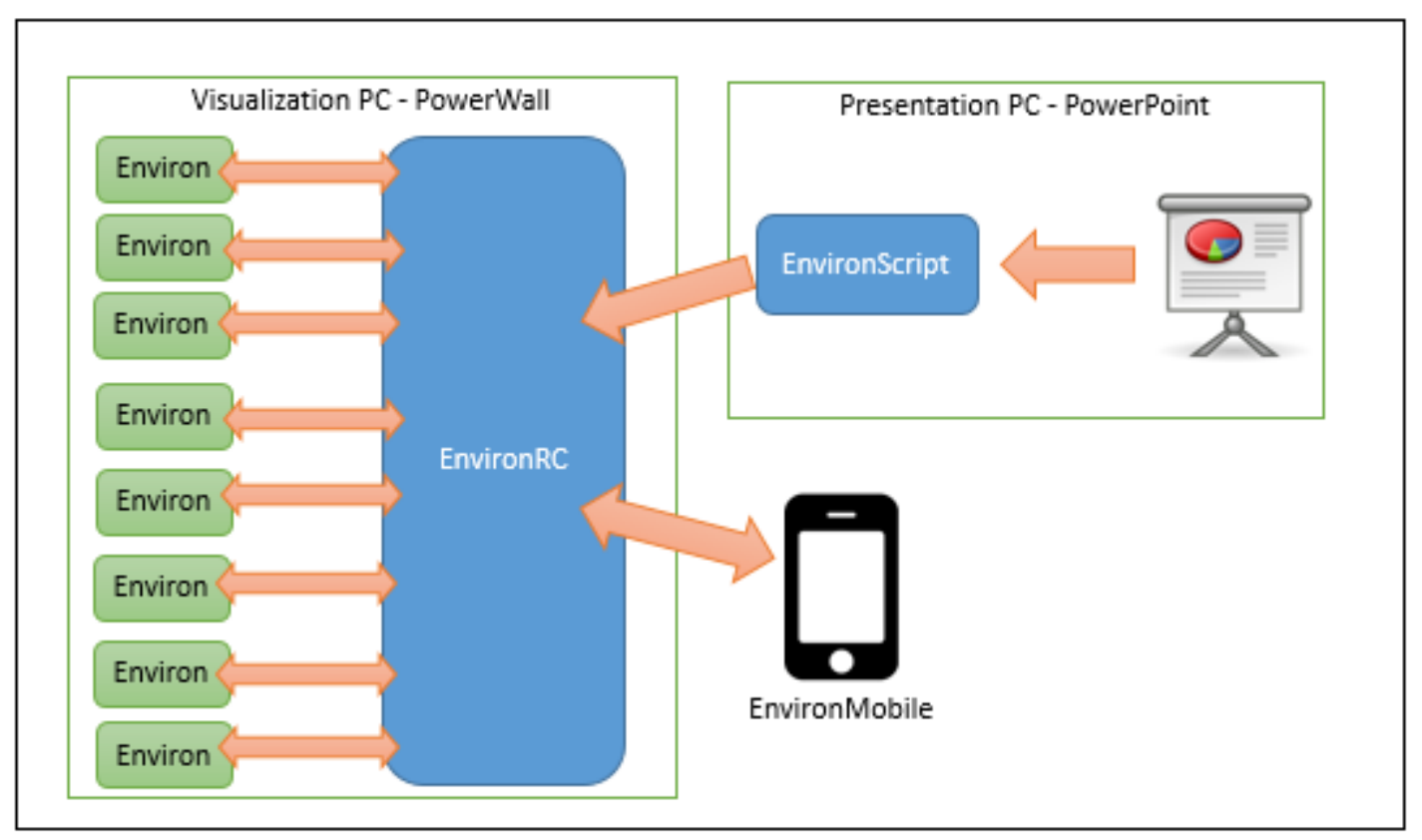

Figure 33 - EnvironRC on BSR Review process

For the review process of the BSR project, seven simulation results were chosen to be presented. Since each simulation takes a very long time to load using the visualization setup, we chose to have all seven simulations loaded using different instances of Environ and have EnvironRC manage them. In total, there were eight instances of Environ connected to the EnvironRC session, seven for each model and one with a general overview model used only to explain the idea behind BSR.

The presentation PC had all the PowerPoints the presenters were going to use. Each PowerPoint was previously setup to be able to invoke EnvironScript to send a command to Environ. As an example, we can see in Figure 34 that the presenter could at any time click in the link in the presentation itself to send the command to bring his simulation to the foreground and start/pause/stop the simulation. 


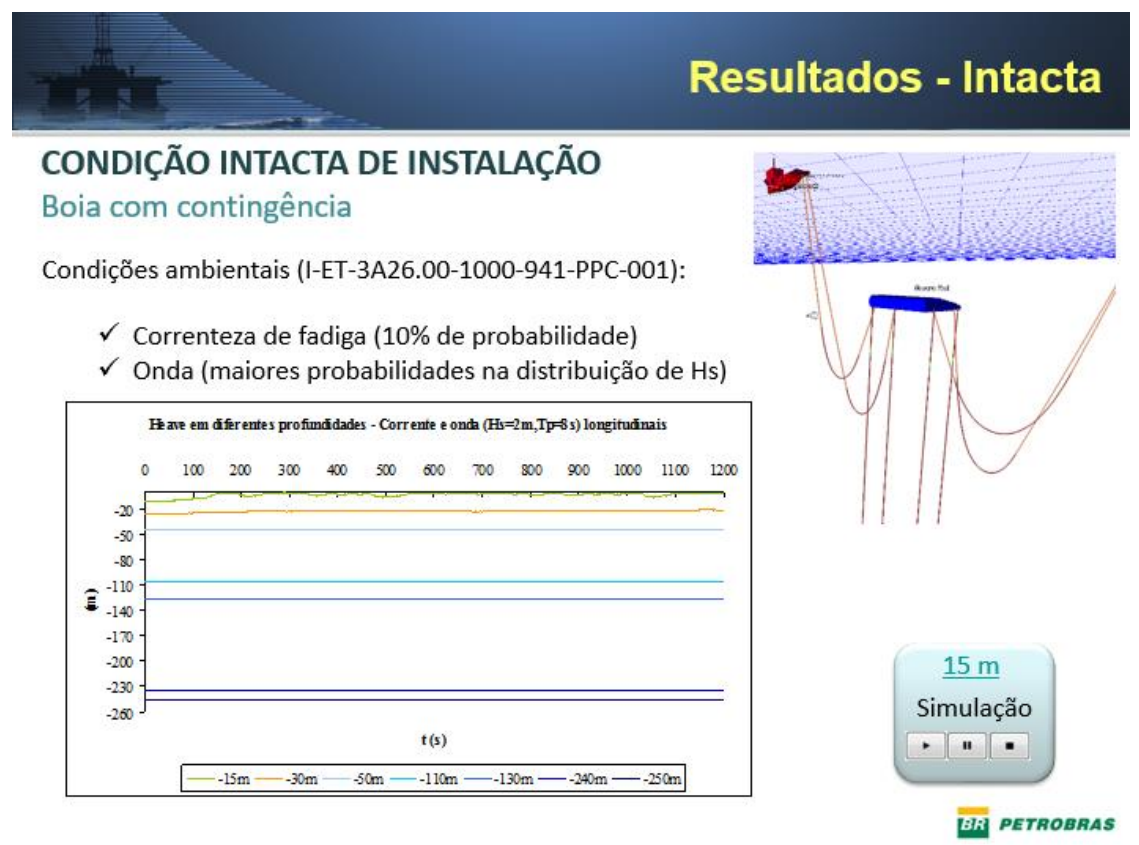

Figure 34 - PowerPoint Slide using EnvironScript

In Figure 35 we show an example script used in the presentation. The scripts begin by sending a control message (“--@BROADCAST_BEGIN”) telling EnvironRC that the next messages should be sent to all connected instances. Next comes the LUA commands responsible for minimizing the application instance. Then the script tells EnvironRC to stop broadcast with another control message ("-@BROADCAST_END”) and selects which Environ instance should be targeted next (“--@USE_APP(Environ_0)") and finally sends the commands to do some visualization setup for the targeted model, in this case, make a model visible and show the plot of a graph.

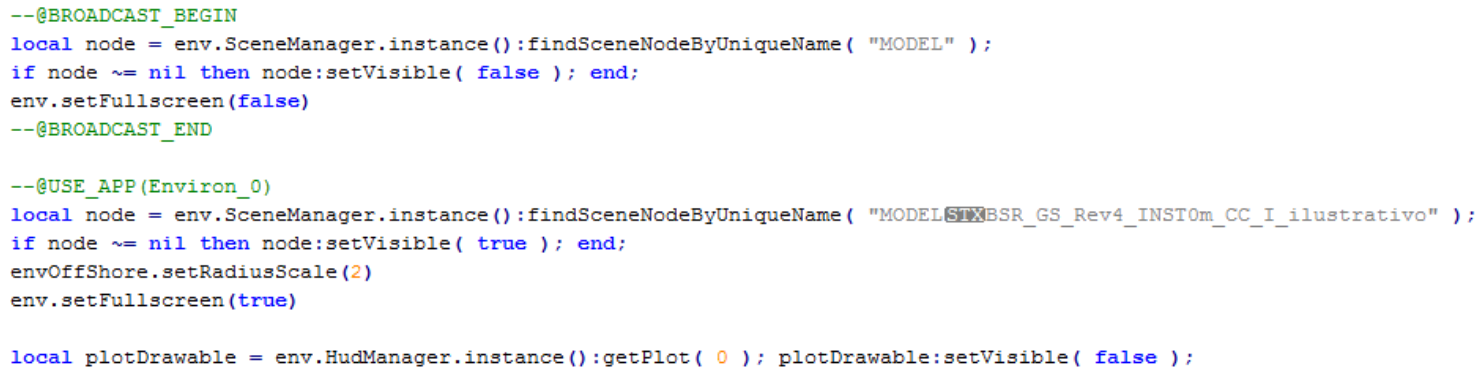

Figure 35 - Example BSR Environ script

On top of the integration with the PowerPoint PC, we had a mobile device assisting the entire process, as seen in Figure 36. With the mobile device, the presenter could, in real time, change the visualization and navigate to a different 
spot in the scene. He could also check engineering data of the model to better answer the questions of the viewers. Using the already discussed functionalities of EnvironMobile, the presenter was able to control and communicate with all eight instances of the application at the same time.

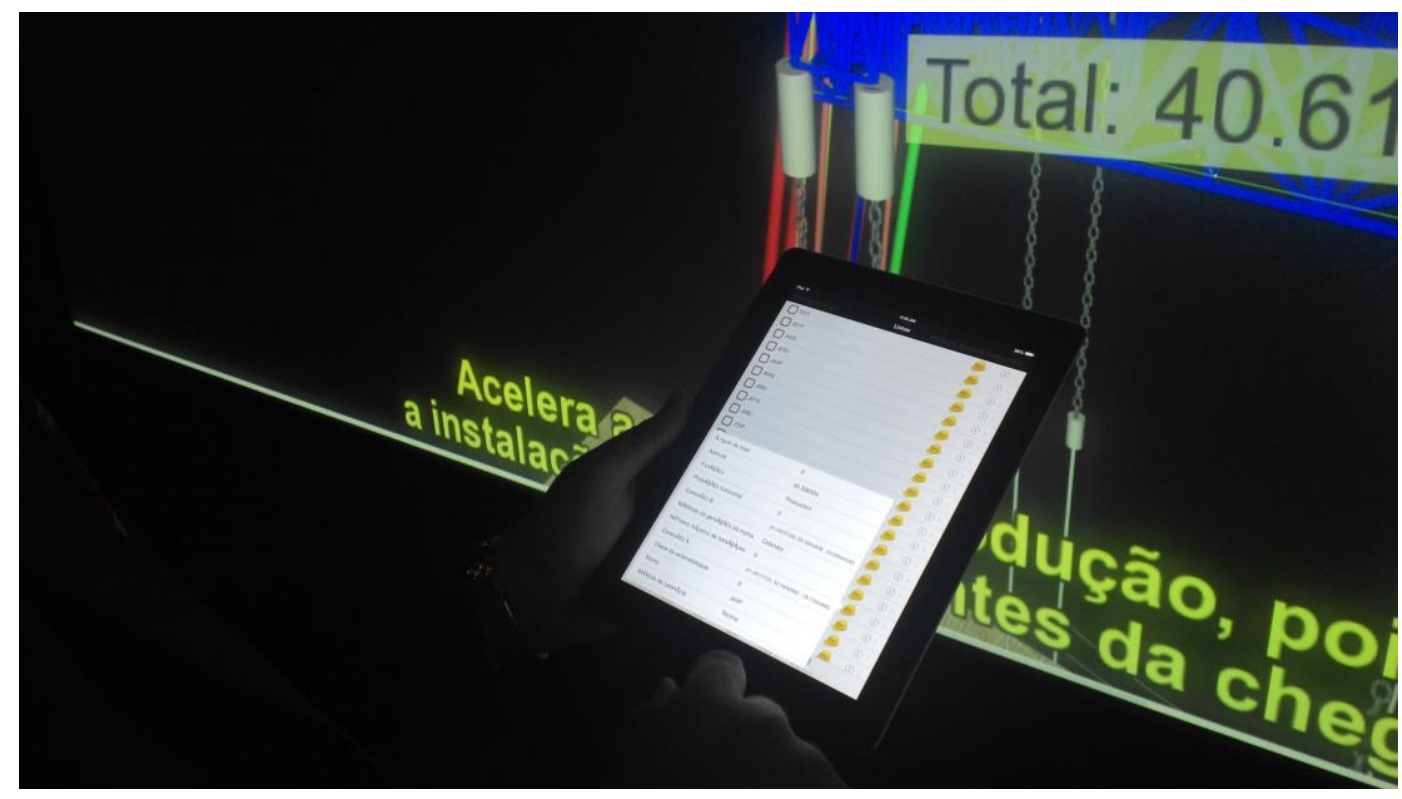

Figure 36 - Mobile on BSR review

The PC running on the main visualization screen was a custom build state of the art machine running a 32 core CPU with two dedicated external NVDIA Quadro Plex graphic cards. The presentation PC was a standard laptop since it was used only to run PowerPoint and the mobile device used was an IPad 2. All devices were connected to the same network via WiFi and we achieved real time manipulation and collaboration.

The review process of BSR was a real world, heavy load test case for our solution and we were able to handle all the communication in a real time scenario and still add all the benefits of having a collaborating system in an offshore engineering project review in a VR environment.

\subsubsection{Performance}

The average response time of a request from the mobile device to the main visualization application was of 0.67 seconds. Jakob [27] defined three main time 
limits for applications responses. Our result stay inside the second limit category where the users has the impression that the computer is working on the request but can still freely navigate the interface.

We performed tests of Environ running with and without EnvironRC connected, but could not find any significant performance difference. This probably happens because of the nature of Environ (and engineering applications), the load of the visualization and simulation part of Environ is much greater than the load of the communications between applications, making the performance difference negligible. 


\section{Conclusion}

Our goal with this work was to study the use of EnvironRC to help offshore engineering applications run in VR environments. On top of that we wanted to enable collaboration unaware application to collaborate and exchange messages.

As the result of this work, we could demonstrate that EnvironRC brought real benefits to offshore visualization applications running in VR setups. The main benefits were that having a connected tablet device when inside a CAVE setup enabled the users to manipulate engineering data and configure the visualization parameters. Furthermore, we showed that using a tablet had a lesser negative impact to the immersion experience then traditional input devices.

EnvironRC is in use by PETROBRAS at CENPES as a way to enhance the experience of Environ in many different kinds of virtual reality setups like a CAVE and an L-shape display. EnvironRC is also in use with an Ultra-HD display (20x HD) that, because of the very high resolution, enables the use of multiple instance s of Environ on the same display with many users at the same time. Furthermore, it enables the user of Environ to navigate the 3D world, review engineering data, create 3D annotations or even take snapshot pictures of the simulations from a mobile device.

Furthermore, AppRC was designed to be lightweight, extensible, as well as flexible enough to accommodate the different kinds of needs of any kind of application. AppRC requires little development work in order to achieve the integration. By implementing only two basic classes, and with minimum change to the base application, it is possible for any application to export its functionalities, not only to a mobile device, but also to any other application using one of the four available input channels. AppRC meets all of the requirements we listed in chapter 4 and offers easy way to integrate collaboration layer to any application.

We had success running EnvironRC in a collaborative setup (as described in section 7.2.2), but further studies are still needed. When adding collaboration capabilities to an application, we add a large amount of new ways to interact with the application and other users. A possible future work is to conduct a more 
complete study with different collaboration sessions and how much each session type benefits the users.

Although most immersive VR setups share the same kinds of problems with a CAVE setup, further studies running the same experiment in different VR setups could help to validate our results.

One problem we would like to address in the future is to also streamline the mobile application development process. As it is right now, to integrate mobile functionalities to a new application, the user needs to develop the mobile application from scratch. Moreover, if the user wants the mobile App on different platforms (IOS and Android, for example), the work would be doubled. We are beginning to study ways to define a protocol to try to extract the commands from an application and programmatically build a mobile application interface based on HTML5 for the application that will work with any mobile platform.

Further studies not included this work involve the use of our solution to integrate applications outside the field of offshore engineering. One possible focus of a further study is Geophysical analysis application. The review process of geophysical simulations requires the real-time comparison of different models. This kind of review process fits very well with the benefits that our solution adds, allowing the user to control many instances of the application simultaneously.

The benefits of having collaborating applications in VR Setups could be studied other kinds of applications outside the scope of engineering. One field that could possibly be of interest is medical applications. There are already many 3D visualization applications in the field of medicine that could use our solution to run different visualizations to compare data. 


\section{Bibliography}

1. RAPOSO, A., SANTOS, I., SOARES, L., WAGNER, G., CORSEUIL, E., GATTASS, M. Environ: Integrating VR and CAD in Engineering Projects. IEEE Computer Graphics \& Applications, v.29, n.6, p.91-95, 2009.

2. DOS SANTOS, Ismael HF; RAPOSO, Alberto B.; GATTASS, Marcelo. A software architecture for an engineering collaborative problem solving environment. In: 32nd Annual IEEE Software Engineering Workshop. IEEE, 2008. p. 43-51

3. W. Reinhard et al., "CSCW Tools: Concepts and Architectures", IEEE Computer, 27(5): 28-36, 1994.

4. SANTOS, I. H. F., RAPOSO, A. B., GATTASS, M. Finding Solutions for Effective Collaboration in a Heterogeneous Industrial Scenario. 7th International Conference on Computer Supported Cooperative Work in Design - CSCWD 2002, p.74 - 79. Rio de Janeiro, Brazil. 2002

5. PEDRAS, Bernardo FV; RAPOSO, Alberto; SANTOS, Ismael HF. AppRC: A framework for integrating mobile communication to virtual reality applications. In: Proceedings of the 12th ACM SIGGRAPH International Conference on Virtual-Reality Continuum and Its Applications in Industry. ACM, 2013. p. 305-308.

6. C. Cruz-Neira, D. J. Sandin, T. A. DeFanti, R. V. Kenyon, and J. C. Hart, "The cave: audio visual experience automatic virtual environment," Commun. ACM, vol. 35,no. 6, pp. 64-72, Jun. 1992. [Online]. Available: http://doi.acm.org/10.1145/129888.129892

7. MEDEIROS, D., CARVALHO, F., RAPOSO, A., AND SANTOS, I. H. 2013. An interaction tool for immersive environments using mobile devices. 90-96.

8. NORONHA, H., CAMPOS, P., JORGE, J., ARAÚJO, B., SOARES, L., AND RAPOSO, A. 2012. Designing a mobile collaborative system for navigating and reviewing oil industry cad models. 
9. KATZAKIS, N., HORI, M., AND . 2011. Smartphone game controller (). ŁŁ $35,25,55-60$.

10. DE PAIVA GUIMARAES, M., GNECCO, B. B., AND ZUFFO, M. K. 2004. Graphical interaction devices for distributed virtual reality systems. In Proceedings of the 2004 ACM SIGGRAPH international conference on Virtual Reality continuum and its applications in industry, ACM, New York, NY, USA, VRCAI '04, 363-367.

11. TAYLOR, R. M., II, II, R. M. T., HUDSON, T. C., SEEGER, A., WEBER, H., JULIANO, J., AND HELSER, A. T., 2001. Vrpn: A device-independent, network-transparent vr peripheral system.

12. TEIXEIRA, L., TRINDADE, D., LOAIZA, M., CARVAlHO, F. G. D., RAPOSO, A., AND SANTOS, I. 2012. A vr framework for desktop applications. In Proceedings of the 2012 14th Symposium on Virtual and Augmented Reality, IEEE Computer Society, Washington, DC, USA, SVR '12, $10-17$

13. FLICK SOFTWARE, 2015. http://flicksoftware.com/flick-technologies/flickdevelopment-libraries/.

14. MAXIMO, 2015. http://www03.ibm.com/software/products/us/en/maximoassetmanagement/

15. EZMAXMOBILE, 2015. http://ezmaxmobile.interprosoft.com/.

16. IMAXEAM, 2015. http://imaxeam.com/maxinterface-integration-tool.

17. SANTOS, Ismael HF et al. Integrating The Galileo Applications For Simulation of Offshore Systems Via The GXML Unified Format. In: XXX CILAMCEIberian Latin American Congress on Computational Methods in Engineering. 2009. p. 1-15.

18. FUKS, Hugo et al. Applying the $3 \mathrm{C}$ model to groupware development. International Journal of Cooperative Information Systems, v. 14, n. 02n03, p. 299-328, 2005. 
19. BRIGGS, Robert et al. Defining key concepts for collaboration engineering. AMCIS 2006 Proceedings, p. 17, 2006.

20. W.E. Mackay. "Media Spaces: environments for informal multimedia interaction". In Computer Supported Cooperative Work, M. Beaudouin-Lafon, Ed., vol. 7 of Trends in Software. John Wiley \& Sons, 55-82, 1999.

21. IERUSALIMSCHY, R. 2006. Programming in Lua, Second Edition.Lua.Org.

22. MASSOL, Vincent; O'BRIEN, Timothy M. Maven: A Developer's Notebook: A Developer's Notebook. " O'Reilly Media, Inc.", 2005.

23. MULE ESB FRAMEWORK, 2015. http://www.mulesoft.org/documentation/display/current/Home.

24. APACHE CAMEL ENTERPRISE APPLICATION INTEGRATION, 2015. http://camel.apache.org/.

25. SPRING INTEGRATION，2015. http://www.springsource.org/springintegration.

26. BURKE, Bill. RESTful Java with JaX-RS. " O'Reilly Media, Inc.", 2009.

27. NIELSEN, Jakob. Usability engineering. Elsevier, 1994. 


\section{A Appendix}

\section{A.1 Manual básico Environ e EnvironRC}

\section{Environ}

Para realizar a tarefa, você precisará utilizar o software de visualização de simulação de engenharia chamado ENVIRON. A tela principal do software pode ser vista na figura abaixo:

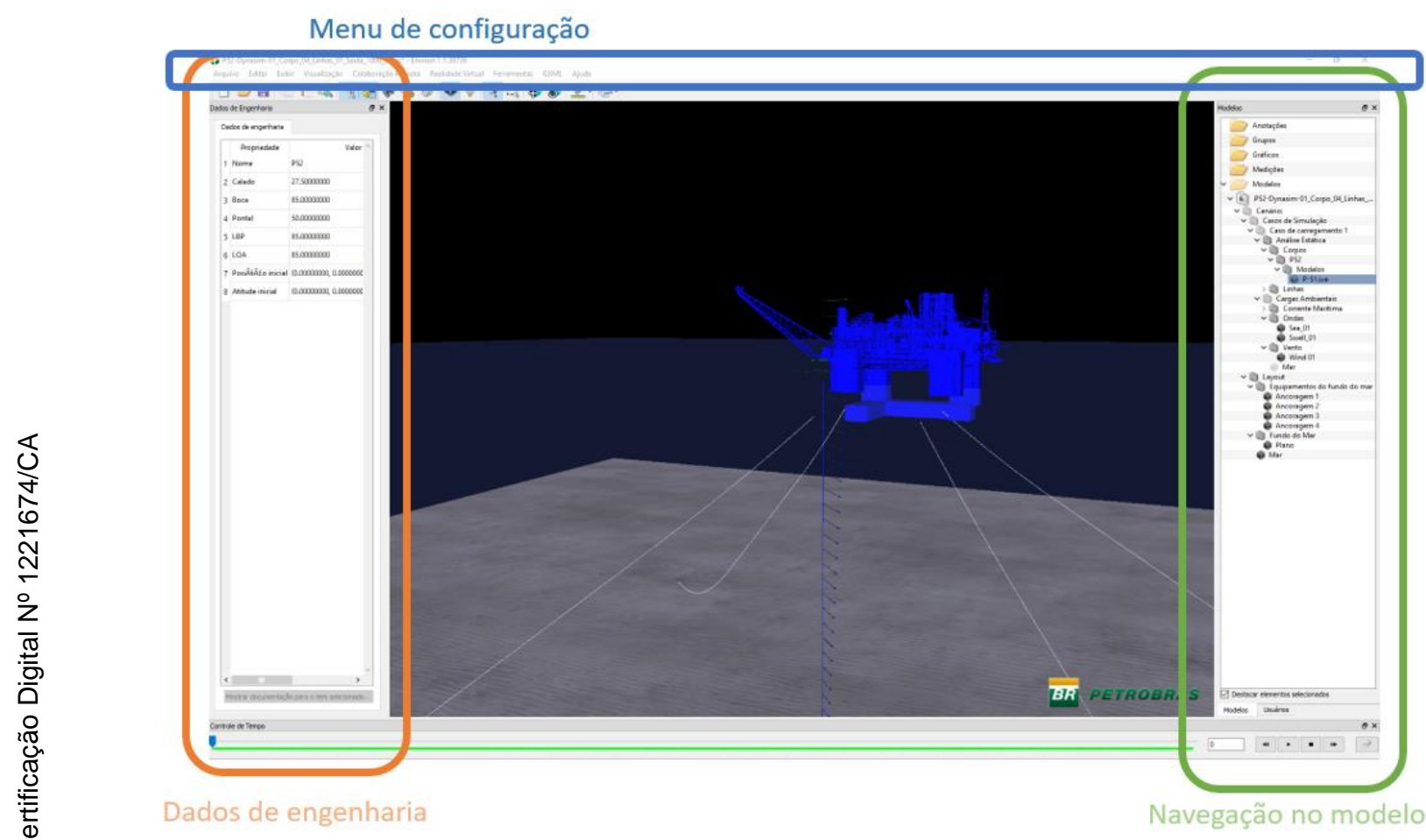

À direita temos a área de navegação na estrutura do modelo de engenharia. Com esta tela, é possível navegar em uma estrutura de árvore e manipular qualquer objeto do modelo. Já no lado esquerdo, temos os detalhes dos dados de engenharia do objeto selecionado. Dentro da tela da direita (Navegação) você pode usar o botão da direita do mouse para realizar operações com o objeto desejado. Uma destas operações é a operação de "ir para" que será usada na tarefa 1.

Já a tela de esquerda (Dados de engenharia) é usada exclusivamente para consulta de dados do objeto selecionado.

Na parte superior, temos o menu de configurações gerais da aplicação. Este menu será usado na tarefa 2

Em especial o submenu "visualização/plano de fundo" para alterar o plano de fundo da visualização e o submenu "realidade virtual/Projeção" para alterar os parâmetros de visualização 3D. 


\section{$\underline{\text { EnvironRC }}$}

Para realizar a tarefa usando o dispositivo móvel, você receberá um IPad com o aplicativo "EnvironMobile" rodando e conectado ao sistema de visualização principal. A tela principal do aplicativo pode ser vista na imagem abaixo:

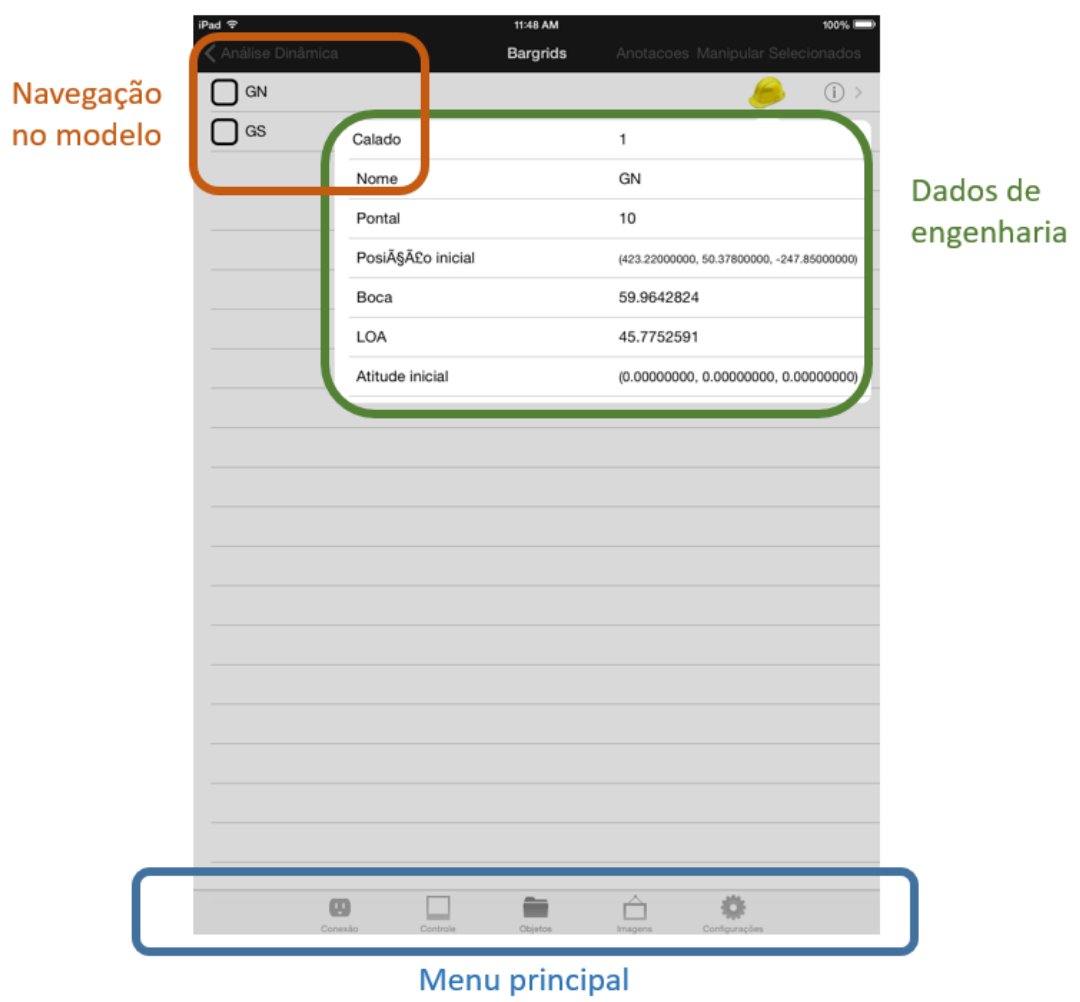

Na parte de baixo da aplicação, temos o menu principal, que estará com a opção "Objetos" selecionada. Em "Objetos", temos a tela de "Navegação no modelo" equivalente a mesma tela na aplicação Environ, possibilitando a navegação na forma de árvore pelo modelo de engenharia. Ao navegar até o objeto desejado, existe um botão na forma de um chapéu de engenheiro para visualizar os dados de engenharia do objeto.

Além disso, no canto superior direito, existe um botão com o nome "manipular selecionados" que permite a realização de operações nos objetos selecionados, em especial a operação "ir para".

Temos ainda, no "Menu principal", a tela de "configurações" onde é possível acessar as configurações do menu de configurações da aplicação ENVIRON e alterar os valores conforme descrito na tarefa 2. 


\section{A.2 Descrição das Tarefas 1 e 2}

Tarefa 1: navegar e visualizar um objeto na cena usando o comando "ir para" e consultar dados de engenharia

Nesta tarefa você inicia com o modelo carregado e com uma visão geral de todo o arranjo submarino. O Objetivo é navegar com a câmera até um determinado objeto na cena que está localizado no fundo do oceano.

Para completar esta tarefa, você deve navegar na estrutura do modelo até o objeto "Ancoragem 3" e usar o comando "Ir para".

O Objeto "Ancoragem 3" se encontra no seguinte caminho dentro do modelo GXML: "Cenário/layout/Equipamentos de fundo do mar/Ancoragem 3". Com o Objeto selecionado e sendo visualizado, você deve consultar o valor das propriedades "Largura", "Altura" e "Profundidade" do modelo, lendo seus valores em voz alta.

Tarefa 2: Alterar parâmetros da visualização

Nesta tarefa você inicia com o modelo carregado e com uma visão geral de todo o arranjo submarino. O Objetivo é alterar os seguintes parâmetros de visualização:

1. Habilitar exibição do céu do tipo "Pôr do sol";

2. Distância de paralaxe zero -> alterar para 0.12;

3. Separação entre os olhos -> alterar para 0.0172 ; 


\section{A.3 Termo de Consentimento}

\section{Termo de Consentimento para Avaliação de usabilidade em Ambientes Imersivos}

Você foi convidado (a) para participar da pesquisa de dissertação de mestrado em Informática de Bernardo Pedras (PUC-Rio) com o objetivo de avaliar o uso de um dispositivo móvel como método de interação em ambientes imersivos. Neste estudo, buscamos verificar os benefícios de utilizar um dispositivo para auxiliar a manipulação de dados durante a realização de uma análise de modelos de engenharia em ambiente imersivo.

Por esta razão, solicitamos seu consentimento para a realização deste estudo, que utilizará três técnicas de coleta de dados: questionários, registro de tempo e entrevistas. Para isso, é importante que você tenha algumas informações:

1. Os dados coletados durante o estudo destinam-se estritamente a atividades de pesquisa e desenvolvimento.

2. A equipe desta pesquisa tem o compromisso de divulgar os resultados de suas pesquisas somente para fins acadêmicos. A divulgação destes resultados pauta-se no respeito a sua privacidade e o anonimato dos mesmos é preservado em quaisquer documentos que elaborarmos.

3. O consentimento para o estudo é uma escolha livre, feita mediante a prestação de todos os esclarecimentos necessários sobre a pesquisa.

4. Nossa equipe encontra-se disponível para prestar esclarecimentos e tirar quaisquer dúvidas sobre os procedimentos da pesquisa durante todo o período de sua execução. Para isto, entre em contato pelo e-mail bernspedras@gmail.com.

Por favor, marque um X para indicar a sua decisão com relação à participação do estudo:

( ) Concordo em participar da pesquisa.

( ) Não desejo participar da pesquisa.

\section{Pesquisador responsável}

Nome:

Assinatura: Data:

\section{Participante}

Nome:

Assinatura: Data:

Caso você tenha optado por participar, por favor, responda ao breve questionário na próxima folha. 


\section{A.4 Questionário pré-uso}

Dados Pessoais

1. Idade:

2. Sexo:

3. Formação:

Experiência com Ambientes virtuais e modelos de engenharia offshore

4.Com que frequência você...?

Responda os itens a seguir com uma das seguintes pontuações:

5 - Pelo menos uma vez por dia; $\quad 2$ - Pelo menos uma vez a cada 15 dias;

4 - Pelo menos três vezes por semana; 1 - Raramente

3 - Pelo menos uma vez por semana; $\quad 0$ - Nunca

a) Navega em ambientes 3D:

b) Seleciona objetos em ambientes 3D:

d) Usa ambientes imersivos:

e) Utiliza simuladores de engenharia offshore

5. Qual(s) tipo(s) de aplicação 3D você utiliza?

( ) Modelagem 3D

( ) Visualização 3D

( ) Jogos 3D

( ) Simuladores

( ) Outro(s):

( ) N/A

6. Qual sua experiência utilizando aplicações de realidade virtual em ambientes imersivos?

( ) Profunda

() Boa

( ) Média

( ) Pouca

( ) Nenhuma

7. Qual sua experiência com o software ENVIRON?

( ) Profunda

() Boa

( ) Média

() Pouca

( ) Nenhuma 


\section{A.5 Questionário pós-teste}

Participante\#

Por favor, responda ao questionário a seguir sobre a sua interação no último cenário. Nas questões 1 a 11 marque um $X$ de acordo com a escala que representa o seu grau de concordância com a afirmação.

1) Foi fácil navegar até o objeto (T1) usando mouse e teclado no Desktop

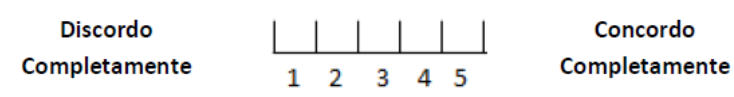

2) Foi fácil navegar até o objeto (T1) usando mouse na CAVE

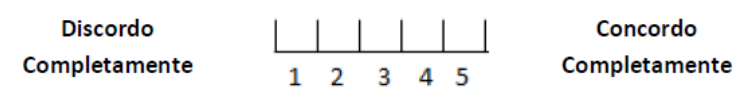

3) Foi fácil navegar até o objeto (T1) usando o dispositivo móvel na CAVE

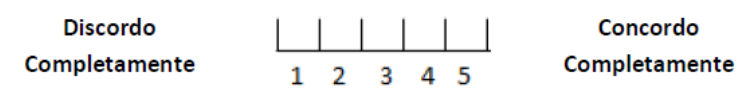

4) Foi fácil alterar as configurações (T2) usando mouse e teclado na CAVE

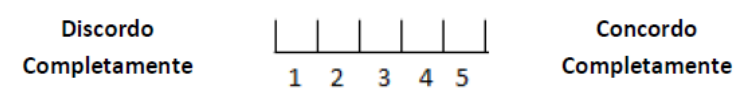

5) Foi fácil alterar as configurações (T2) usando dispositivo móvel na CAVE

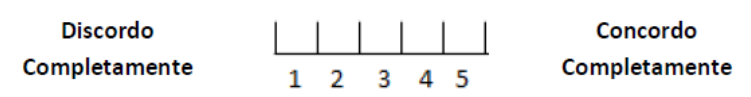

6) O dispositivo móvel trouxe benefícios para minha experiência em ambientes imersivos
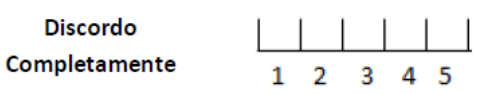

Concordo

Completamente

7) Eu aprendi a usar a interface do tablet rapidamente.
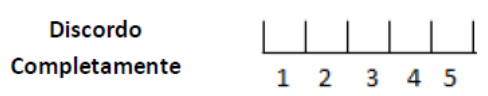

Concordo Completamente

8) Eu me senti confortável utilizando o tablet.
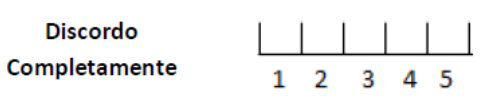

Concordo

Completamente

9) O óculos 3D atrapalhou a utilização do tablet
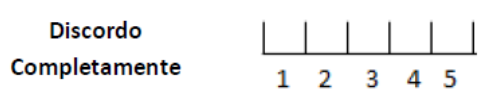

Concordo Completamente 
10) Estou satisfeito com o tempo que gastei para completar a tarefa 1 na CAVE.

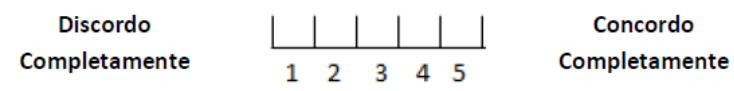

11) Estou satisfeito com o tempo que gastei para completar a tarefa 2 na CAVE.

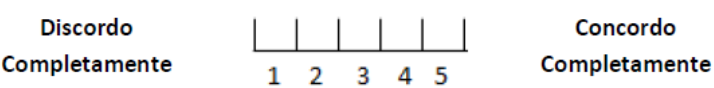




\section{A.6 Roteiro de entrevista semi-estruturada}

Tópicos a serem abordados:

1) De uma forma geral, o que o participante achou do uso da ferramenta?

2) Pedir para o participante esclarecer pontuações negativas do questionário

3) Perguntar ao participante se ele possui sugestões de melhorias

4) Perguntar ao participante o impacto do uso do dispositivo móvel na imersão 